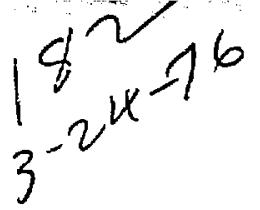

$$
\text { DWR. \#2 }
$$

\title{
GAS-INITIATED CRACK PROPAGATION IN A POROUS SOLID
}

John H. P1tts

Ph. D. Thesis

January 15,1976

Prepared for U.S. Energy Research \& Dovelopment Administration under contract No. W-7405-Eng-48

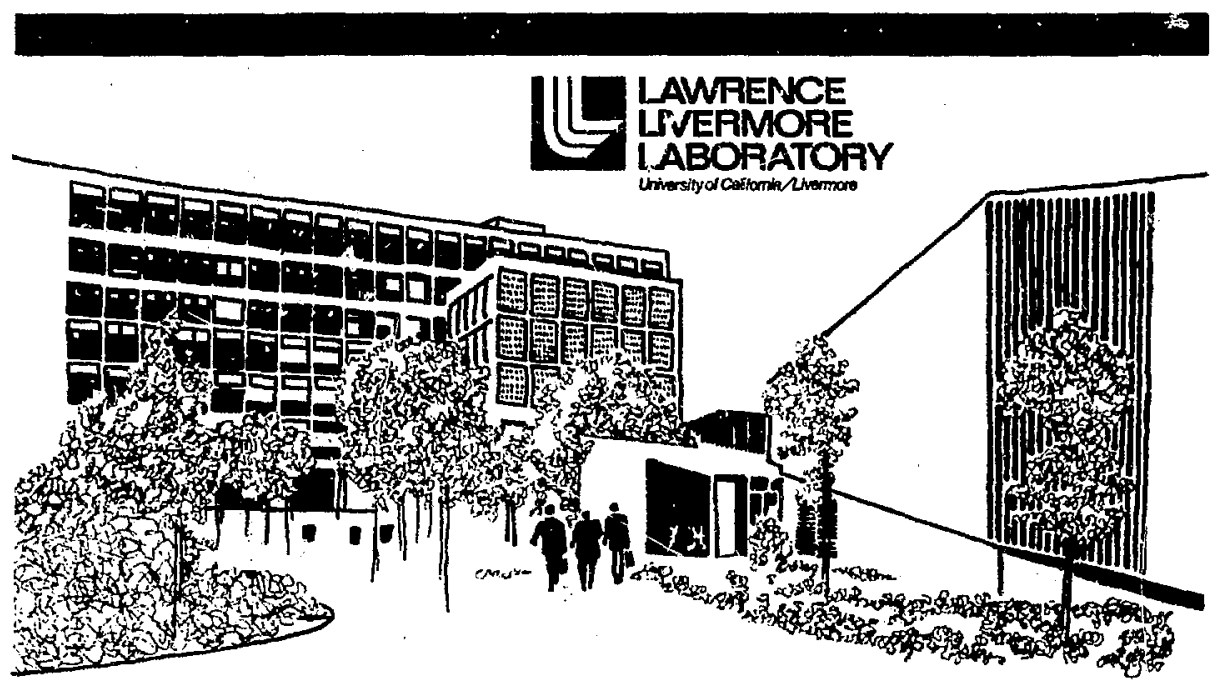


$r$

NOTICE

"This report was prepared as an eccount of work sponsored by the United States Governmant. Nefther the United Stutes not the United States Enetgy Research \& Development Administration, not any of their employies, nor any of their contrectors, subcontractors, or their employees, makes any wartinty, express or impled, of assumes any lezal liability or cesponsibillty for the sccurscy. completeness or usefulness of any information, apperatus, product or process ditchosed, of represents that its wo would not infringe privately-owned rights."

Printed in the United States of America Available from

National Technical Information Service

U.S. Department of Commerce 5285 Fort Royal Road

Springfield, Virginia 22151

Price: Prinied Copy \$ *; Microfiche $\$ 2.25$

is

$\frac{* \text { Pages }}{1-50}$
$51-150$
$151-325$
$326-500$
$501-1000$

NTIS

Selling Price

$\$ 4.00$

$\$ 5.45$

$\$ 7.60$

$\$ 10.60$

$\$ 13.60$ 


\title{
㢟 \\ LAMPENCE LNEAMOAE LABOAATOAY

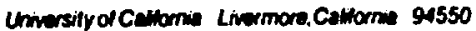

\section{IICRI.-519.48 \\ GAS-INITIATED CRACK PROPAGATION IN A POROUS SOLID}

\author{
fohn H. Pites
}

Ph. 1). ihesis

Ys. Hate: Jecomber 31, 1975

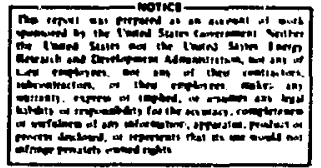




\section{Conicuts}

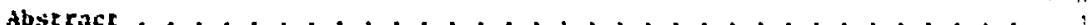

Incroduct lon . . . . . . . . . . . . . . . . . . . . . . I

$\operatorname{sinalysts.....~.~.~.~.~.~.~.~.~.~.~.~.~.~.~.~.~.~.~.~.~.~;~}$

Deflection of the crack kill . . . . . . . . . . . . . . . . . :

Flow in the porous solld . . . . . . . . . . . . . . . . . II

flow in tin crack . . . . . . . . . . . . . . . . . . . . . . l.!

Calculatlonil lechos . . . . . . . . . . . . . . . . . . . 1,

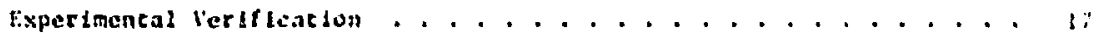

Results . . . . . . . . . . . . . . . . . . . . . . . . $1 !$

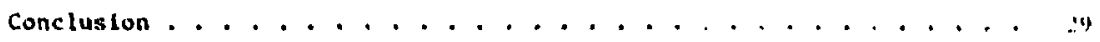

Tomenclature . . . . . . . . . . . . . . . . . . . . . . . H

ncknow ledgrents . . . . . . . . . . . . . . . . . . . . . . . . i..

References . . . . . . . . . . . . . . . . . . . . . . . 11

hppendix A - Derivation of the Coverning Equaclens . . . . . . , . . . in

Deflectlon of the crack Wall . . . . . . . . . . . . . . . . in

flow in the forous solld . . . . . . . . . . . . . . . . . . . . . . .

Flow in the crack . . . . . . . . . . . . . . . . . . . . . . ".

Calculation of che frictlonal Coefrlclent. . . . . . . . . . . . is

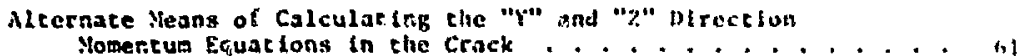

References for Appendix $A$. . . . . . . . . . . . . . . ".in

Appendix 8 - Developmunt of the Equatont: lised for Computation . . . M

Crack Wall D lections . . . . . . . . . . . . . . . . n;

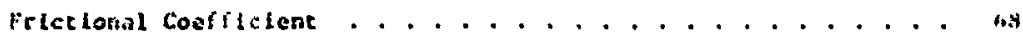

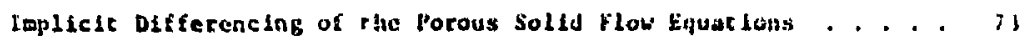

"X" Detrection Lmplicit Dfferencing . . . . . . . . . . . . is

"T" Direction Inplicic Differencins . . . . . . . . . . . . sil

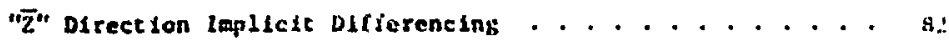

Itaplicit Differencing of the Crack Flow Equations........... . M

hicernate sechad for Diffarencing the Crack Flow Equacions . . . . 95

Evaluetion of an Effective Crack Thlckness at she Tlp of che Cruck. 99

keferences for Appendix . . . . . . . . . . . . . . . . . 102

Appendix C - The Compurer Code Clinsu . . . . . . . . . . . . . . . 103

Listing of Computer Code, CllASM . . . . . . . . . . . . . . . 104

Sample Input ... . . . . . . . . . . . . . . . . . . 130

Sample Output ........................... 130 


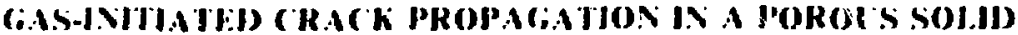

\section{Abstract}

The propagat lon of a crack in

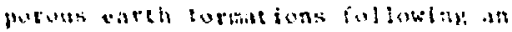

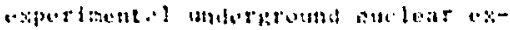

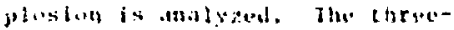
discontonad malysis fincludes lnterA. tiva of bas pressure dithis the

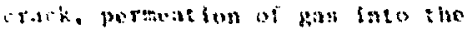

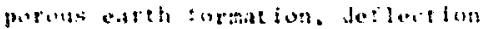

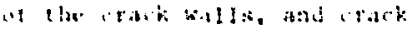

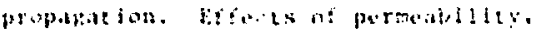

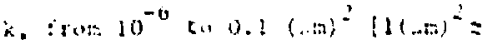

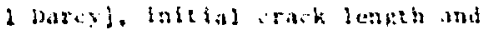

wideh up to 110 and $970 \mathrm{~m}$, and ratio ot saxtmus eath fortiation resistive pressure to Initlal drluting pressure,

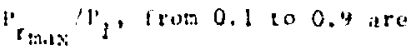
delincited, lropagation of a iraci to the carthes surfare

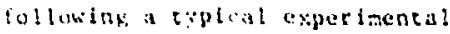
mderproum! nulear exploston ourled at a deptin of 500 m o.curs only ander unlikely condiflons, such as when $k$ $10^{-4}(\ldots+)^{2}$ and $P_{r_{\text {max }}} P_{I}$ 0.75 .

\section{Introduction}

Sasely and environgent al

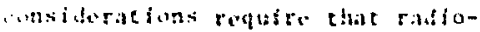

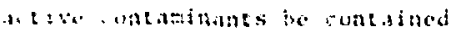

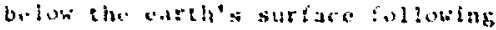

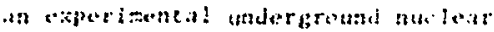
apluston, ar lollowing propused fotelear sefaulation of libhe suberranean has reservolis. To insige that mulear testin, and situlation can he carrieal out safely, fectings need to be avallable to dotergine the

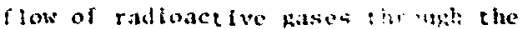
interstices and cracks of t'il. earth formations. This p.ipor anribes one potential release mechanism whlch involves propasation at a crack in an earth formite the throuth

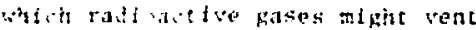
Lit the attosplore.

Consider the experimental underformen nu-lear explosion shown at the top of Fin. 1. A larie amuant if energy is released almost instantaneously at the time of the explosion and all matcer in the immediat vicinity of the explosion is vaporized. Within a second or [wo an unjerground cav!fy is formed which is illled with radioactive gases al, or slight ly above, the earth formation overburden pressure. These radioactive gases permeate the 

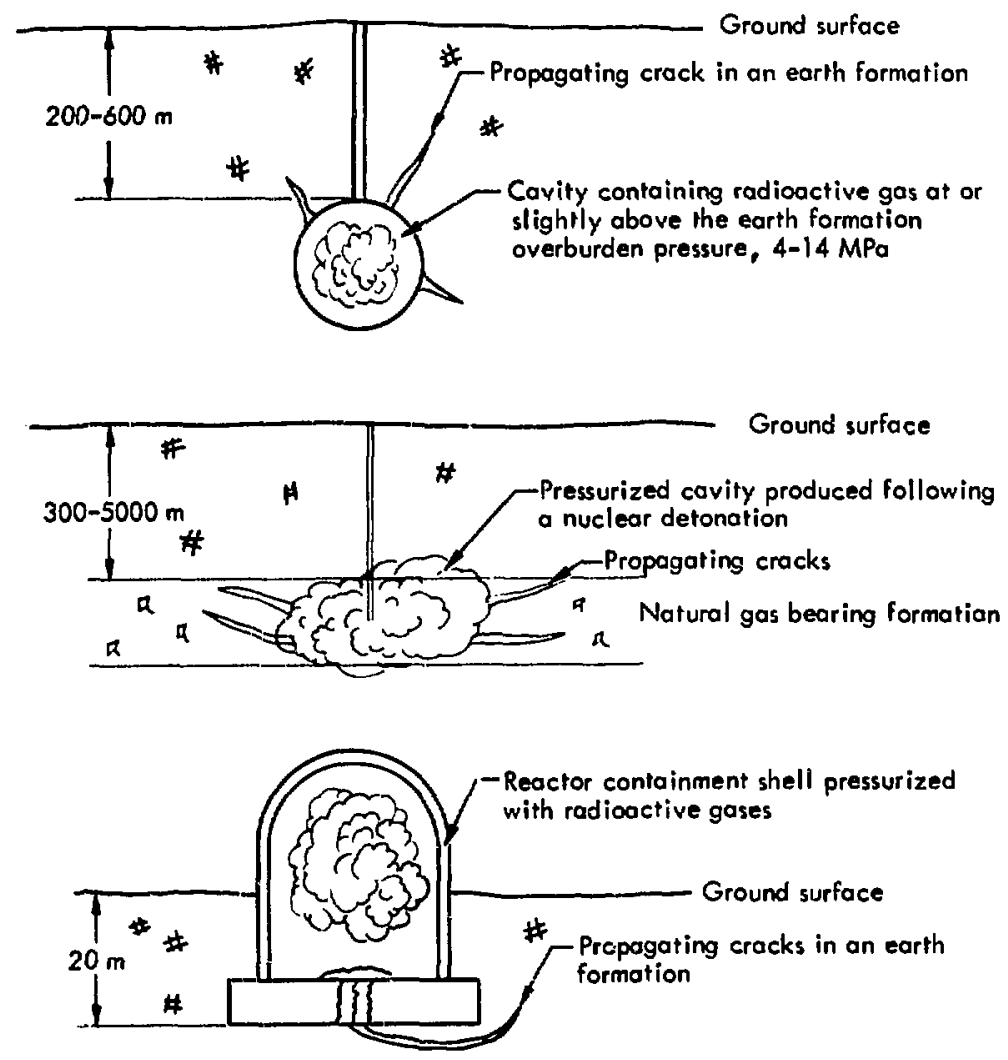

Fig. 1. Three examples of gas-initiated crack propagation.

earth formation and also flow into cracks formed during the same $t$ ime period as the formation of the underground cavity. Forces due to gas pressure rithin the cracks may cause the cracks to be enlarged. Should the enlarged cracks propagate to the surface of the earth, shey would form open passages through which radioactive contaminanes could reach the atmosphere.

A second example of a potential vent to the atmosphere is shown in the middle portion of Fig. 1 where a gas bearing formation is fractured by detonating a nuclear charge. Nuclear fracturing has been carried out on an experimental basis and is being 
considered for use with tight and deep formations where it might not be economical to produce natural gas by other means 1,2 . Although we wish to form many large fractures in the gas bearing formation, we need to insure that the fractures do not extend to the surface of the earth and vent radioactive material. Hence, before gas stimulation can be performed safely, the growth pattern of fractures leading to the surface needs to be computed.

A third application involves the analysis of a hypothetical accidunt in a nuclear power generating station. Should a loss-of-coolant accident ever occur, with subsequent core meltdown, the floo: of the contalnment shell (below the earth's surface) could be cracked by ensuing thermal stresses as shown schematically in the botiom portion of Fig. 1 . Radioactive gases from the reactor couid be released into the sirrounding earth formation through this break in the containment shell. Any cracks present in the earth formation could then be extended to the surface of the earth and form passages through which radioactive tases might reach tiue atmosphere.

Our objective is to determine the condicions under which a pre-existing crack in a porous earth formation will propagate when exposed to high pressure gas. This apparently is the first study that shows the 1nteraction of gas pressure witnin the crack, permeation of the gas into the earth formation, deflection of the crack wall, and the phenomenon of crack propagation.

Althotgh three applications have been indlcated, our inain interest is in contalning radioactive contamirants below the eartil's surface following an experimental underaround nuclear explosion.

$$
\text { At the Nevada Test site (XIS) }
$$
of the lawrence Livermure Laboratory, the most conkon carth formation in which experthental underground nuclear Lests are conducted, is alluvium. This alluvium has a permeability ranging $\operatorname{lom} 10^{-2}$ [o $1(\ldots \mathrm{m})^{2} \mid 1(. \mathrm{m})^{2} \quad 1$ harcs $]^{3}$ and has a negligible censile strength when compared to the pressures involved in this study ${ }^{4,5}$. The nuclear explosive charge is buried typically between 200 and $600 \mathrm{~m}$ below the surface of the earth. Inttial temperature variation in the earth formation to this depth is only a few degrees which we neglected. The Initial crack thickness is generally on the order of the average grain size of the alluvium formation, which at NTS is about $1 \mathrm{~mm}$. This crack thickness enlarges up to about 150 $\mathrm{mm}$ as deflection of the crack wails occurs. Cracks present in the alluvium have lengths ${ }^{4}$ of over $40 \mathrm{~m}$. 
The lfterature indfcates that relat ively It th le work has been done in the field of gas-initiated craok propagation. Seller. Davis, and Stewart inalyzed propagation of small cracks ranglng up to a maximut length of 2 or $3 \pi$. They constared I mixture of condensing steam and water and predliced whether it crack would intially grow. Their study dis nut detarmine it the crack would reach the surtace at the earth and rosult in the release of radicactive contaminants. Rather. they vere able a place a bound on condltons necessary for Inltial crack growti which could lead to eventual propagation of eracks to the surface of the eartin.

Literature is avallable on Iydrauli: fracturing as applied to the petroleum industry, e.g. Howard and Fast ${ }^{2}$ and Cleary". Hydraulic iracturing involves pressurlating fon permeabilicy, pecroleum producing; formations next to it section of well bore. Hydraulis iracturlaf dffers from nuclear fracturing in that a ligquid rather than a gas is used to fracture the formation. Furthermnre, in the hydraulic iracturing licerature, the complete inceraction of pressures within the crack, the flaw of fluids, deformation of the earth formation, and extension of the crack has not been included. Therefore, this study also is of interest to the petrolel.m industry. By changing the equation of state from a gas to a liquid, the propagation of a ivdrialif: ira.ture could be predlcted.

In the present analusis we consider a puruss earth furmat lon, ds shown in $\mathrm{r}$ ig. $\because$, whete a crack is seen alont the leit side. The top of the volume is subjocted to acmospherlo pressure at the promil surface. The hoteon of the volume is at the fievation of the underground nuclear explosion. The brlin of the coordinate syatem is in the left front with the "\%" axis vertical. lias generated by the explaston exerts a driving pressure aver a portion of the $z=0$ plane bounded by the ashed lines and the " $x$ " and "y" axes. The $x=0$ and $Y=0$ surfaces are planes of symmetry, ather surfaces are positioned at remote distinces from the oripin so that sin pressire bradient perpendicular tc these surfaces is zero.

las froin the explosion permeates the eisth iarmat ion and simultaneous ly flows upward in the crack from the $\mathrm{Z}=0$ plane. The resistance to flow in the crack is less than that in the formation. This results in pressures in the crack that are greater than those in the pores of the solid at the same elevation. Thus, gas flows out of the sides of the crack and into the formation from the $X=0$ plane. 


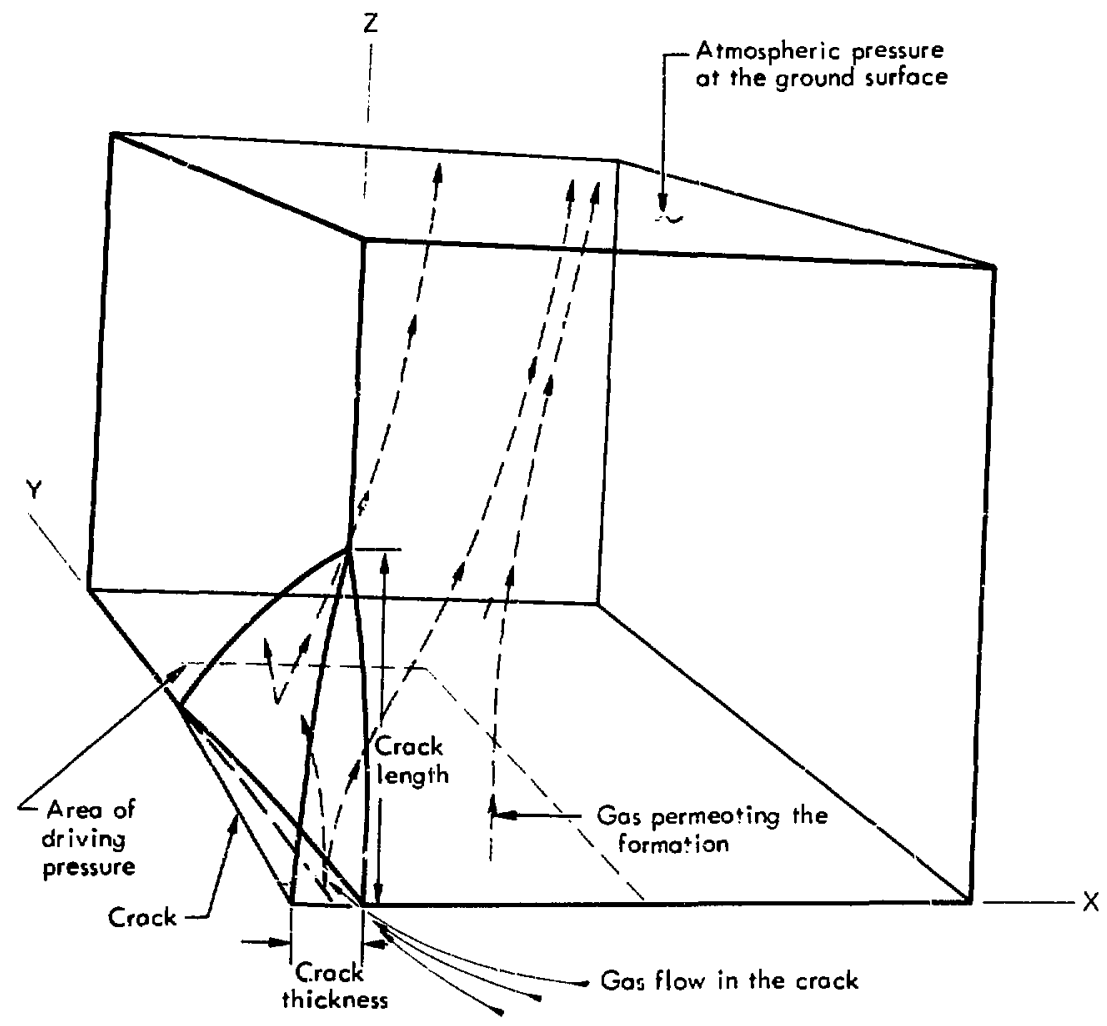

Fig. 2. stodel of a propagating crack in a porous earth formation.

The sides of the crack deflect in the " $x$ " direction and extend in the " $Y$ " and " $Z$ " directions. These deflections are produced when the forces due to gas pressure, which tend to open the crack, exceed the resistive pressure forces in the earth formation, which tend to keep the crack closed. The resistive pressure forces, due to the weight of material present above, are transmittel through the solid matriy of the earth formation.

The problem is analyzed in three parts, consisting of deflection of the crack wall, flow of gas in the solid, and flow of gas in the crack. The extent of the crack $1 \mathrm{i}$ 
the $X=0$ plane beyond its initial

value consists of the region where the deflection is $>0$. Deflection of the crack wall is calculated by considering the plane of the crack $(X=0)$ to be the surface oi a semiInfinite solid. We find elemental surface deflections caused by a unte load applied in the " " direction on an elemental area. To:al surface deflection is found using superposition. The data of Gerrard and Morgan ${ }^{8}$ are used to establish elemental surface deflection away from the area where a unit load is applied. lierrard and Morgan's data establesh a multiplier to reduce the elemental surface deflection with distance away from the loading area. A circle of influence exists beyond which the loads have no effect.

The analysis for gas flow in the porous earth formation follows that of Morrison ${ }^{9}$. The conservation equations are combined with an ideal gas equation of state and placed $1 \pi$ dimensionless form. Experimental data are included that verify this portion of the analysis.

The gas flow in the formation is considered isothermal for two reasons. First, in spite of the fact that the initial gas temperature is high, the energy carried by the gas is small in comparison with the heat capacity of the earth formation.
Second, the $1 \mathrm{~mm}$ average grain size of the alluvium results in a large surface-co-volume ratlo which offers rapid heat transfor irom the gas to the formation. Consequently, the gas reaches the formation semperature afcer traveling no mors ining a few metres.

Gas flow in the crack is calculated by consider." fully developed internal flow be us close?y spaced parallel wall se; dents ${ }^{10}$. The crack is thickest at the orfgin and is tapered toward the edges. Up to 200 segments ar? used to repasent the tanered edge of the crack. Changes Ir crack rlickness are gradual so that use of parallel wall segments in thcalculation is a good approximation. Transtent and acceleration terms present in the complete momentum equations for flow in the crack are neglected. Experimental frictional coefficients dependent on Reynolds number and relative roughness are incorporated.

A solution of the entire problem is obtained by combining the three parts of the analysis into a single, implicit finite-difference iteration procedure, Scarting with given crack dimensions and pressures, we calculate a revised crack wall deflection. This calculation also establishes the extent of the crack in the " $Y$ " and " 2 " directions. Next we find a 
frictionai coefficient using the newly calculated dimensions of the crack and known values of pressure. We then decermine the gas flow hoth in the porous earth formist lon and in the crack. The flow calculations result in pressures at a new time which can be used in the next time Iteration to calculate a new crack wall Jeflection.

\section{Analysis}

This section discusses the analysis for deflection of the crack wall, gas flow in the carth formation and gas flow in the erack. The development of eciuations for the frictional coefficlent are included in the anniysts for gas flow in the crack.

DEFI.ECTION OF THE CRACK WAL.

The analysis of the " $x$ " d1rection deflection considers the crack wall to be a portion of the surfice of a semi-infinite solid, as shown in Fig. 3. Two opposing forces are present. Forces due to gas pressure in the crack tend to deflect the surface and thereby open the crack while the horizontal resistive pressure forces in the earth formation tend to prevent deflection and keep the crack closed. Also present is a pore pressure equal to the hydrostatic head of fludd in the formation. since the porer in alluvium at NTS are filled with air to the depth of interest in this study, we take the
Inttial pore pressure throughout the solid to be atmospheric.

cleary" has suggested that the resistlve pressure forces are equal to the overi:"rden. This assumption Is valid if the earth formation has little strangch and is subject to creep, since over geological time, motion would occur in the earth formation until a hydrostatic stress state was reached. On the other hand, If a hydrostatic state is not reacheci, then a three-dImensional stress state would exist where the resistive pressure forces would be a fraction of the overourden. At NTS, where the earth formation of interest consist of low-strength alluvium, we expect the resistive pressure forces in undisturbed alluvium to be close to overburden. Analytical results are included which show the effect of variations in resistive pressure forces.

To determine crack deflection, we first consider the effect of a force acting on an elemental surface area of a semi-infinite 


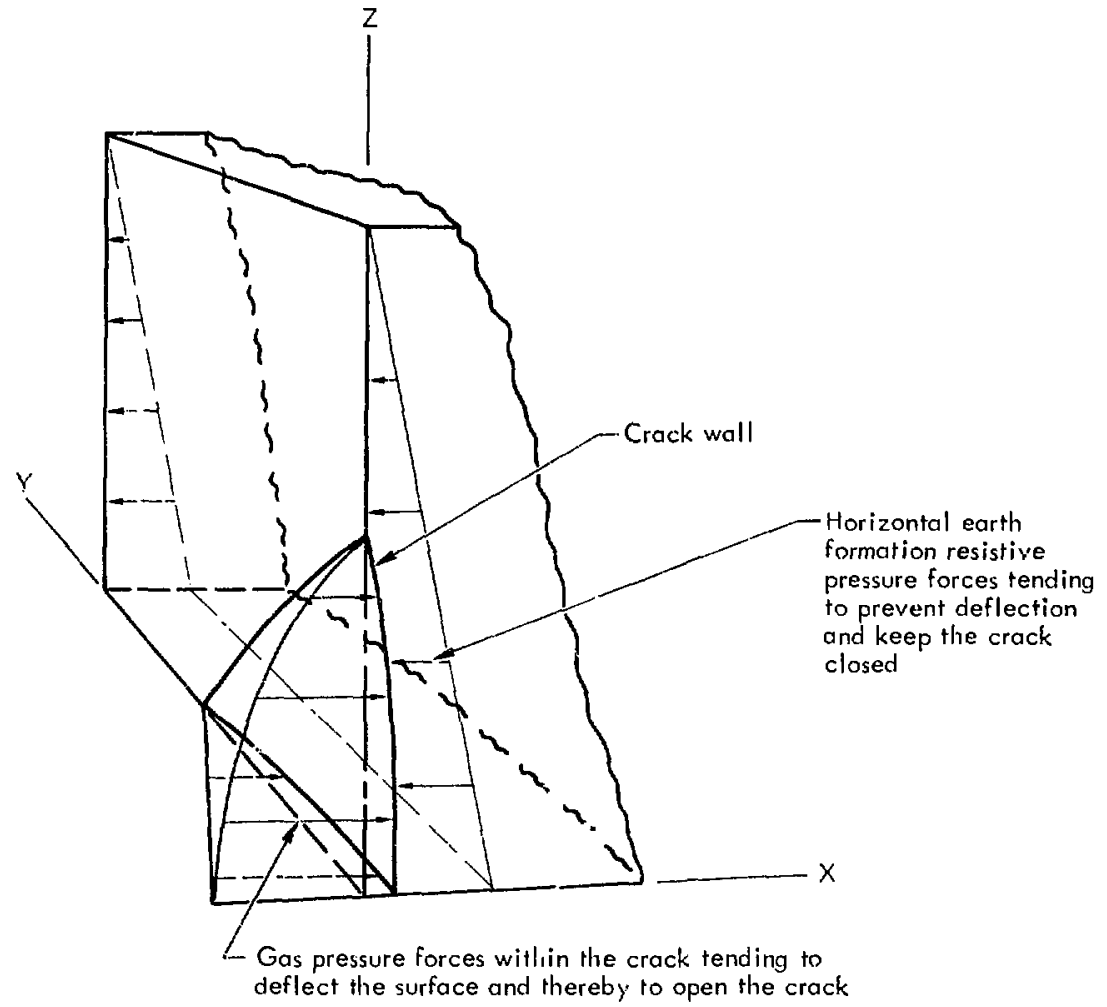

yig. 3. lresisure forees alcing on une wall of the crack.

clastic solid, which is given by

Timoshenke and coodier ${ }^{11}$ as

$$
i^{1}=\frac{\left(1-\nu^{2}\right) E}{\pi E R}
$$

where is the surface deflection in the " $\mathrm{x}$ " direction; $v$ is loisson"s ratio; E is the modulus of elasticity: $F$ is the force equal to the gas pressure in the crack that is in excess of the intial pore pressure, less the earth formation resistive pressure, an t times the elemental area where the pressures are applied; and $R$ is the radius along the crack wall from the elemental area to the point where the derlection is being calculited. 
Next, we integrate the furce calculated in Eq. (1) over a finite surface area to obtain the deflection due to pressure acting on a portion of the surface. This problem was inalyzed in detail by love ${ }^{12}$. Two difficulties are that the solution is singular at $R=0$ and that a deflect lon occurs at any radius however large. When R-ro, Timoshenko and foodier ut llized an average def lection under a small suriace area. For a squareshaped area this deflection $1 \mathrm{~s}$

$$
D_{\mathrm{k}+0}=\frac{0.95\left(1-v^{2}\right)}{E}(\mathrm{P}-\mathrm{P}) \mathrm{s}^{\frac{1}{2}}
$$

where ' is the gas pressure in the crack, $P_{r}$ is the earth formation resistive pressure; and $A$ is the surface area of a single grid where the pressure is applied. When the radius becomes large, the data of Gerrard and Morgan 8 can be used to obtain a surface deflection profile. Their data were obtained experimentally for a load applied uniformly over a flnite circular area. Extrapolation of Gerrard and Morgan's data is in reasonable agreement with the data of Campen and $S m i t h^{13}$ wich show a zero surfare deflection beyond a distance equal to about five radil. In other words, a circle of influence exists out to a normalized radius of about five beyond which $P$ and $P_{r}$ have no influence on the surface deflection.
We converted Gerrard and Morgan's data [or a circular surface area loading to an equivalent square surface area loading and obtained coefficients for use in a formula for any raulus similar to Eq. (2). That is, a circle of radius $(4 / \pi)^{\frac{1}{2}}$ a would be equivalent to a square with a side of $2 a$. For the finite square area directly below the load the coefficient would be 0.95 and for equlvalent radius rat los beyond five the coefficient would be zero. We also normalized the deflection and area using reference length, $L$, equal to the vertical distance between the $\mathrm{Z}=0$ plane and the ground surface. Pressure and modulus of elasticity were normalized to the difference between the initial gas driving pressure, ${ }_{1}$, and the initial earth formation pore pressure, $\mathrm{p}_{0}$. The Initial earth formation pore pressure is considered constant and equal to the atmospheris pressure. Finally, we obtain a relationship for the total surface deflection at a point by suming over the entire $x=0$ plane. This gives

$$
\bar{D}=\sum_{\bar{A}} C_{G} \frac{\left(1-v^{2}\right)}{\bar{E}}\left(\bar{P}-\vec{p}{ }_{r}\right)\left(\bar{A}^{\frac{1}{2}}\right.
$$

where $\bar{D}$ is the normalized toral surface deflection and $C_{G}$ is the Gerrard and Morgan deflection coefficient. The bar above the variables indicates 
they are normalized. The summation may be terminated for equlvalent radius ratios beyond five since $C_{G}$ Is zero there.

The region where $\bar{D}>0$ deffines the extent of crack propagation and the location of the crack tip. No other criteria are necessary because by definition a crack exists only if its thickness is positive.

$$
\text { Utilization of Eq. (3) Implies }
$$
that the earth formation is elastic during initial loading and therefore that superposition is applicable. Earth formations in general are not elastic and a more complex soil model would 1mprove the accuracy of the calculation. However, the experimental data of Gerrard and Morgan indicate that the inftial loaddefle, tion curve for sand is within five per cent of elastic. Further, we were able to make a linear approximation of the stress-strain data for alluvium from $\operatorname{NTs}^{14}$ between 0 and $12 \%$ strain. Actual stress-strain data deviated a maximum of $25 \%$ from this linear approximation. This deviation of alluvium from a linear approximation was considered acceptable for the purpose of this study. Therefore the initial loading of alluvium was considered in the analysis to be elastic.

Total deflection, $\vec{D}$, is permitted to increase (but not decrease) in magnitude because in our range of pressures the initial loading causes a reduction of pore volume which does not increase appreciably when the load is reduced ${ }^{15}$. In other words, a reasonable approximation for alluvium at NTS for the range of pressures used in this study is elastic behavior during Initial loading with negligtble change in deflection during unloading.

We considered two other methods of calculating crack wall deflection. One method is based on an analysis by Sneddon $^{16}$ which is used by Keller, Davis, and Stewart ${ }^{6}$ and which gives a solution in closed form for deflection of axisymmetric crack shapes. In applying Sneddon's analysis to an underground nuclear explosion, the axis of symmetry is horfzontal and the crack length along which propagation would occur is in the radial direction. This radial airection includes both vertical and horizontal rays. We find that the cracks grow more vertically (upward) than horizontally since the earth formation reststive pressure is proportional to the distance below the earth's surface. Thus the axisymmetric assumption limits the results to small lengths of crack propagation. The other method utilized a finite-element computer code developed by Wilson, Farhoomand, and Bathe 17,18 and modified by Tokarz ${ }^{19}$. We used Wilson's analysis 
to calculate crack wall deflection in a two-dimensional problem which we analyzed earlier ${ }^{20}$. We found the deflection calculation satisfactory in two dimensions but not readily extendable to three dimensions without requiring excessive computer time. Consequently, netther of these analyses were considered satisfactory for this study.

FLOW IN THE POROUS SOLID

The control volume used for analysis includes both pore space and solid grains. We write the continulty equation as

$$
\frac{\partial \rho u_{x}}{\partial X}+\frac{\partial \rho u_{y}}{\partial Y}+\frac{\partial \rho u_{z}}{\partial z}+\varepsilon \frac{\partial \rho}{\partial t}=0
$$

where $X, Y$, and $Z$ are spatial coordinates; $\rho$ is the gas density; $u_{x}, u_{y}$, and $u_{z}$ are apparent velocities; $\varepsilon$ is the porosity; and $t$ is time.

The apparent velocities equal the volume flow rate passing through a face of the control volume divided by the cross-sectional area of the face, including both void and solid portions. These apparent velocities are different from the actual gas velocities since only a fraction of the control volume is available for occupancy by the gas.
We use Darcy's $1 \mathrm{aw}^{21}$ for the mementum equations, which are

$$
\begin{aligned}
& u_{x}=-\frac{k}{\mu} \frac{\partial P}{\partial X} \\
& u_{y}=-\frac{k_{y}}{\mu} \frac{\partial P}{\partial Y} \\
& u_{z}=-\frac{k z}{\mu} \frac{\partial P}{\partial Z}
\end{aligned}
$$

where $k_{x}, k_{y}$, and $k_{z}$ represent directional permeabllities that are normally determined by experiment, and $\mu$ is the gas viscosity. Gravity forces are omitted since they are negligible in compartson to the pressure forces.

An ideal gas equation of state 1s used since this is a good approximation for non-condensible gases at ambient temperature and pressures 22 up to $10 \mathrm{MPa}$, which are the maxima of interest in this study. The gas equation of state is written as

$$
\rho=\frac{\mathrm{P}}{R \mathrm{~T}}
$$

where $R$ is the gas constant and $\mathrm{T}$ is the absolute temperature of the gas which we consider constant. Combining Eqs. (4) through (8) gives the equation

$\bar{k}_{x} \frac{\partial^{2} F}{\partial \bar{X}^{2}}+\bar{k}_{y} \frac{\partial^{2} F}{\partial \bar{Y}^{2}}+\bar{k}_{z} \frac{\partial^{2} F}{\partial \bar{Z}^{2}}=F^{-\frac{1}{2}} \frac{\partial F}{\partial \tau}$ 
where the quantities with a bar represent normalized vartables and

$$
\begin{aligned}
& F=\left(\bar{P}+\frac{1}{N-1}\right)^{2} \\
& N=p_{1} / P_{0}
\end{aligned}
$$

ancl

$$
\tau=\frac{k_{0}\left(P_{1}-P_{0}\right) t}{\varepsilon+L^{2}}
$$

Values of $\bar{k}_{x}, \bar{k}_{y}$, and $\bar{k}_{z}$ are made dimensionless using a constant reference permeability, $k_{0}$.

Eq. (9) is differenced using an implicit method because the spatial derivatives taken individually with the time derivative form a parabolic equation. We use Brian's method $23-25$ since this reduces to the alternatingdirection implicit method in two spatial dimensions identical to the "Y" and " $Z$ " directions difference algorithm used for calculating flow in the crack. The coefficient on the right hand side of $\mathrm{Eq}$. (9) is evaluated using values of $F$ at an average of the $\Delta l d$ and new times until convergence is obtained.

Increased accuracy for a given number of grid points is achieved by using a variable grid spacing for the " " direction based on Blottner's grid-stretching relationship 26,27 . Blottner's relationship is

$$
x=x_{0} \frac{\left(k^{i / I}-1\right)}{\left(k^{1 / I}-1\right)} \quad i=1,2 \ldots . I(13)
$$

where $x_{0}$ is the cotal length in the " $x$ " direction; $k$ is a variable normally between 1.5 and 2.718 (1.e. the value of $e$ ), and $I$ is the number of spatial intervals in the " $X$ " direction.

\section{FLON IN THE CRACK}

The crack is divided into parts and the analysis considers internal flow between two parallel porous wall segments through which the gas permeates the earth formation. The continuity equation may be written as

$$
\frac{\partial \rho u_{x}}{\partial X}+\frac{\partial \rho u_{y}}{\partial Y}+\frac{\partial \rho u_{z}}{\partial Z}+\frac{\partial \rho}{\partial t}=0 .
$$

We establish a contral yolume so that a single finite difference mesh spans one half the crack thickness and takes advantage of a plane of symmetry at the crack centerline across whlch there is no mass flow. Such a control volume prevents the determination of a velocity profile in the " $\mathrm{X}$ " direction within the crack. However, this Information is not germane to our analysis. The momentum equations take on a different form in the " $X$ " direction than in the " $Y$ " and " $Z$ " directions. Flow through the walls of the crack in the " " direction is governed by the pressure distribution in the 
adjacent earth formation so that Darcy's law is applicable. Flow in the " $Y$ " and " $Z$ " directions is

approximated by the momentum equation. for fully developed internal flow ${ }^{10}$ that is rearranged for an explicit solution of the velocity. The momentum equations used are

$$
\begin{aligned}
& u_{x}=-\frac{k}{\mu} \frac{\partial P}{\partial x} \\
& u_{y}= \pm\left(\left|\frac{4 d}{\rho} \frac{\partial P}{\partial Y}\right|\right)^{\frac{1}{2}} \\
& u_{z}= \pm\left(\left|\frac{4 d_{c}}{\lambda \rho} \frac{\partial P}{\partial z}\right|\right)^{\frac{1}{2}}
\end{aligned}
$$

where $d_{c}$ is the crack thickness in the " $X$ " direction and $\lambda$ is a frictional coefficient.

The plus sign in Eqs. (16) and (17) is used when the pressure gradient is $<0$ and the minus sign when the pressure gradient is $>0$. The flow may be efther laminar or turbulent. These different i iow condit lons are accounted for In the calculation of $\lambda$ which is dependent on Reynclds number and the relat ive roughness of the crack walls.

We took computed results and used these to determine the magnitude of the neglected transient and acceleration terms in the " $Y$ " and " $Z$ " direction momentum equations. The magnitude of these neglected terms was then compared with the included pressure gradient term. This comparison shows the neglected terms to be less than $10 \%$ of the included terms except at times less than about one eighth of the total problem time. Even at tnese early times the neglected terms are probably negligible stice the actual driving pressure is applied over a short period of time rather than the instantaneous fashion we have used mathematically. Application to translent conditions of a frictional coefficient, $\lambda$, evaluated under steady flow conditions, has been used by several authors. Ginzburg 28 assumed that the resistance properties established for steady flow are preserved for transient flow. Petrova also determined the magnitude of the frictional coefficient using steady flow conditions. Yeremenko and Markov ${ }^{30}$ used Prandtl's mixing length hypothesis with \& IInear variation in shear stress to obtain mathematically variations in frictional coefficients from their steady state values. Yeremenko and Markov expanded the sheal stress of Prandt l's mixing length hypothesis in the form of a polynominal based on open channel flow. They showed quantitative incrcases in frictional coefficient for accelerating flow using an unsteady flow parameter. $\delta_{0}$. 
Unfortunately, no method of determining $\delta_{0}$ is indicated without knowledge of the velocity distribution In the flow channel. This velocity distribution has been analyzed in the laminar flow regime ${ }^{31}$ but in gereral is unknown. Further studies relating the effects of acceleration on frictional coefficient are needed but in their absence we use the values corresponding to steady flow.

An Ideal gas equation of state,

$$
\rho=\frac{\mathrm{P}}{P \mathrm{~T}} \text {, }
$$

is again taken under 1sothermal conditions so that Eqs. (15) through (18) may be combined using normalized variables and neglecting gravity to give

$$
\begin{aligned}
-\overline{\mathrm{k}}_{c x} \frac{\partial F}{\partial \overline{\mathrm{X}}} \pm \frac{\partial}{\partial \overline{\mathrm{Y}}}\left(\overline{\mathrm{k}}_{\mathrm{cyz}}\left(\left|\frac{\partial \bar{F}}{\partial \overline{\mathrm{Y}}}\right|\right)^{\frac{1 / 2}{2}}\right) \pm \\
\\
\frac{\partial}{\partial \bar{z}}\left(\overline{\mathrm{k}}_{c y z}\left(\left|\frac{\partial \bar{F}}{\partial \bar{Z}}\right|\right)^{\frac{1}{2}}\right)+\frac{\partial \overline{\mathrm{P}}}{\partial \tau}=0
\end{aligned}
$$

where

$$
\begin{gathered}
\overline{\mathrm{k}}_{c \mathrm{x}}=\frac{\varepsilon \mathrm{L} \overline{\mathrm{k}}_{\mathrm{x}}}{\mathrm{d}} \\
\overline{\mathrm{k}}_{c y z}=\frac{\varepsilon \mu}{\left(\mathrm{P}_{1}-\mathrm{P}_{0}\right) \mathrm{k}_{0}}\left(\frac{2 \mathrm{~d}_{c} \mathrm{~L} R \mathrm{~T}^{\frac{1}{2}}}{\lambda}\right)^{\frac{1}{2}}
\end{gathered}
$$

The reference permeability, $k_{0}$, is set so that the Initial value of $\overrightarrow{\mathrm{k}}_{\text {cyz }}$ is unity at the origin.
Equation (19) may he placed in an efficient and convenient form for numerical solution by differentiating the " $Y$ " and " $Z$ " terms which, after rearranging and using Eq. (10), ylelds

$$
\begin{aligned}
& \overline{\mathrm{k}}_{\mathrm{cx}} \frac{\partial \mathrm{F}}{\partial \bar{X}}+\left(\frac{\partial \mathrm{F}}{\partial \bar{Y}} /\left(\left|\frac{\partial \mathrm{F}}{\partial \bar{Y}}\right|\right)^{\frac{1}{2}}\right) \frac{\partial \overline{\mathrm{k}} c y z}{\partial \bar{Y}}+ \\
& {\left[\overrightarrow{\mathrm{k}}_{c y z} / 2\left(\mid \frac{\partial F}{\partial \bar{Y}}\right)^{\frac{1}{2}}\right] \frac{\partial^{2} \bar{F}}{\partial \bar{Y}^{-2}}+}
\end{aligned}
$$$$
\left(\frac{\partial F}{\partial \bar{z}} /\left(\left|\frac{\partial F}{\partial \bar{z}}\right|\right)^{\frac{1}{z}}\right) \frac{\partial \bar{k}}{c \bar{z}}+
$$$$
\left[\bar{k}_{c y z} / 2\left(\mid \frac{\partial F}{\partial \bar{Z}}\right)^{\frac{1}{2}}\right] \frac{\partial^{2} F}{\partial \bar{Z}^{2}}=\frac{1}{2} F^{-\frac{1}{2}} \frac{\partial F}{\partial \tau} \text {. }
$$
The terms in Eq. (22) containing
$\partial \bar{k}_{\text {cyz } / \partial \bar{Y} \text { and } \partial \bar{k}_{\text {cyz } / \partial \bar{Z}} \text { are calculated }}$ explicitly since they vary mainly with spatial location and are nearly constant with time. The terms in square brackets make Eq. (22) nonlinear. If the " $X$ " direction spatial derivative dominates over the " $Y$ " and " " direction derivatives of $F$, the equation becomes hyperbolic in nature. An expliclt differencing technique would then be necessary to prevent artificial numerical damping ${ }^{32}$. If either the "Y" or " $\mathrm{Z}$ " direction derivatives of $\mathrm{F}$ dominate, the equation becomes parabolic and an implicit solution 
is most efficienf. Because dominance by any one spatial derivative may occur, we use an op rator splitting technique $^{33}$ to solve Eq. (22). This increases the speed of computation because the stability inherent with implicit dfferencing may be used to advantage. Eq. (22) is broken into two separate equations

$$
\begin{aligned}
& \bar{k}_{c x} \frac{\partial F}{\partial \bar{X}}=\frac{1}{2} F^{-\frac{b}{2}} \frac{\partial F}{\partial \tau} \\
& \left(\frac{\partial F}{\partial \bar{Y}} /\left(\left|\frac{\partial \bar{F}}{\partial \bar{Y}}\right|\right)^{\frac{1}{2}}\right) \frac{\partial \bar{k}}{\frac{\bar{c} y z}{\partial \bar{Y}}}+ \\
& {\left[\bar{k}_{c y z} / 2\left(\left|\frac{\partial F}{\partial \bar{Y}}\right|\right)^{\frac{1}{2}}\right] \frac{\partial^{2} F}{\partial \bar{X}^{2}}+}
\end{aligned}
$$

\section{Calculational Method}

The problem posed in this study is solved numerlcally using nearly the encire small core memory of a Contro1 Data Corporation* 7600 computer. Although use of just the small core memory results in faster speed, the calculations are still

* Reference to a company or product name does not imply approval or recommendation of the product by the Untversity of California or the U.S. Energy Research \& Development Administration to the exclusion of ochers that may be suitable.

$$
\begin{aligned}
& \left(\frac{\partial F}{\partial \bar{z}} /\left(\left|\frac{\partial F}{\partial \bar{L}}\right|\right)^{\frac{1}{z}}\right) \frac{\partial \bar{k} c y z}{\partial \bar{z}}+ \\
& {\left[\bar{k}_{c y z} / 2\left(\left|\frac{\partial F}{\partial \bar{z}}\right|\right)^{\frac{1}{2}}\right] \frac{\partial^{2} F}{\partial \bar{z}^{2}}=\frac{1}{2} \mathrm{~F}^{-\frac{1}{2}} \frac{\partial F}{\partial \tau}}
\end{aligned}
$$

with Eq. (23a) Eirit solved repeatedly in an explicit fashion using a small time step to assure stablitity. The resulting new values of $F$ from $E q$. (23a) are used as Initial values to solve Eq. (23b) which is solved by the alternating-direction implicit method $^{23}$. The total time increment in solving both Eqs. (23a) and (23b) is kept identical. time consuming. The 65,000 word capactty of the small core memory permitted the inclusion of about 3000 spatial nodes. A larger number of spatial nodes could have been included but at a sacrifice in the speed of computation. Typical computer run times using just the small core memory range from 15 minutes to one hour. The total computer time to generate the results for this study was about 50 hours.

Both the crack wall deflection and the frictional coefficient are 
found at each node within the crack from the governing equations. The bulk of the calculations in ear'। time step are required to decermine the pressure function, $F$, in the porous solid and in the crack. At each node we select the applicable governing equation. The calculation of $F$ at the new time step is performed in three parts. First, Intermediate values of $F$ are found using Eq. (23a) If the node is within the crack or, if the node is in the porous solid, by setting up a matrix with the " $x$ " direction calculations implicit. These first intermediate values of $F$ are determined for each node before the calculations are continued. Next, we use the first intermediate values of $F$ to determine a secont intermediate value of $F$ at each node by considering the "Y" direction calculations to be implicit Finally, the value of $F$ at the end of the time step is determined at each ncde using the second intermedlate values of $F$ and by considering the "z" direction calculations to be implicit. In this fashton, the calculations for nodes in the crack are interspersed wth calculations for nodes in the solid.

The governing equat lons are nonlinear so that stabilfty is not assured even lhough the differencing is lmplictt unless tho t imo step is kept below an upper bound. This upper bound was determined by trial calculations. Values at pressure need only be determined for calculation of the crack wall deflection and for printout of the results. We find that results are independent of variations in the time step over a factor of one hundred as long as stablliry is malntafned. This is an Indication that writhg the governIng equations in tertis of $F$ was a Judiclous cholce.

Up to a point, results are also independent of changes in the " $Y$ " and " 7 " direstion spatial mesh size. However, a decrease of the " $X$ " direction spatial mesh size by a factor of 100 typlcally was found to increase the time for crack propagation to the surfact of the earth by $20 \%$. This is due to the dependence of gas permeation into the porous solid from the crack on the pressure function derivative, the approximation of which improves as the mesh size is reduced. Because our interest is in prevention of crack propagation, selection of a given " $X$ " direction spatial mesh size acts as a conservarl us bound on the time requlred for crack propagation. That is, inclusion of a finer grid spacing has the effect of Increasing crask propagation time. If no propagation occurs under the selected " $X$ " Utrection mesh size, then a reduction in 
mesh size would only confira that the crack will not propagate. Although it might appear desirable to continually decrease the " $\mathrm{X}$ " drection grid size, a limit is reached where the $\mathrm{CDC} 7600$ small core memory is exceeded if the necessary spatial distances are maintained, Computer run time would then increase beyond our allowable budget. The computer program consists of a main portion used for input and output and which updates necessary variables prior to calling three calculational subroutines. These three subroutines determine the crack wall deflection, rrictional coefficient, and flow both in the crack and in the porous solid. A typical real-time step was $0.005 \mathrm{~s}$.

\section{Experimental Verification}

The primary application of this study is to assure the safety of underground nuclear explosions. Experimental verification by means of a underground nuclear explosion with subsequent release of contaminants to the atmosphere is in conflict with this study's basic purpose of preventing the release of contaminants. Full scale tests using high explosives are costly since enough sxplosive must be used to propagate the crack a significant distance. Perhaps some laboratory scale model of the complete analysis is nossible; however, one is conserned about the accuracy of measuring the location of a propagating crack in an earti formation on a reduced scale. Consequenily, experimental vorification of the complete analysis does not appear feasible.
We found experimental data in the literature for the frictional coefficient used to calculate flow in the crack. We also found experimental data in the literature relating load, surface deflection, and distance away from the polnt of load application which could be used to determine deflection of the crack wall. Data necessary to adequately verify the nonlinear, transient gas flow in the solld was not found in the literature so we constructed an experimental facility and generated the required information. Each portion of this analysis then is either experimentally verffied or based on experimental results from the literature.

The experimental test apparatus constructed to obtain data for transient gas flow in a porous solid consisted of a $0.3 \mathrm{~m}$ diameter, 
$4.6 \mathrm{~m}$ long steel pipe fil.led with Overton sand as shown schematically in Fig. 4. 0verton sand has a permeability of $20(\mu \mathrm{m})^{2}$, which is within the raage of perne for alluvium at NTS, anc was selected rather than alluvium formation because of the ease in installation and because no economical means exists to obtain samples of alluvium formation at depths over a hundred meters of the size necessary for our tests without significantly changing its permeability and other flow properties. Dry nitrogen was forced through the column of sand by using a pneumatically operated valve controlled by an analog computer. Flow rate has determined by measuring the gas pressure on each side of sharp edged orifices placed in the inlet line. Measurements of gas pressure in the column of sand were made as a function of time at eight axial locations.

Pressure was obtalned with strain-gage type pressure transducers having an accuracy of $0.1 \%$ of $\mathrm{ful}$ ? scale. Readout of pressure was performed on strip chart recorders capable of resolving prensures to $2 \%$ of the 3.5 bar inlet pressure. The facility was designed to permit use of a mixture of steam and nitrogen; however, these data are not applicable to the present study.

Each test was conducted by first establishing the approximate intial flowrace using a bypass line. An orifice was Installed in the bypass line to simulate the initial resistance of the colum of sand. At the appropriate time a three-way, full-flow valve was actuated that switched flow from the bypass 1 ine to the line leading to the column of sand. A zero time was established when the pressure tranducer at the inlet to the column of sand recorded the resulting step change in pressure.

A comparison of these data with the theoretical results which are used to predict the non-1inear transient gas flow in the porous solid is shown in Fig. 5. The theoretical results for selected times are indicated as solid lines with the experimental data points related by the varlous symbols. Agreement is felt to be excellent thereby confirming the accuracy of the analysis for gas flow in the porous solid. The analysis for the " $x$ " direction Bas flow out of the sides of the crack has the same form as gas flow in the porous solid since it is governed by the pressule distribution in the poraus solid. 


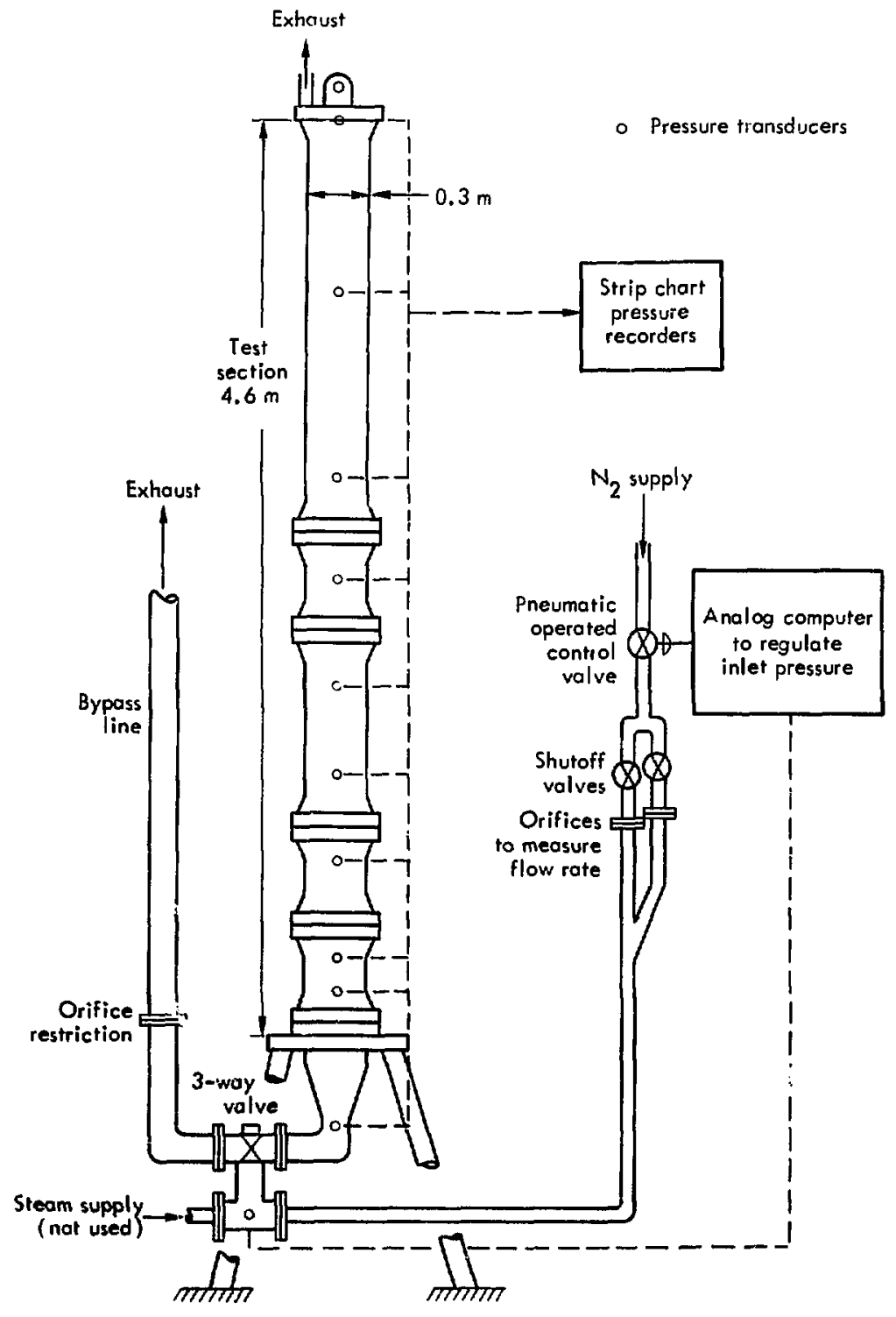

Fig. 4. Test apparatus for measuring transient gas flow in a porous solid. 


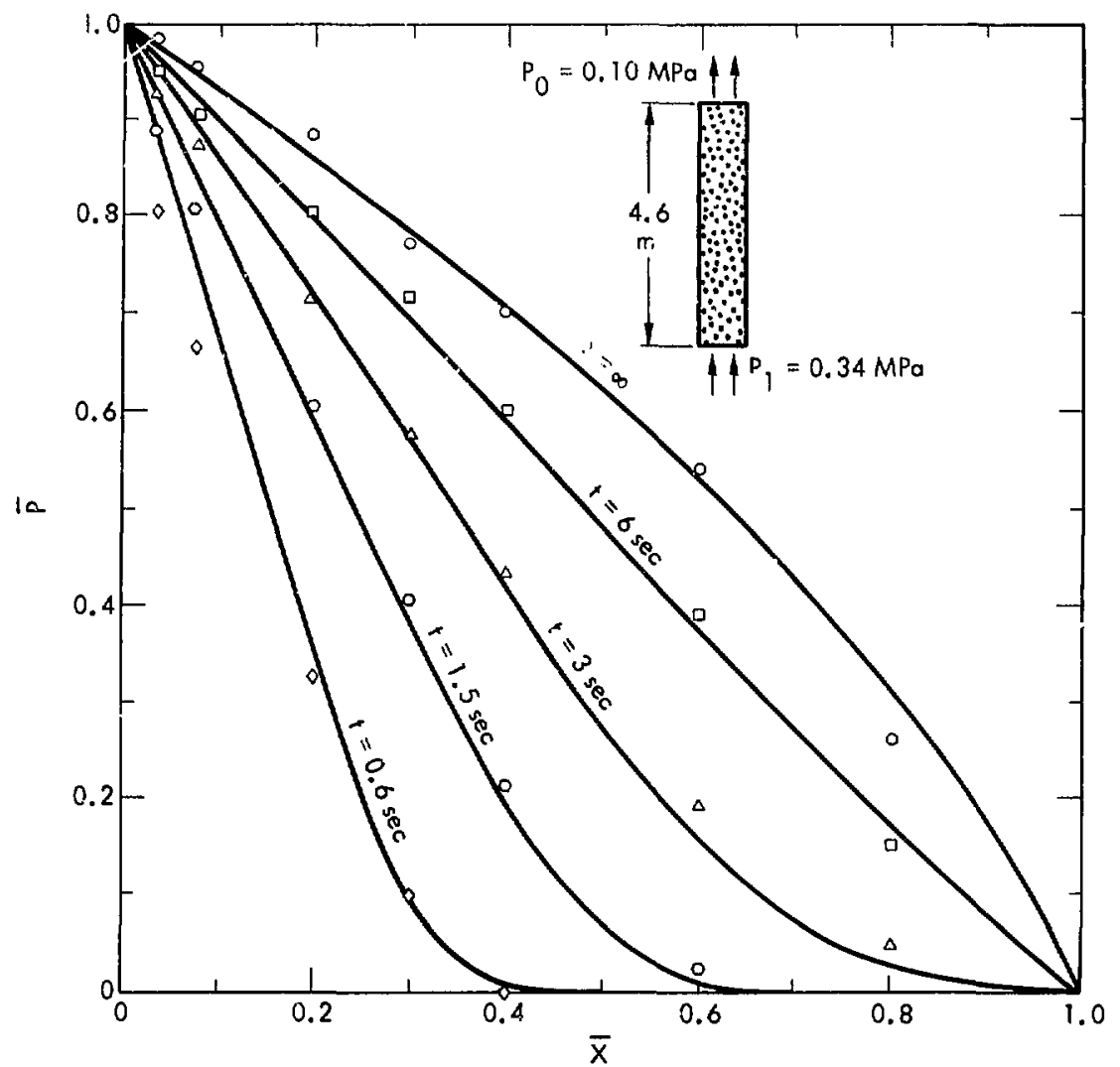

Fig. 5. Comparison between theoretical and experimental results for nitrogen flow through a coluinn of $20(\mathrm{um})^{2}$ permeability overton sand. 


\section{Results}

Results were generated using the parameters shown in Table 1. for a proposed underground nuclear test. A hypothetical crack with initial length and width up to their maximum feasible values of $110 \mathrm{~m}$ and $170 \mathrm{~m}$, respectively, was incorporated since this presented an upper bound on posstble propagation of the crack. An exponential decay of the driving pressure was included to approximate the expected conditions of the proposed test. This reduces the driving prassure to about $95 \%$ of its initial valte in 60 seconds. The exponential decay continues for perhaps 10 minutes, after which lise pressure decreases abruptly. This abrupt decrease in pressure occurs as the formation starcs to fall into the cavity vrid space and rapidly cools the gases present there.

A parametric study was completed to assure that radioactive contaminants would be contained below the surface of the earth if the proposed test were actually conducted. Figure 6 shows results for maximum feasible values of Initial crack length and width. Time for crack propagation to the surface of the earth is seen to increase as permeability and the ratio of maximum resistive
Table 1

Parameters from a Proposed Underground Nuclear Test. Use for Generating Results

$$
\begin{aligned}
& \text { Distance to satface } \\
& \text { of the earth } \quad-530 \mathrm{~m} \\
& \text { Lnitial crack length - } 30 \text { to } 110 \mathrm{~m} \\
& \text { Initlal crack width - } 60 \text { to } 170 \mathrm{~m}
\end{aligned}
$$

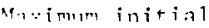

$$
\begin{aligned}
& \text { clack thlckness - } 10 \text { to } 50 \mathrm{~mm} \\
& \text { Permeability of the } \\
& \text { formation } \\
& -10^{-6} \text { to } 1(1, \mathrm{~m})^{?} \\
& \text { Porosity of the } \\
& \text { formation } \\
& -0.3 \\
& \text { Poisson's ratio of } \\
& \text { the formation } \quad-0.25 \\
& \text { Modulus of elasticity } \\
& \text { of the formation }-3.5 \mathrm{GPa} \\
& \text { Initial driving } \\
& \text { pressure } \\
& \text { - } 10 \mathrm{MPa} \\
& \text { Gas viscosity } \\
& -2.4 \times 10^{-5} \mathrm{~Pa} \cdot \mathrm{s}
\end{aligned}
$$

pressure, ${ }^{P} r_{\max }$, to initial driving gas pressure, $P_{1}$, increases. Because the driving pressure decays with time, each curve approaches an asymptote. That is, propagation will occur in the first few minutes if it occurs at all. Maximur penetration of cavity gases into the formation beyond the crack tip was found to be less than $1 \%$ of the distance to the surface of the earth. For the proposed test, the permeability 


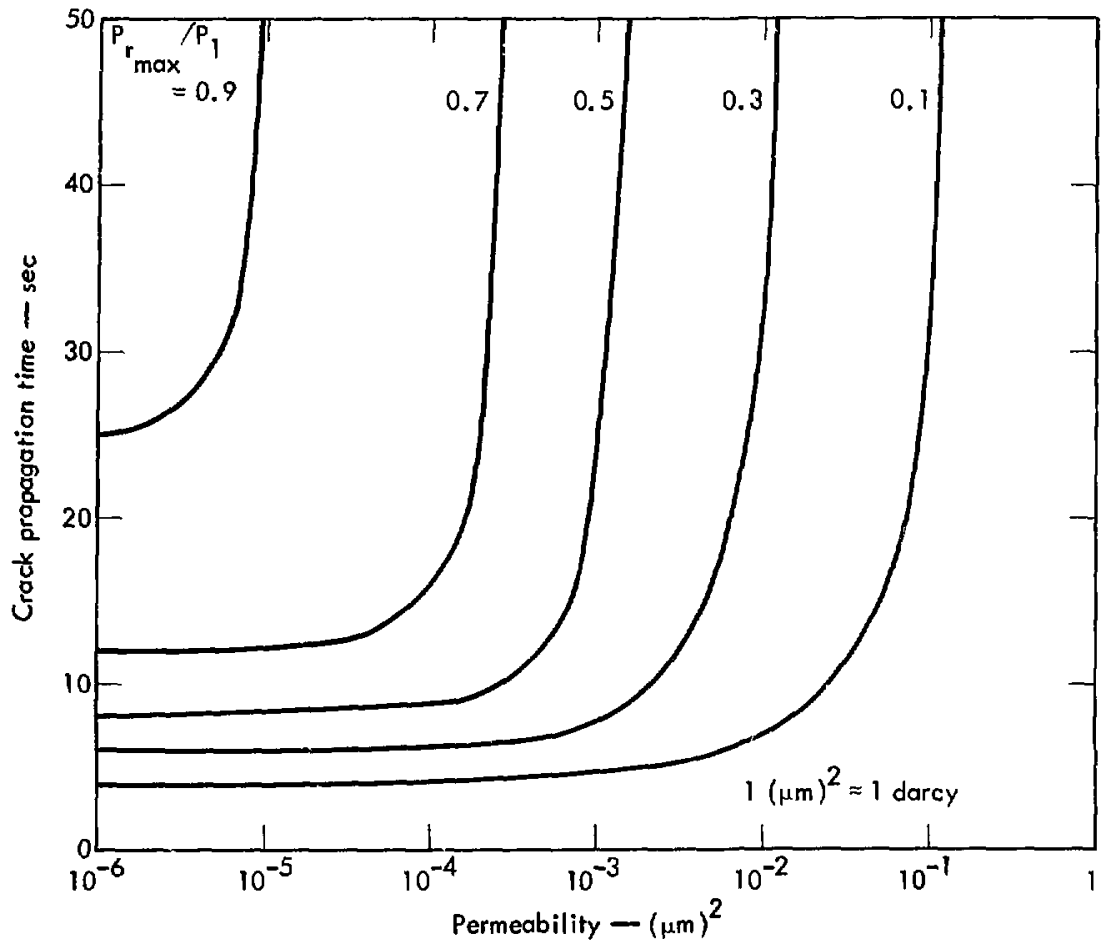

Fis. 6. Crack propagation time vs permeability for various ratios of maxinum resistive pressure to initial driving pressure.

of the earth formation ranges between $10^{-2}$ and $1(\mu \mathrm{m})^{2}$. The expected ratio of ${ }^{P} r_{\max } / P_{1}$ is close to unity with the lowest feasible value equal to $1 / 3$. Under these conditions we find that a crack would not propagate to the surface of the earth and therefore no radioactive material would be released into the atmosphere should the proposed test be conducted.

For any given set of parameters, there is a permeability large enough to prevent crack propagation. That is, gas flowing into the crack from the source permeates the earth formation so rapidly that pressures inside the erack do not exceed the 
resistive pressure forces of the earth formation which tend to prevent crack propagation. As the permeability is decreased, the crack propagates a short distance and stops. This is due to a reduction In gas pressure inside the crack as propagation occurs. Inttially the gas flowing into the crack from the source cannot be dissipated into the earth format:on fast enough to prevent propagation. As the crack grows, the area of the crack walls through which gas permeates the earth formation increases thereby decreasing the resistance to gas flow out of the crack. The resistance to gas flow inside the crack remains more nearly constant, increasing as the length of the crack increases and decreasing as the flow area inside the crack increases. The net effect is to reduce gas pressure inside the crack.

With additional decreases in permeability, the crack propagates farther until a magnitude of permeability is reached where the crack just propagates to the surface of the earth. Further decreases in permeability shorten the time necessary for crack propagation. This is seen in Fig. 7 where the normalized crack tip location along the " " axts is presented as a function of time for three values of permeability near that which causes the crack to just reach the surface of the earth. The slope of the curves represent the speed of propagation which is rapid at first decreasing with time as the resistance for gas to permeate the earth formation decreases. Near the surface of the earth the resistive pressure forces of the formation, which are proportHonal to the depth below the surface, decrease faster than the pressure near the tip of the crack. Hence, for those cases where the crack reaches the surface of the earth, the speed of propagation increases at late times. For the middle curve on Fig. 7, the minimum speed is about $15 \%$ of the maximum speed.

Figure 8 shows the vartation of crack tip location on the " $\mathrm{"} \mathrm{axis}$ vs time for several inftial crack sizes. The length and width values selected correspond to multiples of the spatial zone size. A crack with initial length and width of $30 \mathrm{~m}$ by $30 \mathrm{~m}$ travels rapldly untll it reaches the length and width of an initially larger crack. Beyond this time the speed of crack propagation for both cracks is nearly the same. Hence a variation in crack length and width by a factor of four results in a change in propagation time of only $15 \%$. The maximum initial crack thickness chosen at the origin 


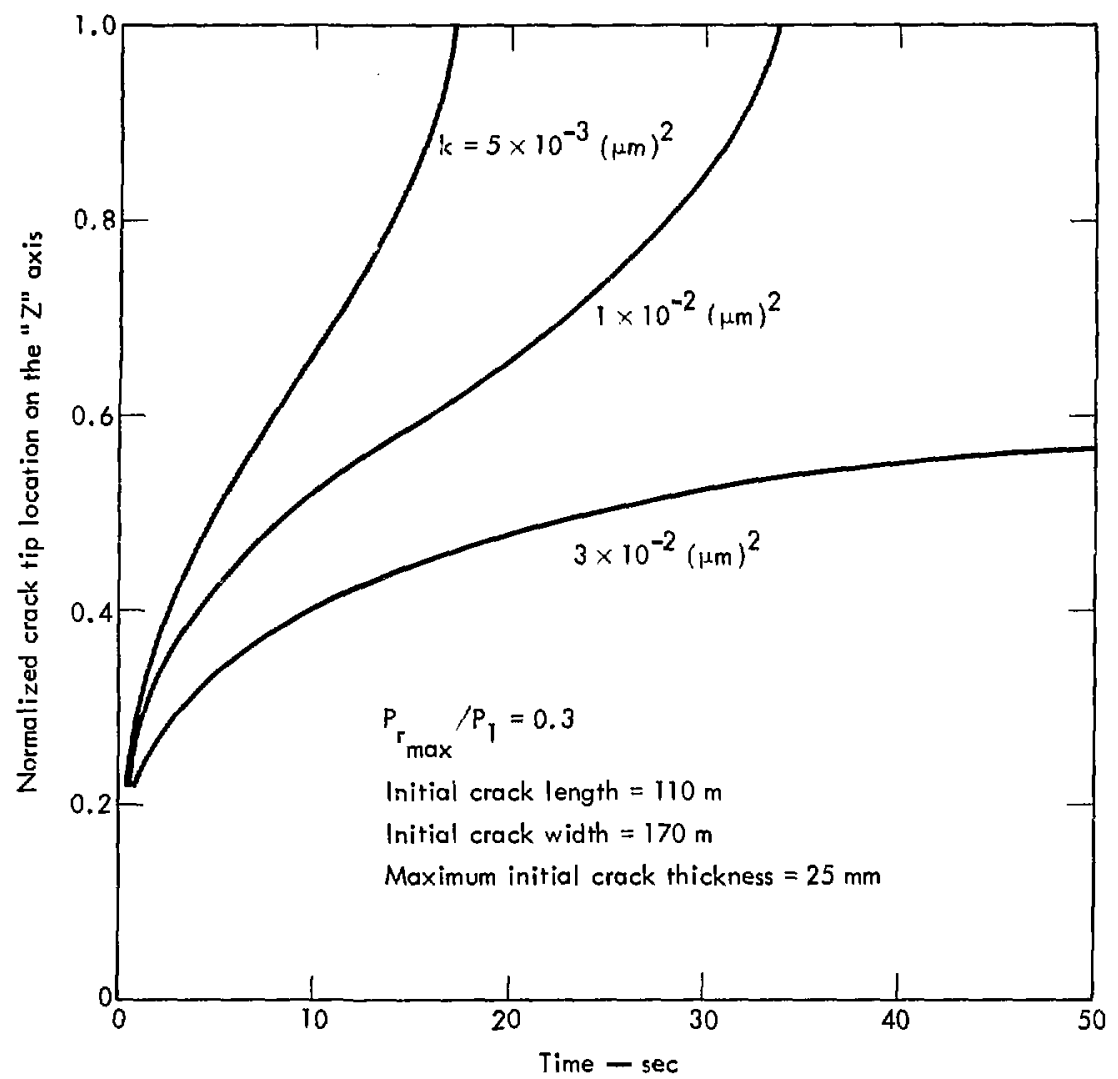

Fig. 7. Crack-tip locaticn on the " $Z$ " axis vs time for three magnitudes of permeability near that required for the crack to just reach the surface of the earth.

is less than $10 \%$ of the crack thickness at the origin after deflection occurs so that changes in initial crack thickness by a factor of four affect the crack propagacion time by less than $25 \%$.
The initial shape of the crack in the "Y" and " $Z$ " directions was chosen to be rectangular. Figure 9 indicates that the crack becomes fan shaped as propagation occurs. The crack grows more vertically than 


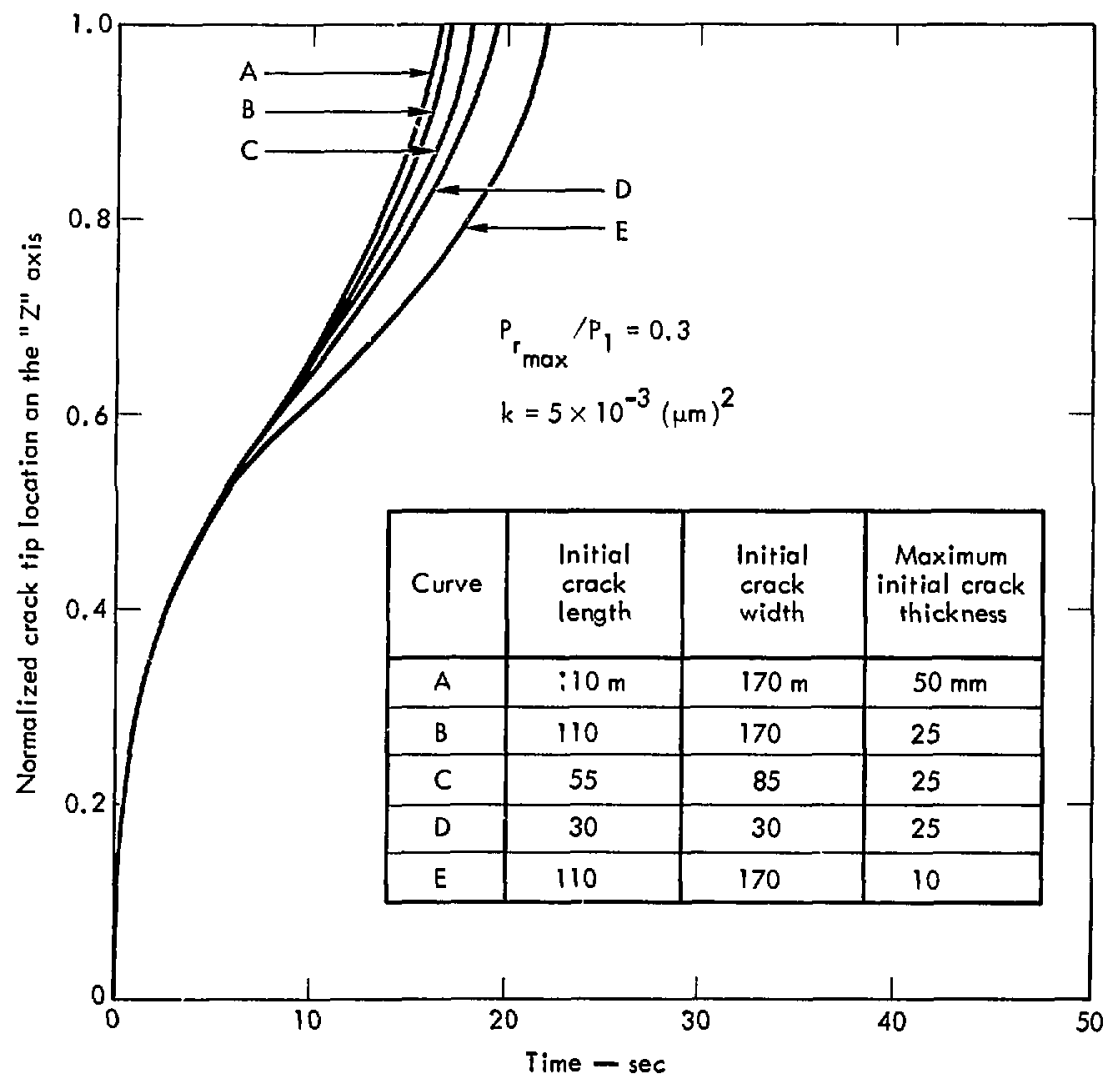

Fig. 8. Crack-tip location on the " $\mathrm{"} \mathrm{axis} \mathrm{vs} \mathrm{time} \mathrm{for} \mathrm{several} \mathrm{initial} \mathrm{crack}$ sizes.

horizontally because the earth

formation resistive pressure, ${ }^{P_{r}}$, which tends to prevent crack deflection, is proportional to depth below the surface.

Because gas pressure at the crack tip in the region near the horizontal depends mainly on the distance froin the pressure source to the crack tip, equal crack wall deflection, or crack thickness, occurs at a larger distance from the pressure source above the horizontal where $P_{r}$ is less than its value on 


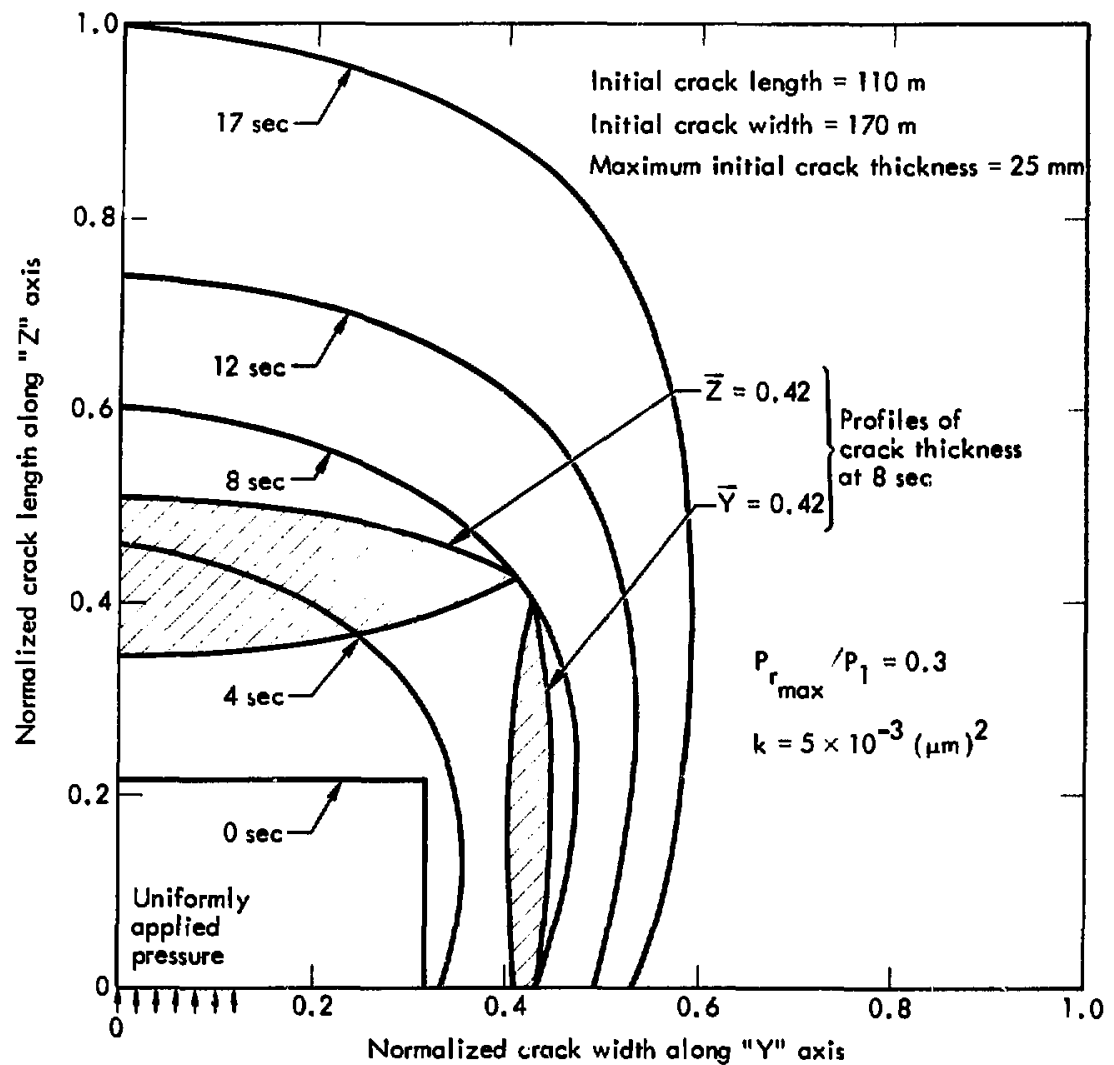

Fig. 9. Crack length vs width at various times. Also shown are profiles of crack thickness at 8 seconds for $\bar{Y}=0.42$ and $\bar{Z}=0.42$.

the horizontal. Hence, the locus of the crack tip is convex to the right. The cross hatched areas in Fig. 9 show profiles of crack thickness for constant values of " $\mathrm{"}$ " and " $\mathrm{Z}$ " at 8 seconds. The scale of the cross hatched areas is different than the rest of the graph with the maximum thickness for $Y=0.42$ equal to $20 \mathrm{~mm}$ and for $z=0.42$ equal to $85 \mathrm{~mm}$.

Figs. 10 and 11 show the variation of crack thickness and normalized pressure as a function 


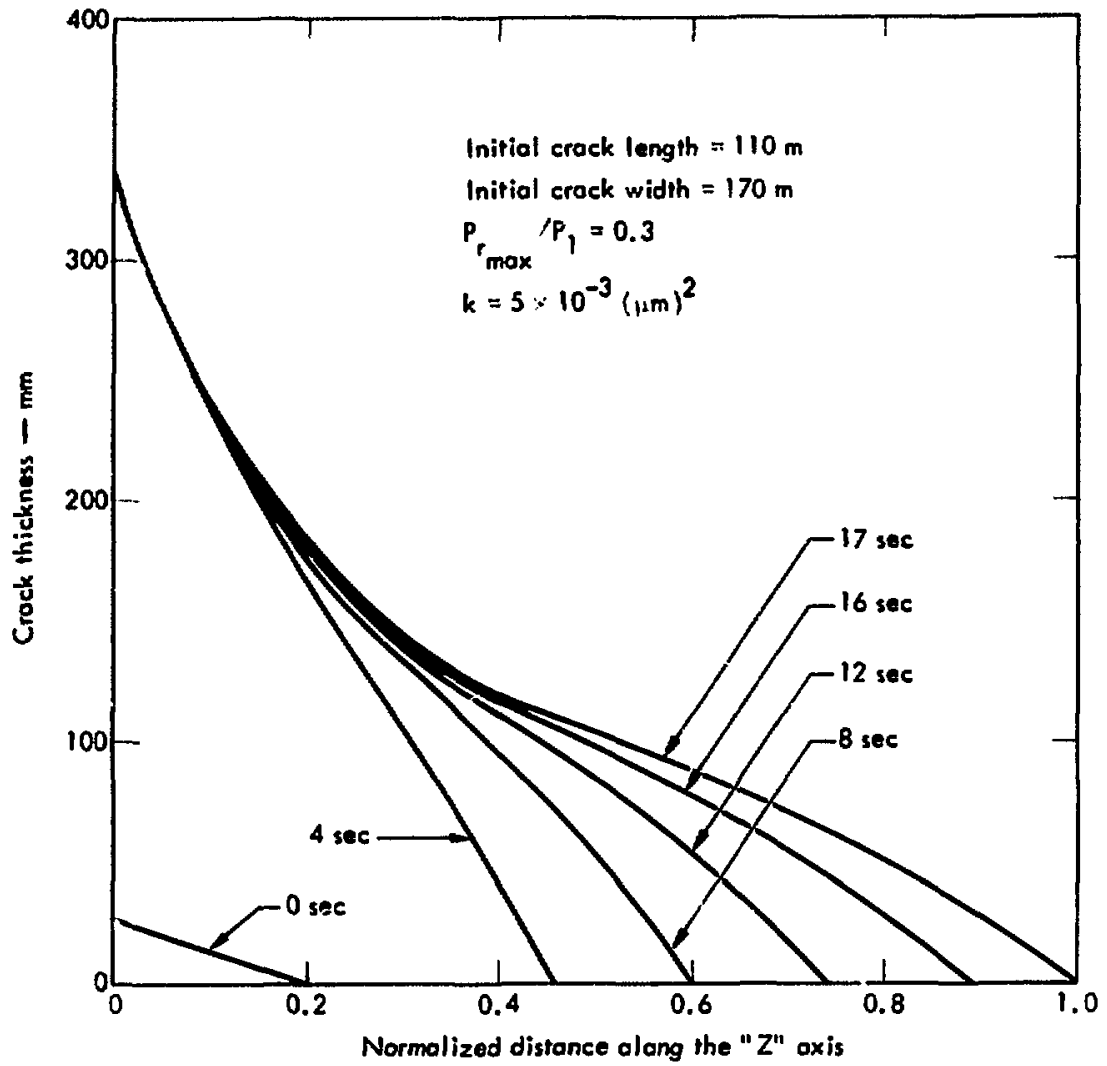

F1g. 10. Crack thickness vs normalized distance along " $z$ " axis for vartous times.

of distance along the " $Z$ " axis for varlous times. Both graphs are interrelated. Initial crack thickness was taken as linear with distance as shown by the lower left curve of Fig. 10. As gas flows into the crack, the crack thickness and pressure increase. The Increased crack thickness reduces the resistance to gas flow and allows for further increase in pressure within the crack. A complex variation of crack thickness and pressure with distance along the " $Z$ " axis develops 


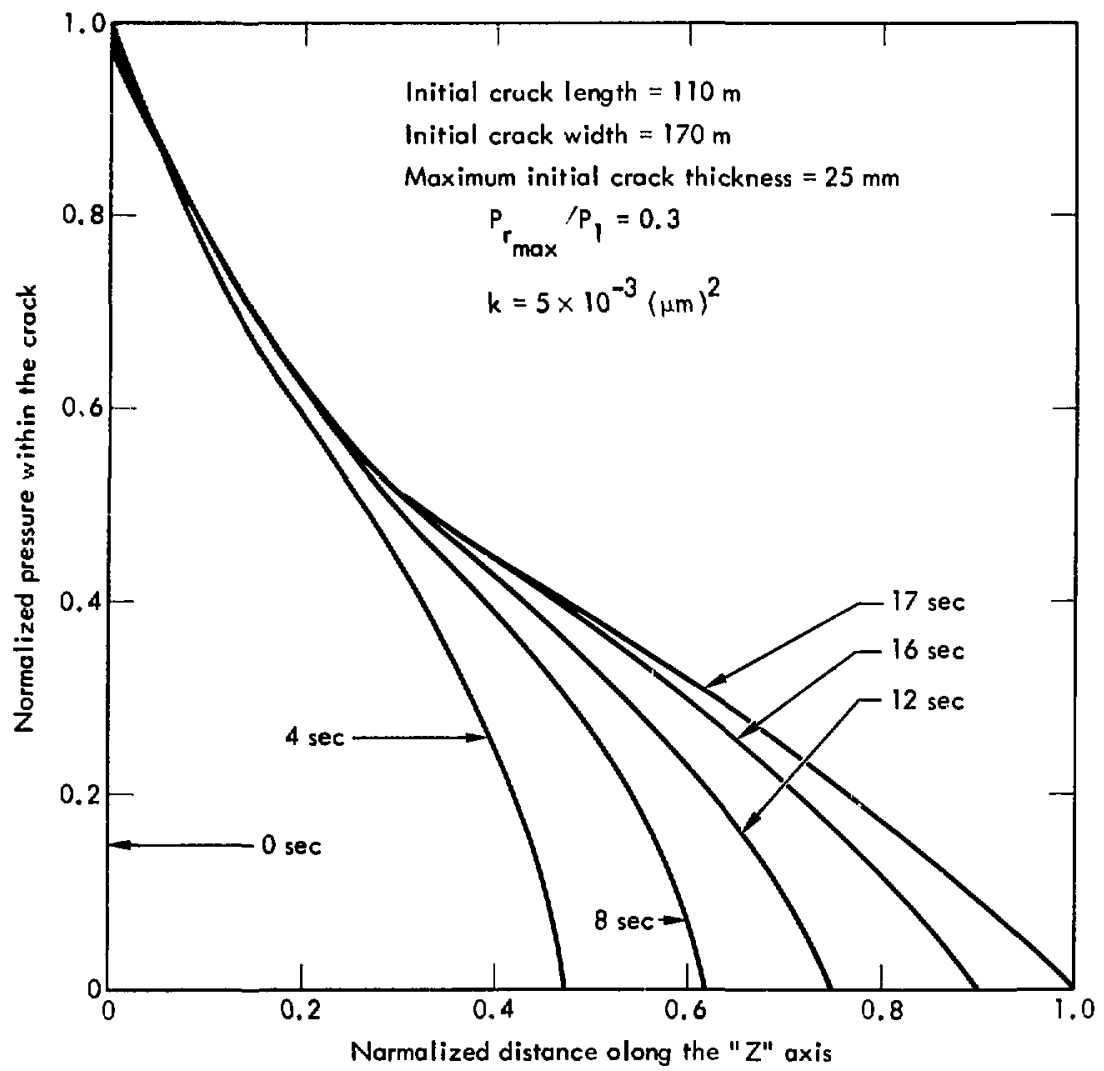

Fig. 11. Normalized pressure within the crack vs normalized distance along the " $\mathrm{Z}$ " axis for various times.

as time elapses. The concave upward shape near the left side of the curves in both graphs is characteristic of a channel with porous walls. The crack thickness and pressure are depressed due to loss of gas through the walls of the crack into the earth formation. Near the crack tip the curves become concave downward. Here the crack thickness becomes small and the resistance to gas flow inside the crack increases. Consequently, gas flow into the formation is less important in comparison to gas flow inside the crack near the crack tip than it is near the " $\mathrm{"}$ " axis. 


\section{Conclusion}

To our knowladge, this is the first study that shows the interaction of gas pressure within a crack, permeation of gas into a porous enrth formation, deflection of the crack wall, and the phenomenon of crack propagation. One other analysis by Keller, Davis, and Stewart ${ }^{6}$ defermined if a small crack of length up to $75 \mathrm{~mm}$ would inftially grow but not if propagation would continue. Although conditions were difterent, results that can be compared are in reasonable agreement.

Crack propagation to the surface of the earth following an underground explosion occurs as shown in Fig. 6 and the parameters of Table 1 only under unlikely conditions. For example, if the permeability is $3 \times 10^{-4}(\mu \mathrm{m})^{2}$ and the ratio of maximum earth formation resistive pressure due to overburden to initial driving pressure is 0.7 , the crack would reach the surface of the earth in 50 to 60 seconds.

Normally, the permeablitity of the earth formation at the Nevada Test site where experimental underground nuclear explosions are conducted ranges hetween $10^{-2}$ and 1 $(u m)^{2}$. The corresponding value of maximum earth formation resistive pressure is close to the intial driving pressure so that crack propagation to the suriace of the earth is not anticlpated. Conditions of each test may be checked with this analysis to assure radioactive contaminants are contained below the surface of the earth following an underground nuclear explosion. 


\section{Nonienclature}

$\lambda$ - Surface area of pressure $\bar{D}$ applicat ton

$\overline{\mathbf{A}}$

a eq

C

$\mathrm{C}_{\mathrm{G}}$

d

$d_{c}$

$\mathrm{d}_{\mathrm{h}}$

dp

$D$

D
- Normalized area equal to $\mathrm{A} / \mathrm{L}^{2}$

- Equivalent radius of a square area of sldes 2 a

- Dimensionless constint used in deriving Darcy's Law

- Gerrard and Morgan deflection coefflcient

- Characteristic leng,th approximating the grain size direction which is half of the hydraulic diameter, $d_{h}$

- Hydraulic diameter equal to four times the flow area divided by the wetted perimeter

- Average particle stze of graing in the earth formation

- Deflection of the crack boundary in the " $X$ " direction due to a point force or pressure acting on a small area

- Total deflection of the crack boundary in the " $\mathrm{X}$ " direction
- Crack thickness in " $X$ "

- Sormalfzed cotal surtace deflect

$d X, d Y, d 7 . \quad-$ Elementai dtstinces in the "x", "y", s "\%" directions

- Filemental distance In the direction of the total velocity vartor within the crack

E

$\overline{\mathrm{E}}$

F

F

g

$1, j, k$

I

$k_{x}, k_{y}, k_{z}$
- Modulus of clatstite of the earth formation

- Normalized modulus of elasticity equal to $E /\left(P_{1}-P_{0}\right)$

- Pressure function equal to $\left(\overline{\mathrm{P}}+\frac{1}{\mathrm{~N}-1}\right)^{2}$

- Porce equal to gas pressure in the crack less the resistive pressure, times the area of application

- Acceleration of gravity

- Spatial Indices

- Number of spatial intervals in the " $X$ " direction used in Blottner's grid stretching relationship

- Directional permeabilities for gas in the " $X ", " Y ", \&$ " $Z$ " directions 


$$
\begin{aligned}
& \begin{array}{r}
\bar{k}_{x}, \widetilde{k}_{y}, \bar{k}_{z}- \\
\\
\bar{k}_{x} \\
\\
\bar{k}_{0}
\end{array} \\
& \mathbf{q} \\
& \text { meablicles equal to } \\
& \vec{k}_{x}=\frac{k_{x}}{k_{0}}, \vec{k}_{y}=\frac{k_{y}}{k_{0}}, \bar{k}_{z}= \\
& \bar{k}_{c x} \\
& \mathrm{k}_{\mathrm{cyz}} \\
& \text { L } \\
& \text { N - Pressure ratio, equal } \\
& \text { NTS } \\
& k_{0} \\
& \text { to } P_{1} / P_{0} \\
& \text { - Nevada Test Site near } \\
& \text { Las Vegas, Nevada } \\
& \text { P - Gas pressure } \\
& P_{r} \quad \text { - Earth formation resis- } \\
& \text { tive pressure } \\
& P_{0} \quad \text { - Initial earth formation } \\
& \text { pore pressure } \\
& \text { Q } \\
& \text { r } \\
& \text { R } \\
& \pi \\
& \text { Re } \\
& \text { t } \\
& \text { T } \\
& u_{x}, u_{y}, u_{z} \\
& \tilde{\mathbf{u}} \\
& \bar{r}
\end{aligned}
$$

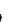

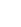

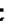

$$
\begin{aligned}
& \left(\mathrm{P}_{\mathrm{r}} \mathrm{P}_{0}\right) /\left(\mathrm{P}_{1} \mathrm{P}_{0}\right) \\
& \text { - Volume flow rate } \\
& \text { - Radius from load area }
\end{aligned}
$$




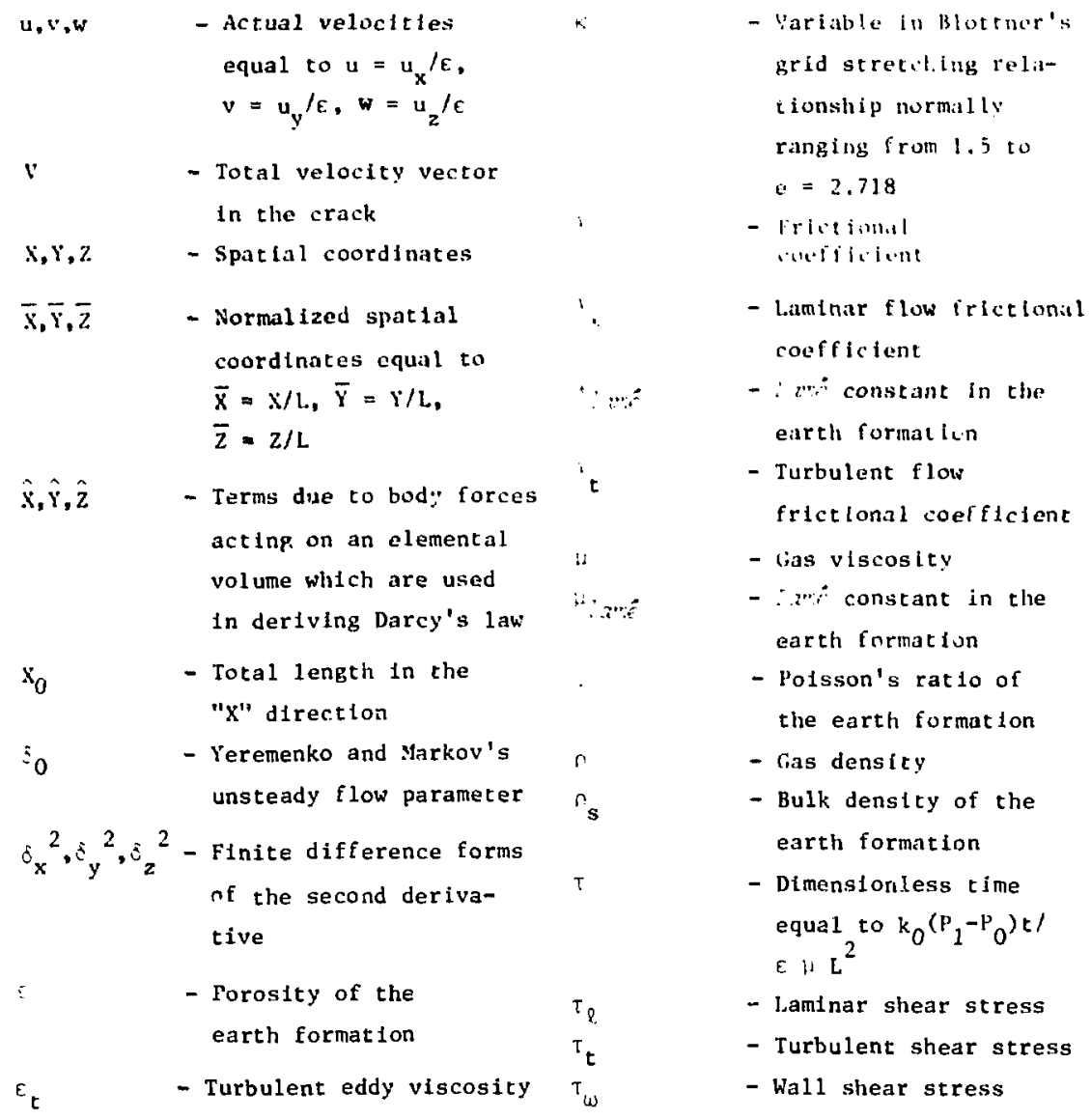

\section{Acknowledgments}

Messrs. W. Arnold, V. Karpenko, and $C$. Walter of the Lawrence Livermore Laboratory authorized and supported this research. Professors
H. Brandt, H. Dwyer, and A. Mckillop of the University of Calffornia at Davis gave technical guldance throughout the project. 


\section{Heferences}

1. (i. C. Howard, and C. R, Fast, Hydraulic Fracturing, (Society of Petroleum Engineers of AIMF. Sew lork, 1970 ).

$\therefore \quad$ M. E. Hauson, B. K. Crowley, and .l. S. Kahn, Masslue Hydraulic Fracturing: Ident Lflcation of Critical Teclanical Issues for dppliriation in Increasing lials Production in the Western linited States, lawrence Livermore laboratory, Rept. (CRL-5i751, (1975).

3. R. Rozsa, D. Snocberger, and 1. Baker, lurmegility of a Nuclear ChImney and Surface Alluulum, diea 2 , JRDA NTS, lawrence l.fvermore laboratory Rept. L'(1)-1672\%, (1975).

4. E. Teller, W. K. Talley, Li, H. Highins, and (i. W. tohnson, The Constructive Lises of Nuclear Explusives (Ycliraw-Hili, New Yorh, 1968) p. 162, Chapter 4.

5. 1. K. Lee, Soll Hechanics, Selected Toplcs, (American Elsevier, New York, 1968) pp 36-3i.

6. C. E. Keller, A. H. Davis, and . N. Stewart, Jr., The Calculation of Steam flow and lydraulic Fracturing in a Porous Medium with the KRAK Code, Los Nlamos Scientiflo Laboratory, Rept. LA-5602-MS, (1974).

7. J. M. Cleary, Hydraulic Fracture Theory, Stace of Ili inols Division of (ieological Survey, Urbana, I1linois, Circulars 251, 252, and 281, (1958, 1959).

8. C. M. Gerrard, and J. R. Morgan, "Inittal loading of a Sand Layer Under a Circular pressure Membrane," Geotechnique, Vol. 22, (1972,) pp 635-651.

9. F. A. Norrison, Jr., "Transient Gas Flow in a Porous Column," I\&EC Fundamentals, Vol, 11. (1972) pp 191-197.

i0. H. Schlichting, Boundary-Layer Theory, McGraw-Hill, New York 6 th Edition, $\left.1968^{\circ}\right)$.

11. S. P. Timoshenko, and J. N. Goodier, Theory of Elasticity, McGraw-Hill, New York, 3rd Edition, 1970) p 402ff.

12. A. E. H. Love, "The Stress Produced in a Semi-Infinite Solld by Pressule on Part of the Boundary," Trans. Royal Soc. of London, Series A, Vo1. 228, 1929, pp $377-420$.

13. W. H. Campen, and J. R. Smith, Use of Load Tests in the Design of Flexible Pavements, ASTM Special Technical Publication No. 79, (1947), pp 51-64.

14. H. Brandt, H. Chu, and r. Scott, Triaxial Tests of Alluvium, Final Report for Contract 648205, University of California at Davis, published as Lawrence Livermore Laboratory Rept., UCRL-13666, (1975).

15. B. Bonner, A. Abey, H. Heard, and R. Schock, High Pressure Nechanical Properties of Merlin Alluvium, Lawrence Livermore Laboratory Rept, UCRL-51252, (1972). 
16. I. N. Sneddon, "The Distribution of Stress in the Neighbourhood of a Crack in an Elastic Sol1d," Proc. Royal Soc. of London, Series A, Vol. 187, 1009, (1946), pp 229-260.

17. E. L. Wilson, I. Farhoomand, and K. J. Bathe, "Nonlinear Dynamic Analysis of Complex Structures," Earthquake Engineering and Structural Dynamics, Vol. 1, (1973), pp 241-252.

18. I. Farhoomand, Nonlinear Dynamic Stress Analys is of Two-Dlmenstonal Solids, Ph.D. Dissertation, University of Callfornia, Berkeley, (1970).

19. F. $\therefore$ Tokarz, User's Manual of NTEDYNS, A Nonlinear Finite Element Code for Analyzing the Response of Underground Structures Subjected to Ground Shock, Lawrence Livermore Laboracory Rept. ULID-20027, Rev. 1, (1971).

20. J. H. Pitts, Gas-In1t1ated Crack Propagation In a Porous Sol1d - A Progress Report, Lawrence Livermore Laboratory Rept, UCtD-16236, (1973).

21. R. J. M. Delle1st, Flow Through Porous Medla, (Academic Press, New York, 1969), pp 5-6.

22. W. H. Giedt, Thermophysics, (Van Nostrand, New York, 1971), pp 394-401, and $574-575$.

23. B. Carnahan, H. A. Luther, and J. O. Wilkes, Applied Numertcal Methods, (John W1ley and Sons, New York, 196\%).

24. P. J. Roache, Compucational Fluld Dynamics, (Hermosa, Albuquerque, N.H., 1972).

25. P. L. T, Brian, "A Finite-Difference Method of High-Order Accuracy for the Solution of Three-Dimensional Translent Heat Conduction Problems," AICHE Journal, Vol. 7, (1961), pp 367-370.

26. F. G. Blottner, "Variable Grid Scheme Applied to Tirbulent Boundary Layers," in Computer Methods in Applied Mechanics and Engineer1ng, VoJ.. 4, (1974), pp 179-194.

27. T. Cebec1, and A. M. O. Smith, "A Fintte-Difference Method for Calculating Compressible Laminar and Turbulent Boundary Layers," ASME J. Bas 1C Englneering, Vo.l 92, (1970), pp 523-535.

28. I, P. Ginzburg, Applied Fluid Mechanles, National Sclences Foundation translation, (1958), p 72 .

29. 0. N. Petrova, "Pressure and Flow Distrfbution Along a Plpeline 1n Unsteady Flow," International Chemical Engineering, Vol. 1:. 2, 1971), pp 242-243.

30. Ye. V. Yeremenko, and 5. B. Markov, "On Calculation of Averaged Velocities and Resistance in Unstable [Transient] Turbulent Flow in a Pressurlzed Rough Channel," Fluld Mechanics-Soviet Research, Vol. 1, 5, (1972), pp 48-58. 
31. J. R. Doughty, "Parallel Porous Plate Channel Flow Characteristics Resulting from Nonuniform Entry Velocity Profiles," Jaurnal of Fluids Engineering, Vol. 97, (1975), pp 78-81.

32. F. B. Hildrebrand, Finite Difference Equations and Simulations, (Prentice Hall, New York, 1968), Chapt. 3 .

33. N. N. Yanenio, The Method of Fract Ional Steps, (Springer-Verlag, 1971), Chapt. 2. 


\section{Appendix A - Derivation of the Governing Equations}

Ineluded are the detailed analyses for determining crack wall deflection and gas flow', ch in a porous solid such as an earth formation and in the crack. (ia:; flow in the crick uses a correlation for frictional coefficfent, - which is also discussed. In the appropriate portions of this appendix, alternate methods of solution are nent foned along with the reasons for using the particular method selected.

\section{DLELEC:[' ION OF 'THE CRACK WAILL}

lotal. detlection of tile crack wall in the " $x$ " direction will normally exceed the inithal crack thiciness. We must account for this deflection to predict the " $\mathrm{Y}$ " and " " direction thow of gas in the crack accurately since the guverning equation (Eq. 19) is dependent on crack thickness.

Roierring to Fig. 3, consider the tight hand crack wall to be a portion oi the surface wi a semi-infinite solid. Deflection of the crack wall in the " $\mathrm{X}$ " dircetion results from two opposiag forces as explained in the analysis section. The gas pressure in the crack exerts a force that tends to deflect the crack wall in the " $\mathrm{X}$ " dicection. The horizontal earth formation resistive presisure results in a force which tends to prevent deflection and keep the crilk clused. Any deflection of the crack wall beyond its initial position is thit the resultant of these two elfects.

In alculating the deflection of the crack wall, the magnitude of the gas pressure in the crack is taken to he that in excess of the initial pore pessute in the earth formation. At Nl's, the pores of the earth formation are lilled with air to the depths of interest of this study so that the initial pore pressitre is atmospheric.

The liorizuntal earth formation resistive pressure is due to the overburden, or weight of material above, and is transmitted through the solid grains of the earth formation. If the earth formation has little strength and is subject to creep over geolugical times, then the horizontal resistive presstie will be close in magnitude to the ovecburden which is about $20 \mathrm{kPa} / \mathrm{m}$ of depth. Alluvium soil at the Nevada iest site falls near to this category. Nltriately. it a hydrustatic state is not reached, then a three-dimensional stress stale would exist where resistive pressure forces are a fraction of the 
overburden. For example, if there has been no lorizontal strain, the magnitucle of this fraction is determined from Hooke's law to be $1-v / v$.

Total deflection in the " $\mathrm{X}$ " direction is found by applying the technique of superposition. We first determine deflection due to force applied at a point on the surface of a semi-infinite solid as showr in Fig. A-1 part a. Following the analysis developed by Bousinesc $\mathrm{A-1}$ and outlined by Timoshenko and coodier" ${ }^{11}$, deflection in the " $X$ " direction caused by an applied force on the surface of a semi-infinite solid is

$$
H(Y, Z)=\frac{\left(1-\nu^{2}\right) E\left(Y^{\prime}, Z^{\prime}\right)}{\pi \mathrm{R}}
$$

where here the deflection, $D$, acts at coordinates $(y, 2)$ and the force $F$, acts at coordinates $\left(Y^{\prime}, Z^{\prime}\right)$.

The applied force is considered equal to the Jifference between the gas pressure in the erack that is in excess of the Initial pore pressure, and the earth formation resistive pressure, times a small area of application as shown in Fig. A-1 part b. The calculated deflection of $\mathrm{kq}$. (A-1) then becomes

$$
D(Y, Z)=\frac{\left(1-v^{2}\right)(P-P r) d Y^{\prime} d Z^{\prime}}{\pi E R}
$$

where $\mathrm{P}_{\mathrm{r}}$ is the earth formation resistive pressure; and $\mathrm{d} \mathrm{Y}^{\prime}$, $\mathrm{d}{ }^{\prime}$ ' is the area over which the pressures are applied. Integrattng the deflection calculated in Eq. (A-2) over a finite area of surface gives a solution for the total 

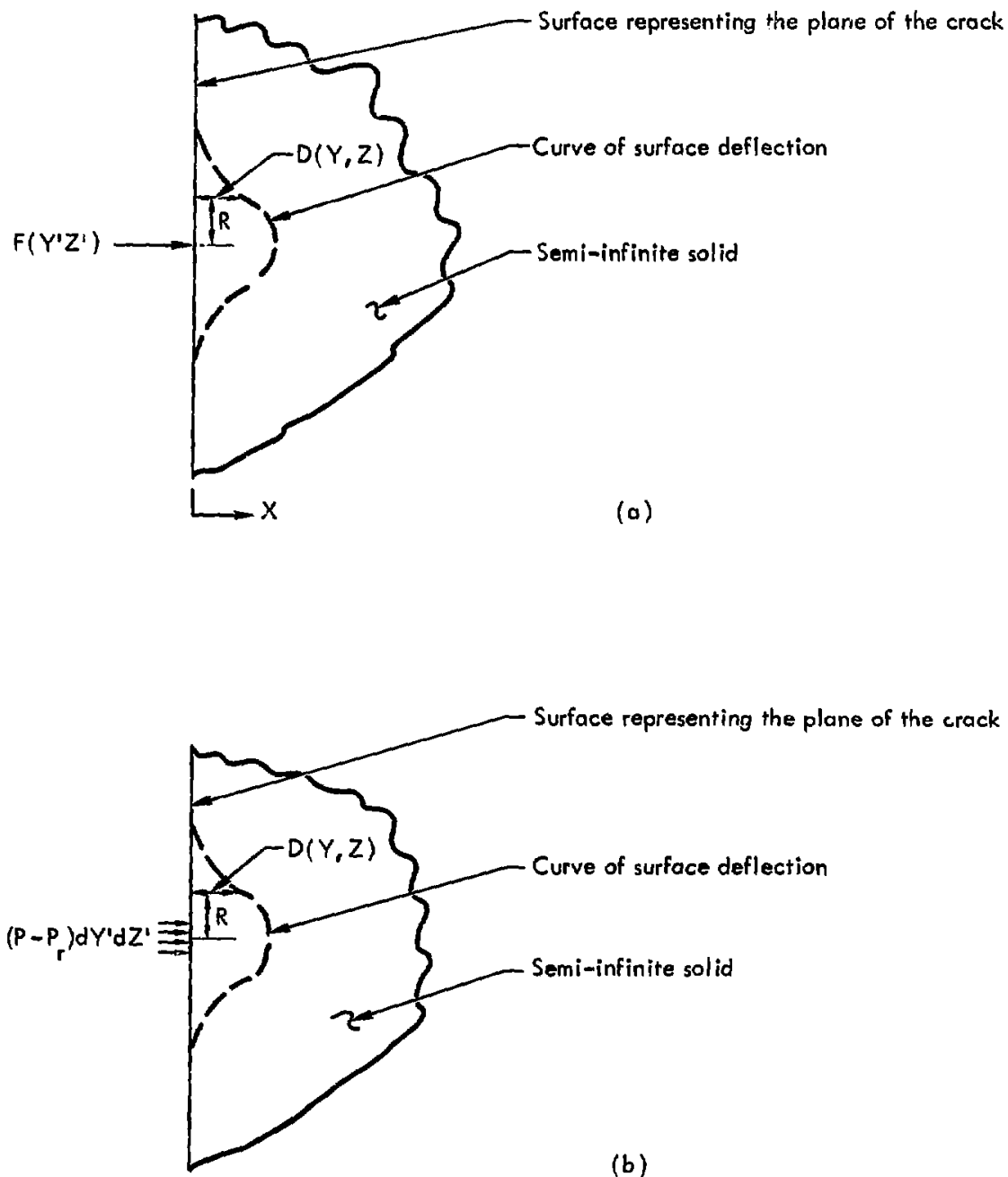

Fig. A-1, Part a. Surface deflection due to a force applied to a point on a semi-infinite solid. (See Eq. (A-1)). Part b. Surface deflection due to a pressure applied over a small area of surface. (See Eq. $(A-2))$. 
deflection, D, at coordinates $(Y, Z)$ due to pressure acting on a portion of the boundary*

$$
D(Y, Z)=\frac{\left(1-\nu^{2}\right)}{\pi E} \iint \frac{\left(P-P_{Y}\right) d Y^{\prime} d Z^{\prime}}{\sqrt{\left(Y-Y^{\prime}\right)^{2}+\left(Z-Z^{\prime}\right)^{2}}}
$$

The deflection at the coordinates $\left(Y^{\prime}, Z^{\prime}\right)$ as calculated by Eq. (A-3) is singular. At this position, the average deflection under a small area is used since in reality the pressures are applied not at a point but over a small area. Timoshenko and Goodter ${ }^{11}$ have calculated average surface deflections for varlous rectangles subjected to a uniform pressure. In the special case of a square, which is conventent for our coordinate mesh spacing,

$$
D\left(Y^{\prime}, Z^{\prime}\right)_{\text {Average }}=\frac{0.95\left(1-\nu^{2}\right)}{E}\left(P-P_{r}\right)(A)^{1 / 2}
$$

Total deflection at any point $(Y, Z)$ due to pressure applied over part of the boundary of a semi-infinite solid may be calculated by using Eqs. (A-3) and $(A-4)$.

*The form of $\mathrm{Eq}$. (A-3) may be placed into that derived by Love ${ }^{12}$ if relationships between $E$ and $v$ and the Lamé constants $\mu_{\text {Zamé }}$ and $\lambda_{\text {Zamé }}$ are used.

Taking

$$
\begin{aligned}
& \mathbf{E}=2 \mu_{\text {Zamé }}(1+v) \\
& v=\frac{\lambda_{\text {Zamé }}}{2\left(\lambda_{\text {Zamé }}+\mu_{\text {Zamée }}\right)}
\end{aligned}
$$

gives

$$
\frac{1-v^{2}}{\mathrm{E}}=\frac{(1-v)(1+v)}{2 \mu_{\text {Zamé }}(1+v)}=\frac{\lambda_{\text {Zamé }}+2 \mu_{\text {Zamé }}}{4 \mu_{\text {Zamé }}\left(\lambda_{\text {Zané }}+\mu_{\text {Zamé }}\right)}
$$

The right hand side of the above equation is the form used by Love. 
The nature of the calculated deflection is such that a pressure applied over one regton of the surface results in deflections over all areas of the surface. Deflections approach zero only as the radlus approaches infintty. This is a result of the assumption that the medium is elastic. Actual data shows that an elastic analysis gives reasonable results for inftial loading near the point of load application but over-predicts the surface deflections as the distance away from the load Increases.

Fig. a-2 indicates the variation of surface deflection with distance from the point of load application. The theoretical curve is shown for an elastic material calculated using Timoshenko and Goodier's ${ }^{11}$ analysis for a circular loading area. It may be seen to give deflections larger than the experimental data of Gerrard and Morgan ${ }^{8}$ away from where the load is applled. Gerrard and Norgan have developed more accurate theoretical solutions however these solutions st 111 overpredict the data away from the area of load application.

The data of Gerrard and Morgan is extrapolated to zero at a radius of five in conformance with data of Campen and Smith. ${ }^{13}$ The magnitude of deflection at the centerline of the unfform pressure loading area predicted by Timoshenko and Goodier agrees with Gerrard and Morgan's experimental data if an elastic modulus of about 6.9 NPa is Incorporated. Gerrard and Morgan reference data from trlaxial tests by Holden ${ }^{A-2}$ for their soil where the elastic modulus ranges from 3.4 to $10.3 \mathrm{MPa}$. Holden's data confirms that the experimental deflections near the unfform pressure loading area agree with the theory and only differ at locations away from the loading area.

Waterways Experiment Station ${ }^{\mathrm{A}-3}$ reports other data below the surface but off the axis of the point of load application. Extrapolation of this data to the surface glves a result that is also overpredicted by theory. ive felt the more accurate and easier method of determining surface deflection was to utilize Cerrard and Morgan's data directly. The computer program used for this dissertation incorporates a square grid in the $\mathrm{Y}-\mathrm{Z}$ plane. We converted these squares to equivalent clrcles by equating areas. This is, a square with sides of 2 a would be considered equivalent to a circle of radius $(4 / \pi)^{\frac{1}{2}} \mathrm{a}$. Deflection at coordinates $(Y, Z)$ due to a unfform pressure applied over an elemental area at coordinates $\left(Y^{\prime}, Z^{\prime}\right)$ is found using the formula

$$
D(Y, Z)=C_{G} \frac{\left(1-\nu^{2}\right)}{E}\left(P-P_{T}\right)\left(\Delta Y^{\prime} \Delta Z^{\prime}\right)^{\frac{1}{2}} .
$$




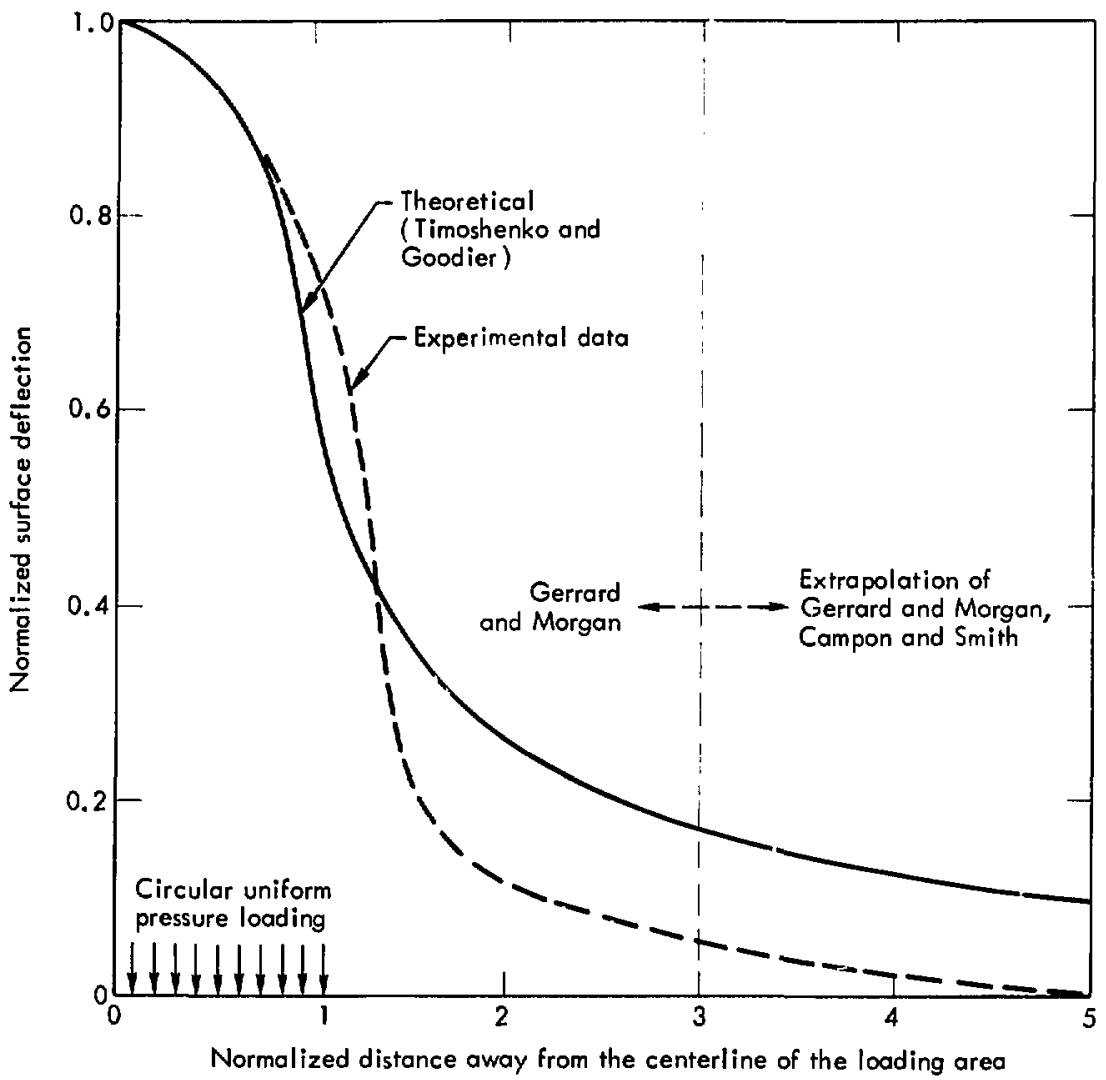

Fig. A-2. Profile of surface displacements. 
The Gerrard and Morgan deflection coefficient, $\mathrm{C}_{\mathrm{G}}$, is set equal to 0.95 if the point where the deflection is calculated is below the loading area in conformance with Eq. (A-4). The coefficlent would be zero for normalized radil beyond five. Table A-1 shows these coefficients for a square coordinate grid. The coefficlents define a circle of influence around the location of uniform pressure load application beyond which the load has no effect on deflection.

Table A-1 - Gerrard and Morgan Deflection Coefflclents for Unfform Pressure Loading of a Square Area with Sides Equal to $2 \mathrm{a}$.

\begin{tabular}{|c|c|c|c|c|}
\hline \multirow[b]{2}{*}{ Mesh } & \multirow[b]{2}{*}{ No. } & \multirow[b]{2}{*}{1} & "Y" Direction & \multirow[b]{2}{*}{3} \\
\hline & & & 2 & \\
\hline \multirow{6}{*}{ 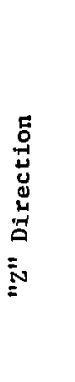 } & 1 & $r / a_{e q}=0$ & 1.77 & 3.55 \\
\hline & & $C_{G}=0.95$ & 0.30 & 0.05 \\
\hline & 2 & $\mathrm{r} / \mathrm{a}_{\mathrm{eq}}=1.77$ & .51 & 3.96 \\
\hline & & $C_{G}=0.30$ & 0.10 & 0.02 \\
\hline & 3 & $\mathrm{r} / \mathrm{a}_{\mathrm{eq}}=3.55$ & 3.96 & 5.01 \\
\hline & & $c_{G}=0.05$ & 0.02 & 0.002 \\
\hline
\end{tabular}

$r / a_{\text {eq }}$ - normalized distance from the center of the mesh indicated, to the center of mesh $(1,1)$. Mesh $(1,1)$ 1s the area subjected to untform pressure loading.

$\mathrm{a}_{\mathrm{eq}}=\left(\frac{4}{\pi}\right)^{\frac{1}{2}} \mathrm{a}$.

$C_{G}$ - Gerrard and Morgan Deflection Coefficient for use in Eq. $(A-5$ to $A-1)$. 
The total deflection, $D$, at a point is found using superposition by summing the component deflections for all non-zero $C_{G}$ using the following equation.

$$
D(Y, Z)_{\text {total }}=\sum C_{G} \frac{\left(1-v^{2}\right)}{E}\left(P-P_{r}\right)\left(\Delta Y^{\prime} \Delta Z^{\prime}\right)^{\frac{2}{2}}
$$

Equation (A-6) is put in dimensionless form

$$
\bar{D}(\bar{Y}, \bar{Z})=\sum c_{G} \frac{\left(1-\nu^{2}\right)}{\bar{E}}\left(\bar{P}_{-} \bar{P}_{r}\right)\left(\Delta \bar{Y}^{\prime} \Delta \bar{Z}^{\prime}\right)^{\frac{1}{2}}
$$

by dividing $D, Y$, and $Z$ by a reference length and, $\left(P-P_{r}\right)$ and $E$ by a reference pressure. We use the length of the " $Z$ " axis and the initial driving pressure less the Initial pore pressure as reference values. The bars above the variables indicate they are normalized. The crack includes all nodes where tne total deflection is positive. The extent of crack propagation is determined automatically by examining the region of pusitive total deflection.

The use of superposition is justified by examination of experimental data as indicated in the analysis section. Because alluvium at NIS has negligible strength in tension when compared to the gas pressures present, ${ }^{4}$ the crack is actually formed more by parting of the surfaces along the plane of che crack rather than fallure of the alluvium material. Even if the alluvium had appreciable strength, the crack could propagate along microfissures developed during the explosion so that formation of the crack would still be by parting of the surfaces. The application of superposition to our study is approprtate since the parting of the crack surfaces is similar to infilal deflection of the earth materials which have experimentally exhibited elastic behavior.

An alternate means of predicting deflection for axisymmetric crack shajes was developed by Sneddon. ${ }^{16}$ Sneddon incorporates a radially varying pressure within the crack with zero deflection beyond the crack as a boundary condition. A solution involving integration over the crack is developed for an elastic solid. In applying the solution, the axis of symmetry is horizontal and the length of the crack is in the radial direction. The crack contains both vertical and horizontal rays. 
Unfortunately, the solution has several drawbacks for our particular application. First, cracks grow more vertically than horizontally since the overburden pressure decreases with depth. Hence, the axisymmetric assumption limlts the use of results to small lengths of crack propagation. Second, the boundary condition of zero deflection at and beyond the crack $t$ ip is imposed in such a Eashion that a separate criteria is required to determine propagation. In the method we utilize, deflection is based on pressures within a circle of influence and the extent of the crack is determined automatically. Third, the form of the integral is inconvenient for incorporation experimental data such as Gerrard and Morgan' $s^{8}$ and as such is difficult to improve based on actual observation.

Another means of predicting deflection is with the use of a finfte element analysis using a computer code such as that developed by Wilson, Farhoomand, and Bathe. ${ }^{17-19}$ We used a modification of this code for the solution to a two-dimensional problem ${ }^{20}$ anzlyzed earlier where the crack grew only in the " 2 " direction and contalned a cross section independent of "y". Extension of the analysis to three dimensions was possible but prediction of the deflection would be time consuming. Since the deflection is calculated repeatedly along with flow in the crack and in the porous solid, limitations on computer time appear to make this method unfeasible for a three-dimensional analysis.

FLOW IN THE POROUS SOLID

We consider a porous solid such as an earth formation on a macroscopic basis and establish a control volume for analysis that contains both pore space and solid grains as shown in Fig. A-3. A continutty equation is developed by equating the net influx of mass to the time change oi mass within the control volume. Apparent velocities $u_{x}, u_{y}$, and $u_{z}$ are defined as the volume flow rate across a face of the control volume divided by the total crosssectional area, including both voids and solid. These apparent velocities are different from the actual velocities since a portion of the control volume is occupied by solld gralns. Conversion to the actual velocities may be made by dividing the apparent velocitles by the porosity. The continuity equation is writcen as 


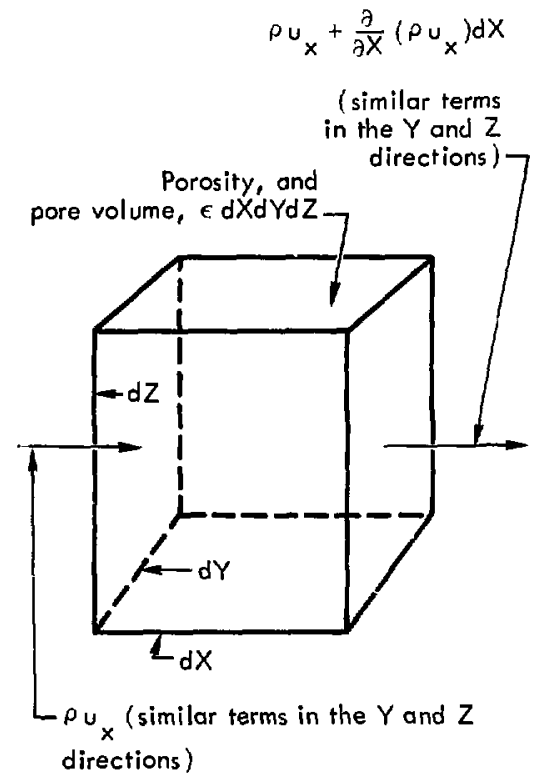

Fig. A-3. Control volume used for derivation of flow through the porous solid.

$$
\begin{aligned}
{\left[\rho u_{x}\right.} & \left.+\frac{\partial}{\partial X}\left(\rho u_{x}\right) d X\right] \dot{Y Y d Z}-\rho u_{x} d Y d Z \\
& +\left[\rho u_{y}+\frac{\partial}{\partial Y}\left(\rho u_{y}\right) d Y\right] d X d Z-\rho u_{y} d X d Z \\
& +\left[\rho u_{z}+\frac{\partial}{\partial Z}\left(\rho u_{z}\right) d Z\right] d X d Y-\rho u_{z} d X d Y \\
& +\varepsilon \frac{\partial \rho}{\partial t} d X d Y d Z=0
\end{aligned}
$$

or

$$
\frac{\partial}{\partial \mathrm{X}}\left(\rho \mathrm{u}_{\mathrm{x}}\right)+\frac{\partial}{\partial \mathrm{Y}}\left(\rho u_{\mathrm{y}}\right)+\frac{\partial}{\partial \mathrm{Z}}\left(\rho \mathrm{u}_{\mathrm{z}}\right)+\varepsilon \frac{\partial \rho}{\partial \mathrm{t}}=0
$$


We may apply a similar control volume and develop the Navier-Stokes equations using the actual gas velocities $u, v$, and $w$. Full development of the Navier-Stokes equations are shown by Schlichting (Ref, 10, Chapt. 3). For brevity, anly the " 2 " direction equation with constant viscosity is shown below where $\hat{z}$ is a cerm due to the net body force acting on the elemental volume.

$$
\begin{aligned}
\rho u \frac{\partial w}{\partial X} & +\rho v \frac{\partial w}{\partial Y}+\rho w \frac{\partial w}{\partial z}+\rho \frac{\partial w}{\partial t}=\hat{z}-\frac{\partial P}{\partial z} \\
& +\psi\left\{\frac{\partial^{2} w}{\partial x^{2}}+\frac{\partial^{2} w}{\partial Y^{2}}+\frac{\partial^{2} w}{\partial z^{2}}+1 / 3\left(\frac{\partial^{2} u}{\partial X \partial z}+\frac{\partial^{2} v}{\partial Y \partial z}+\frac{\partial^{2} w}{\partial z^{2}}\right)\right\} .
\end{aligned}
$$

Velocitles of interest in flow through porous solids are very slow so that Stoke's approximation may be applied (Ref. 10, p 104ff). That is, we can neglect inertia terms which contain multiples of two velocities, in comparison with those which contain a single velocity. Since the time variable is on the order of $\mathrm{Z} / \mathrm{w}$, the last term on the left of $\mathrm{Eq} .(\mathrm{A}-10)$ contains an equivalent of a multiple of two velocities also. Under Stoke's approximation, then, the left side of Eq. $(A-10)$ is zero. In terms of the apparent velocities, this gives

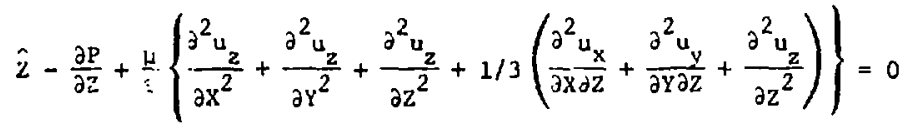

Exact representation of the fluld passing through the solid is not practical because of the multitude of tortuous flow paths which exist. Instead, we view the problem on a macroscopic basis, treating the statistical nature of flow. We assume that

$$
\frac{\partial^{2} u_{z}}{\partial x^{2}}+\frac{\partial^{2} u_{z}}{\partial y^{2}}+\frac{\partial^{2} u_{z}}{\partial z^{2}}+1 / 3\left(\frac{\partial^{2} u_{x}}{\partial x \partial z}+\frac{\partial^{2} u_{y}}{\partial r \partial z}+\frac{\partial^{2} u_{z}}{\partial z^{2}}\right)=-c \frac{u_{z}}{d^{2}}
$$

where $d$ is a characteristic length approximating the grain size and $C$ is a dimensionless constant. This approximation has been used by other investigators, $21, A-4$ has been vertfied experimentally, and is dimenstonally correct. If we define a permeabilicy 


$$
k_{2}=\frac{E d^{2}}{C}
$$

and set che body force term equal to that due to gravity $(Z=-\rho g)^{*}$, then substituting Eq. $(A-12)$ and $(A-13)$ into (A-11) results in

$$
u_{z}=-\frac{k_{z}}{\mu}\left(\frac{\partial P}{\partial z}+\rho g\right) .
$$

The value of permeability, $k_{z}$, is determined for each formation normally by experiment and in addition to the above effects contains such items as tortuosity, surface roughness, etc. Equation (A-14) is Darcy's law. For conditions at the Nevada Test Site the value of $\rho g$ is negligible with respect to the minimum expected " 2 " direction pressure gradient, leaving*:

$$
u_{z} \approx-\frac{k_{z}}{\mu} \frac{\partial P}{\partial Z} .
$$

We can obtain similar expressions for the " $\mathrm{X}$ " and " $\mathrm{Y}$ " directions, but in these cases the values of body forces $\hat{X}$ and $\hat{Y}$ are identically equal to zero leaving

$$
\begin{aligned}
& u_{x}=-\frac{k_{x}}{\mu} \frac{\partial P}{\partial X} \\
& u_{y}=-\frac{k_{y}}{\mu} \frac{\partial P}{\partial Y} .
\end{aligned}
$$

*In the appendices of this renort we include the acceleration of gravity, $\mathrm{g}$, along with the density so that the equations are similar to those used in the computer program, CHASM, where $g$ is required for consistency of units.

* The driving pressure is on the order of the overburden of the aarth formation, so the pressure gradient is approximately equal to the specific weight of the earth formation. That is, $\partial P / \partial z \approx \rho_{s} g$ where $\rho_{s}$ is the density of the earth formation. $\partial P / \partial Z$ ranges between 1.7 and $1.9 \mathrm{~g} / \mathrm{cc}$ for soils of interest. The value of $\rho g$ used in Eq. (A-14) for air is $\sim .13 \mathrm{~g} / \mathrm{cc}$, a negligible value compared to $\partial \mathrm{P} / \partial \mathrm{Z}$. 
Darcy's Law is verified experimentally for Reynolds number, $*$ Re, less than unity but data deviate from this relation as fluid veloctty increases. A modification called Forchheimer's relation, which fncludes a velocity squared term, adequately predicts experimental data up to $\operatorname{Re}>1000 .{ }^{A-5, A-6}$ This added complication is not itecessary for the present investigation because flow in the earth formaion ts within the regime of Darcy's law.

The equation of state used with the analysis is that of an ideal gas at constant temperature

$$
\rho=\frac{p}{R T}
$$

The constant temperature ssumption circumvents the need for an energy equation and is valid since the gas reaches the temperature of the earth formation after having traveled normally less than one per cent of "he " $Z$ " drection total length into the earth formation. Thls rapid change $L$, a constant temperature occurs be ause the heat capacity of the earth for ation is large in comparison to the amount of energy transported into the eart' formation by the gas and becau;e the average grain size of alluvium soil at NTS is small (about $1 \mathrm{~mm}$ ). A small average grain size racults in a large surface area to volume ratio of the particles that erhances heat transfer.

The viscosity of the gas is a strong function of temperature and only a weak function of pressure so trat it is appropriate to consider viscosity constant also, Substituting Eqs, $(A-15)-(A-18)$ into Eq. (A-9) gives

$$
\frac{\partial}{\partial \mathrm{X}}\left(\frac{\mathrm{P}}{R \mathrm{~T}} \frac{\mathrm{k}}{\mu} \frac{\partial \mathrm{P}}{\partial \mathrm{X}}\right)+\frac{\partial}{\partial \mathrm{Y}}\left(\frac{\mathrm{P}}{\because \mathrm{T}} \frac{\mathrm{k}}{\mathrm{H}} \frac{\partial \mathrm{P}}{\partial \mathrm{I}}\right)+\frac{\partial}{\partial Z}\left(\frac{\mathrm{P}}{R \mathrm{~T}} \frac{\mathrm{k}}{\mu} \frac{\partial \mathrm{P}}{\partial \mathrm{Z}}\right)=\varepsilon \frac{\partial \frac{\mathrm{P}}{S \mathrm{~T}}}{\partial \mathrm{t}},
$$

which for constant temperature and viscosity becomes

$$
\frac{\partial}{\partial X}\left(k_{x} P \frac{\partial P}{\partial X}\right)+\frac{\partial}{\partial Y}\left(k_{y} P \frac{\partial P}{\partial Y}\right)+\frac{\partial}{\partial Z}\left(k_{z} P \frac{\partial P}{\partial Z}\right)=\varepsilon \mu \frac{\partial P}{\partial t} .
$$

\footnotetext{
"Here Reynolds number is defined as, $R e=\tilde{u} d p / \mu g$ where $\tilde{u}$ is the magnitude of the total apparent velocity vector and $\mathrm{d}_{\mathrm{p}}^{\mathrm{p}}$ is the average particle size of the grains in the earth formation.
} 


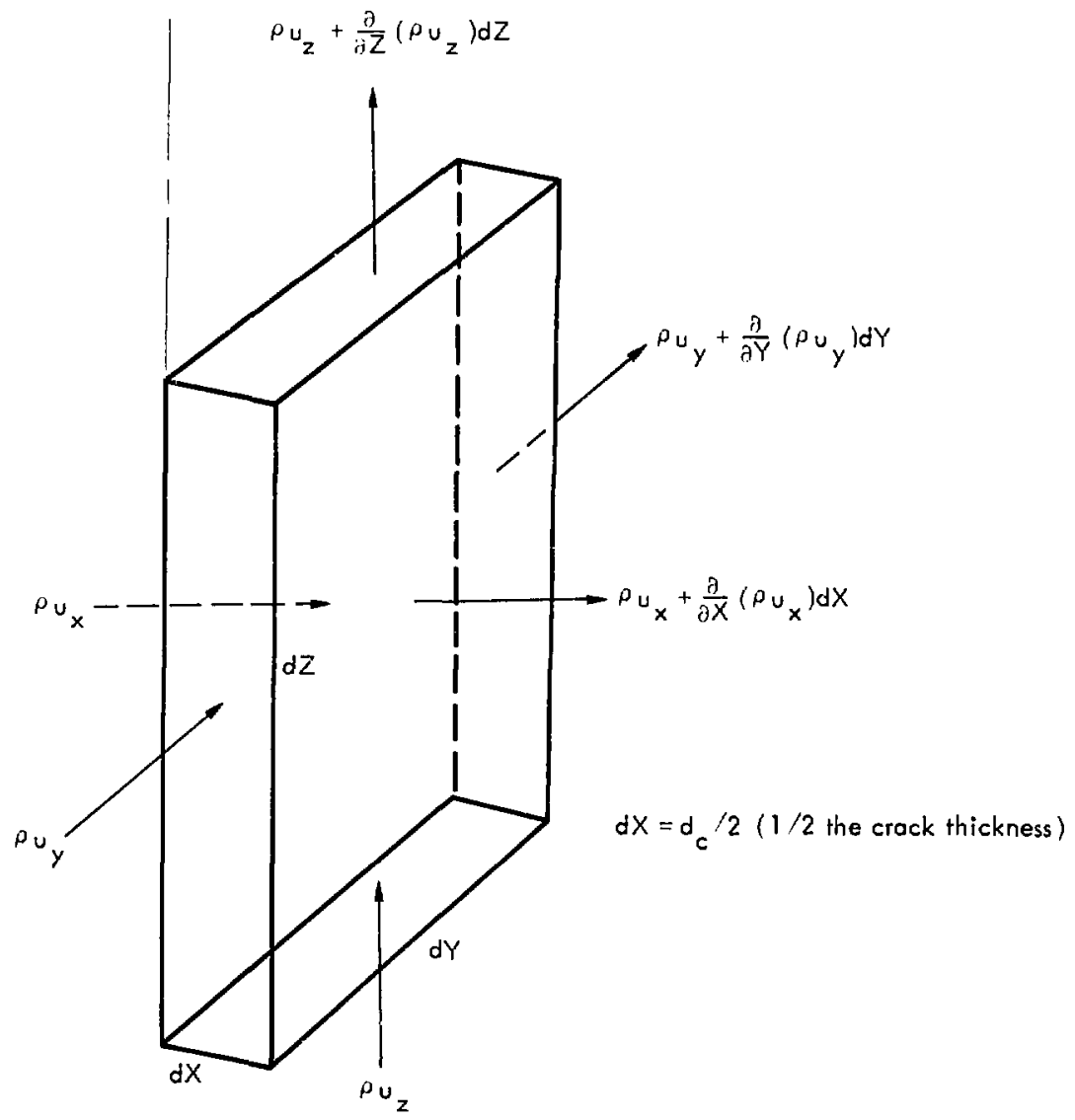

Fir. 1-4. Control volume used to derive equations governing gas flow inside the crack.

If we consider $P_{0}$, the initial pore gas pressure, and $P_{1}$, the initial driving pressure at time zero, we may define a dimensionless pressure

$$
\overline{\mathrm{p}}=\frac{P-P_{0}}{P_{1}-P_{0}},
$$


so that

$$
P=\bar{P}\left(P_{1}-P_{0}\right)+P_{0}
$$

Eq. $(A-20)$ then becomes

$$
\begin{aligned}
& \left(P_{1}-P_{0}\right)^{2}\left\{\frac{\partial}{\partial X}\left[k_{x}\left(\vec{P}+\frac{P_{0}}{P_{1}-P_{0}}\right) \frac{\partial}{\partial X}\left(\vec{P}+\frac{P_{0}}{P_{1}-P_{0}}\right)\right]\right. \\
& +\frac{\partial}{\partial Y}\left[k_{y}\left(\bar{P}+\frac{P_{0}}{P_{1}-P_{0}}\right) \frac{\partial}{\partial Y}\left(\bar{P}+\frac{P_{0}}{P_{1}-P_{0}}\right)\right] \\
& \left.+\frac{\partial}{\partial Z}\left[k_{z}\left(\bar{P}+\frac{P_{0}}{P_{1}-P_{0}}\right) \frac{\partial}{\partial Z}\left(\bar{P}+\frac{P_{0}}{P_{1}-P_{0}}\right)\right]\right\} \\
& =\varepsilon \mu\left(P_{1}-P_{0}\right) \frac{\partial}{\partial t}\left[\bar{P}+\frac{P_{0}}{P_{1}-P_{0}}\right] .
\end{aligned}
$$

We use a reference length, $L$, equal to the length of the " 2 " axis and a constant reference permeability, $k_{0}$, equal to an equivalent crack permeability, discussed later, to make the following definitions

$$
\begin{aligned}
& \bar{X}=\frac{X}{L} \\
& \bar{Y}=\frac{Y}{L} \\
& \bar{z}=\frac{Z}{L} \\
& \bar{k}_{x}=\frac{k_{x}}{k_{0}} \\
& \bar{k}_{y}=\frac{k_{y}}{k_{0}}
\end{aligned}
$$




$$
\begin{gathered}
\bar{k}_{z}=\frac{k_{z}}{k_{0}} \\
\tau=\frac{k_{0}\left(P_{1}-P_{0}\right) t}{\varepsilon \mu L^{2}} .
\end{gathered}
$$

The variables with bars then are normalized and $\tau$ is a dimensionless time. Combining these definitions with the constant

$$
\mathrm{N}=\frac{\mathrm{P}_{1}}{\mathrm{P}_{0}}
$$

In Eq. (A-23) gives

$$
\begin{aligned}
\frac{\partial}{\partial \bar{X}}\left[\bar{k}_{x}\left(\bar{P}+\frac{1}{N-1}\right) \frac{\partial}{\partial \bar{X}}\left(\bar{P}+\frac{1}{N-1}\right)\right] \\
+\frac{\partial}{\partial \bar{Y}}\left[\bar{k}_{y}\left(\bar{P}+\frac{1}{N-1}\right) \frac{\partial}{\partial \bar{Y}}\left(\bar{P}+\frac{1}{N-1}\right)\right] \\
+\frac{\partial}{\partial \bar{Z}}\left[\bar{k}_{z}\left(\bar{P}+\frac{1}{N-1}\right) \frac{\partial}{\partial \bar{Z}}\left(\bar{P}+\frac{1}{N-1}\right)\right] \\
=\frac{\partial\left[\bar{P}+\frac{1}{N-1}\right]}{\partial \tau} .
\end{aligned}
$$

If $\bar{k}_{x}, \bar{k}_{y}$, and $\bar{k}_{z}$ are considered independent of their associated spatial conrdinate, then Eq. (A-28) may be simplified to

$$
\begin{gathered}
\frac{\bar{k}_{x}}{2} \frac{\partial^{2}}{\partial \overline{\mathrm{X}}^{2}}\left[\left(\overline{\mathrm{P}}+\frac{1}{\mathrm{~N}-1}\right)^{2}\right]+\frac{\overline{\mathrm{k}}}{2} \frac{\partial^{2}}{\partial \overline{\mathrm{Y}}^{2}}\left[\left(\overline{\mathrm{P}}+\frac{1}{\mathrm{~N}-1}\right)^{2}\right] \\
\quad \div \frac{\overline{\mathrm{k}}}{2} \frac{\partial^{2}}{\partial \overline{\mathrm{Z}}^{2}}\left[\left(\overline{\mathrm{P}}+\frac{1}{\mathrm{~N}-1}\right)^{2}\right]=\frac{\partial}{\partial \mathrm{T}}\left[\overline{\mathrm{P}}+\frac{1}{\mathrm{~N}-1}\right] .
\end{gathered}
$$


This development follows the arguments of Morrison ${ }^{9}$ who reasoned that we could reduce the error involved in approximating the derivatives by finite differences if we take the function

$$
F=\left(\bar{P}+\frac{1}{N-1}\right)^{2}
$$

as the dependent variables for differentiation. Realizing that $\mathrm{N}$ is a constant and using the definition for F, Eq. (A-29) becomes

$$
\frac{\bar{k}_{x}}{2} \frac{\partial^{2} F}{\partial \bar{X}^{2}}+\frac{\bar{k}_{y}}{2} \frac{\partial^{2} F}{\partial \bar{Y}^{2}}+\frac{\bar{k}_{z}}{2} \frac{\partial^{2} F}{\partial \bar{Z}^{2}}=\frac{\partial \bar{P}}{\partial \tau} .
$$

Eq. (A-31) is the governing equation for flow in the solid if the normallzed permeabllitles are constant. If the normalized permeabllitles vary spatially, then the governing equation is

$$
\frac{\partial}{\partial \bar{X}}\left(\frac{\bar{k}_{x}}{2} \frac{\partial F}{\partial \bar{X}}\right)+\frac{\partial}{\partial \bar{Y}}\left(\frac{\bar{k}}{2} \frac{\partial F}{\partial \bar{Y}}\right)+\frac{\partial}{\partial \bar{Z}}\left(\frac{\bar{k}_{z}}{2} \frac{\partial F}{\partial \bar{Z}}\right)=\frac{\partial \bar{P}}{\partial \tau}
$$

\section{FLOW IN THE CRACK}

Flow in the crack is similar to flow within a plpe with porous walls. Consider a control volume which extends from the centerline of the crack to the boundary of the porous solid as shown in Fig. A-4. The total dimensions of the crack In the " $Y$ " and " $Z$ " $d$ lrectlons are considerably larger than those of the control volume. A continuity equation is written by equating the net influx of mass to the time change of mass within the control volume and becomes

$$
\begin{aligned}
{\left[\rho u_{x}\right.} & \left.+\frac{\partial}{\partial X}\left(\rho u_{x}\right) d X\right] d Y d Z-\rho u_{x} d Y d Z+\left[\rho u_{y}+\frac{\partial}{\partial Y}\left(\rho u_{y}\right) d Y\right] d X d Z-\rho_{y} d X d Z \\
& +\left[\rho u_{z}+\frac{\partial}{\partial Z}\left(\rho u_{z}\right) d Z\right] d X d Y-\rho u_{z} d X d Y+\frac{\partial \rho}{\partial t} d X d Y d Z=0
\end{aligned}
$$


or

$$
\frac{\partial}{\partial X}\left(\rho u_{x}\right)+\frac{\partial}{\partial Y}\left(\rho u_{y}\right)+\frac{\partial}{\partial z}\left(\rho u_{z}\right)+\frac{\partial \rho}{\partial t}=0 \text {. }
$$

The porosity does not enter the crack flow equation as was the case in the porous solid because $1 \mathrm{t}$ is unity. The centerline of the crack is a line of symetry and as such, no flow crosses the left hand boundary. Flow across the right hand boundary is dependent on the pressure gradient in the porous solid to the right. Since the distance, dX, fo equal to one-half the crac; thickness and since the velocity is zero across the left face we rewrite Eq. $(A-34)$ as

$$
\frac{\rho u_{x}}{d_{c} / 2}+\frac{\partial}{\partial Y}\left(\rho u_{y}\right)+\frac{\partial}{\partial z}\left(\rho u_{z}\right)+\frac{\partial \rho}{\partial t}=0 .
$$

The velocity $u_{x}$ is identical to the apparent velocity defined when deriving the equations for flow in the porous solid. This velocity may be equated, using Darcy's law, to the pressure in the porous soldd.

$$
u_{x}=-\frac{k}{\mu} \frac{\partial p}{\partial x}
$$

We use the fully developed Internal flow momentum equation (Ref. 10, Chapter 20) in the " $Y$ " and " $Z$ " directions. The shear forces along the sides of the channel are equated to the difference of normal pressure forces between the ends of the control volume as shown In Fig. A-5. The value $d_{h}$ is the hydraulic diameter with $\mathrm{dN}$ equal to an elemental length in the direction of the total velocity vector. That is, the velocity in the crack normally has components in both the " $Y$ " and " $Z$ " directions. The total velocity vector is the sum of these two components. Using a frictional coefficient, $\lambda$, defined with a total velocity vector, $V$, and wall shear stress, $\tau_{\omega}$, as

$$
\lambda=\frac{\tau}{\frac{\omega}{\rho V}}
$$

then a farce balance gaves

$$
\left[P-\left(P+\frac{d P}{d N} d N\right)\right] \quad d_{h}=t_{w} d N=\frac{\lambda \rho v^{2}}{2 g} d N
$$




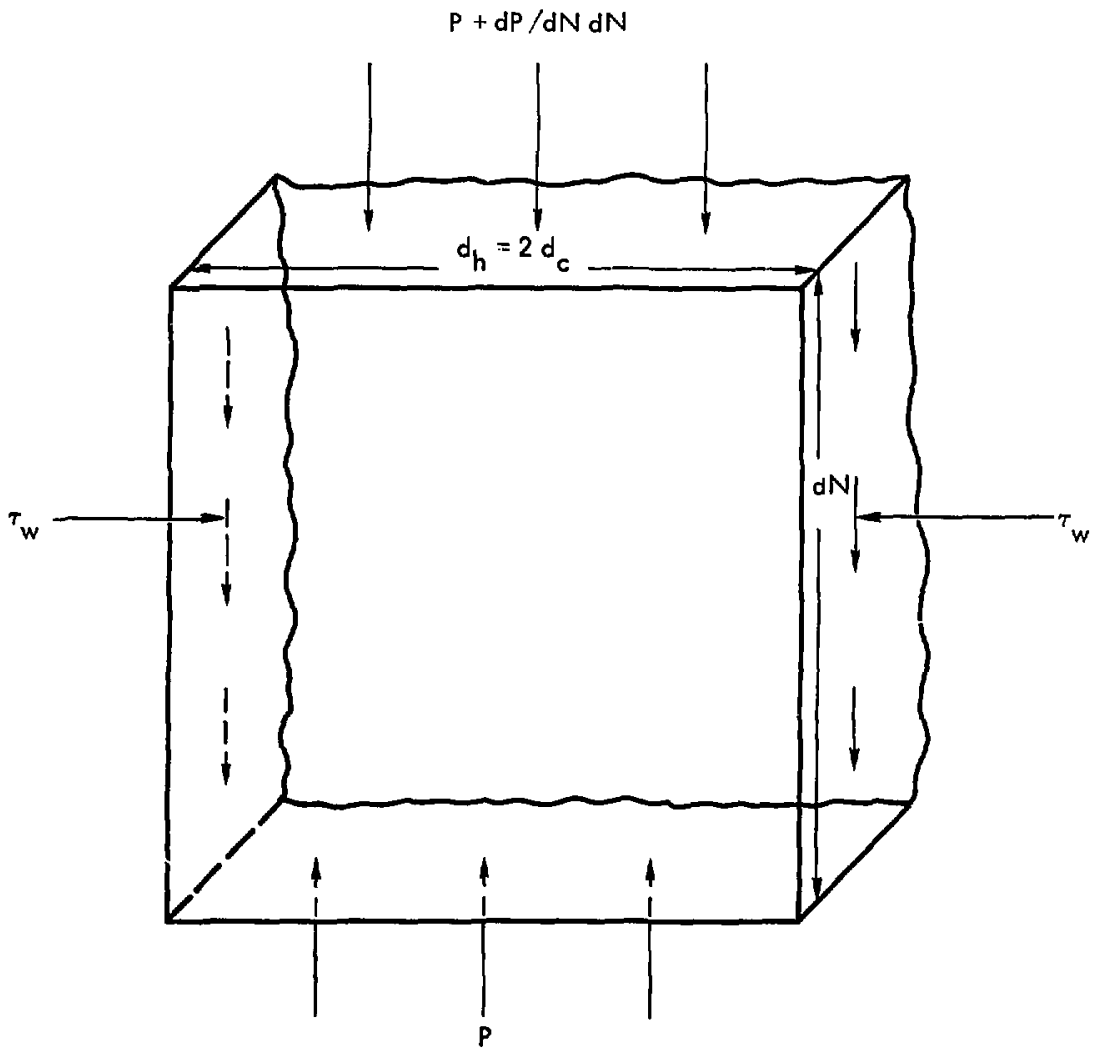

Fig. A-5. Equivalent control volume for determining a force balance in the crack. 
or

$$
\frac{d P}{d N}=-\frac{\lambda}{d_{h}} \frac{\rho V^{2}}{2 g} .
$$

The crack geometry approximates two parallel plates separated by a small distance. The hydraulic diameter* for this geometry is twice the separation or twice the crack width. That is

$$
d_{h}=2 d_{c} .
$$

Eq. (A-39) is broken into the following two component equations using velocities parallel to the " $Y$ " and " $Z$ " directlons.

$$
\begin{aligned}
& \frac{\partial P}{\partial Y}=-\frac{\lambda}{2 d_{c}} \frac{\rho u^{2}}{2 g} \\
& \frac{\partial P}{\partial Z}=-\frac{\lambda}{2 d_{c}} \frac{\rho u^{2}}{2 g}
\end{aligned}
$$

Combining the continulty and momentum equations for flow within the crack with the ideal gas equation of state, (Eq. A-18) gives

$$
\begin{aligned}
& -\frac{2}{{ }_{c}} \frac{P}{R T} \frac{k_{x}}{\mu} \frac{\partial P}{\partial \mathrm{X}} \pm \frac{\partial}{\partial \mathrm{Y}}\left(\frac{\mathrm{P}}{R \mathrm{~T}}\left(\left|\frac{\mathrm{gd}_{\mathrm{c}} R \mathrm{~T}}{\lambda \mathrm{P}} \frac{\partial \mathrm{P}}{\partial \mathrm{Y}}\right|\right)^{\frac{1}{2}}\right) \\
& \pm \frac{\partial}{\partial \mathrm{Z}}\left(\frac{\mathrm{P}}{R \mathrm{~T}}\left(\frac{-\mathrm{gd}_{\mathrm{c}} R \mathrm{~T}}{\lambda \mathrm{P}} \frac{\partial \mathrm{P}}{\partial \mathrm{Z}} \mid\right)^{\frac{1}{2}}\right)+\frac{\partial \frac{\mathrm{P}}{R \mathrm{~T}}}{\partial \mathrm{T}}=0 .
\end{aligned}
$$

\footnotetext{
* The hydraulic dianeter used is equal to four times the flow area divided by the wetted perimeter. Different definitions are used by different authors.
} 
The plus sign on the " $Y$ " and "Z" terms is used if the pressure gradient is $<0$ and the minus sign if the pressure gradient is $>0$. As before we take the flow to be isothermal which gives

$$
\begin{gathered}
-\frac{k_{x}}{\mu_{\mathrm{d}}} \frac{\partial\left(\mathrm{P}^{2}\right)}{\partial \mathrm{X}} \pm \frac{\partial}{\partial \mathrm{Y}}\left(\frac{\mid{ }^{2} \mathrm{~d}_{\mathrm{c}} R \mathrm{~T}}{\lambda} \frac{\partial\left(\mathrm{P}^{2}\right)}{\partial \mathrm{Y}} \mid\right)^{\frac{1}{5}} \\
\pm \frac{\partial}{\partial \mathrm{Z}}\left(\left|\frac{\operatorname{lgd}_{\mathrm{c}} R \mathrm{~T}}{\lambda} \frac{\partial\left(\mathrm{P}^{2}\right)}{\partial \mathrm{Z}}\right|\right)^{1 / 5}+\frac{\partial \mathrm{Y}}{\partial \mathrm{t}}=0 .
\end{gathered}
$$

If we use the definition of the normalized variables for $\bar{P}, \bar{X}, \bar{Y}, \bar{Z}$, $\tau$, and $F$ we find

$$
\begin{aligned}
& \frac{\partial\left(P^{2}\right)}{\partial X}=\frac{\left(P_{1}-P_{0}\right)^{2}}{L} \cdot \frac{\partial F}{\partial \bar{X}} \\
& \frac{\partial\left(P^{2}\right)}{\partial Y}=\frac{\left(P_{1}-P_{0}\right)^{2}}{L} \frac{\partial F}{\partial \bar{Y}} \\
& \frac{\partial\left(P^{2}\right)}{\partial \bar{Z}}=\frac{\left(P_{1}-P_{0}\right)^{2}}{L} \frac{\partial F}{\bar{L}} \\
& \frac{\partial P}{\partial t}=\frac{k_{0}\left(P_{1}-P_{C}\right)^{2}}{E L_{L}{ }^{2}} \frac{\partial \bar{P}}{\partial t}
\end{aligned}
$$


so that Eq. $(A-44)$ becomes

$$
\begin{aligned}
& -\frac{\mathbf{k}_{\mathbf{x}}\left(\mathrm{P}_{1}-\mathrm{P}_{0}\right)}{\mu \mathbf{d}_{\mathrm{c}}} \frac{\partial \mathrm{F}}{\partial \overline{\mathrm{X}}} \pm \frac{1}{\mathrm{~L}} \frac{\partial}{\partial \overline{\mathrm{Y}}}\left(\left(\frac{2 \mathrm{~g} \mathrm{~d}_{\mathrm{c}} L R \mathrm{~T}}{\lambda} \frac{\partial \mathrm{F}}{\partial \overline{\mathrm{Y}}}\right)\right)^{1 / 2} \\
& \pm \frac{1}{L} \frac{\partial}{\partial \overline{\mathrm{Z}}}\left(\left(\frac{2 \mathrm{~g} \mathrm{~d}_{c} L R \mathrm{~T}}{\lambda} \frac{\partial \mathrm{F}}{\partial \overline{\mathrm{Z}}}\right)\right)^{\frac{1}{/ 2}}+\frac{\mathrm{k}_{0}\left(\mathrm{P}_{\perp}-\mathrm{P}_{0}\right)}{\varepsilon+\mathrm{L}} \frac{\partial \overline{\mathrm{p}}}{\partial \tau}=0 .
\end{aligned}
$$

Finally we simplify Eq. $(A-47)$ by definlng effectlve crack permeabilities in the " $X$ " direction and the " $Y$ " or " $Z$ " direction as

$$
\begin{gathered}
\overline{\mathrm{k}}_{\mathrm{cx}}=\frac{\varepsilon \mathrm{L} \mathrm{k}_{\mathrm{x}}}{\mathrm{d}_{\mathrm{c} \mathrm{k}_{0}}} \\
\mathrm{k}_{c y z}=\frac{\varepsilon \mu}{\left(\mathrm{P}_{1}-\mathrm{P}_{0}\right) \mathrm{k}_{0}}\left(\frac{2 g d_{c} \mathrm{~L} R \mathrm{~T}}{\lambda}\right)^{\frac{1}{2}}
\end{gathered}
$$

to give the governing equation for flow inside the crack as

$$
-\bar{k}_{c x} \frac{\partial F}{\partial \bar{X}} \pm \frac{\partial}{\partial \bar{Y}}\left(\bar{k}_{c y z}\left(\left|\frac{\partial F}{\partial \bar{Y}}\right|\right)^{\frac{1}{2}}\right) \pm \frac{\partial}{\partial \bar{z}}\left(\bar{k}_{c y z}\left(\left|\frac{\partial F}{\partial \bar{z}}\right|\right)^{\frac{1}{2}}\right)+\frac{\partial \bar{P}}{\partial \tau}=0 .
$$

The value of reference permeability, $k_{0}$, may be taken as any representative quantity. We set $k_{0}$ so tinat all values of $k_{c y z}$ are inftially less than or equal to unity. That is

$$
k_{0}=\frac{\varepsilon \mu}{\left(P_{1}-P_{0}\right)}\left(\frac{2 B d_{c_{\max }} L R T}{\lambda}\right)^{\frac{1}{2}} .
$$

where $d_{c_{\max }}$ is evaluated as its maximum initial value. This reference permeability is a constant for each problem. 
The value of frictional coefficient, $\lambda$, depends on Reynolds number and relative roughness. Both laminar and curbulent frictional coefficients are calculated at each node withi! the crack based on the Reynolds number and relative roughness present. The larger of the frictional coefficlent values is used since in accordance with reported data (Ref, 10, Fig. 20.18) the laminar frictional coefficient will be greater only if the flow is laminar. This is explained. graphically in Fig. (A-6).

The frictiunal coefficient for turbulent flow is based on the completely rough regime with one of the turbulent curves selected based on relative ruughness. Even though the crack wall is considered to have $A$ uniform absolute roughness, the relative roughness will be different for each node in the crack because of a varying crack thickness. The transition flow regime is omitted with the completely rough turbulent frictional coefficient used for all Reynolds uumbers unless the flow is laminar.

\section{CALCULATION OF THE FRICTIONAL COEFFICIENTS}

In calculating the laminar frictional coefficient, we find that the shape of the flow channel is important. For the case of parallel plates (or an annular region with small separation between the walls), the experimental data correlates with (Ref. 10, Fig. 20.12)

$$
\lambda_{\ell}=\frac{96}{\operatorname{Re}}
$$

where the subscript $\&$ represents laminar. The value of Reynolds number is based on the total velocity vector, $V$, and the hydraulic diameter, $d_{h}$, whtch for the case of parallel plates is twice the crack thickness, $d_{c}{ }^{*}$ The Reynolds number then is

$$
\begin{aligned}
\operatorname{Re} & =\frac{V d_{h} \rho}{\mu g} \\
& =\frac{2 V d_{c} \rho}{\mu g} .
\end{aligned}
$$




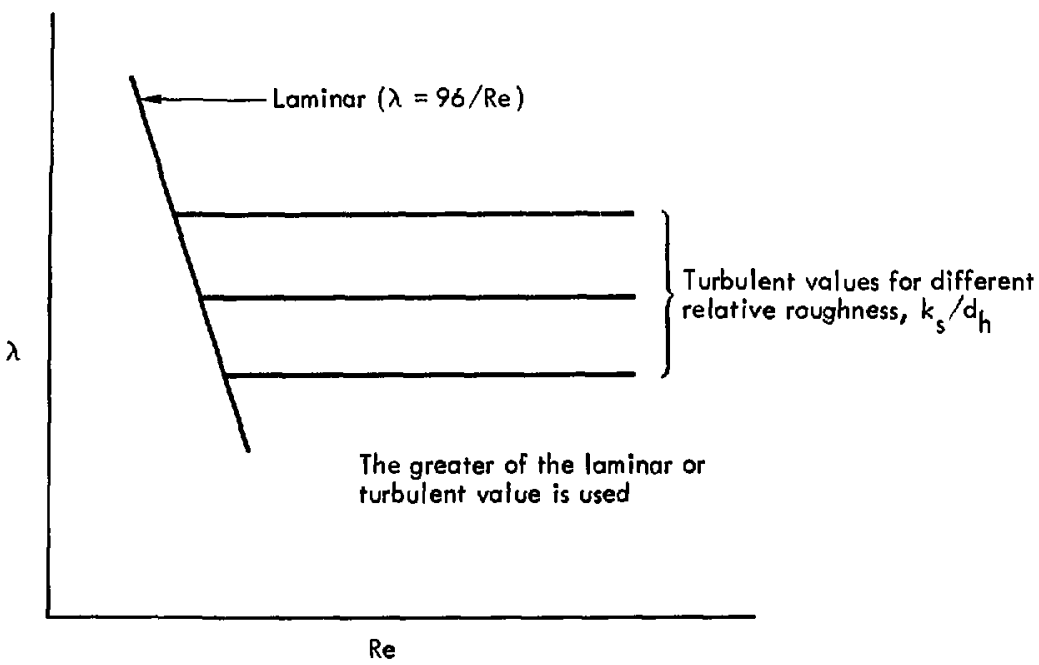

Fig. A-6. Variation of frictional coefficlent with Reynolds number and relative roughness.

A comparison may be made between the experimental values which yield Eq. (A-52) and the theory of steady laminar flow through a straight channel (Ref. 10, p 77). Referring to Fig. A-7 the velocity distribution and volumetric flow rate, $Q$, are

$$
u=-\frac{1}{2 \mu} \frac{d P}{d X}\left(b^{2}-Y^{2}\right)
$$




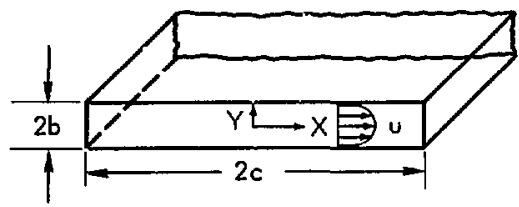

Fig. A-7. Parallel-flow channel used to develop a theoretcal laminar flow frictional coefficient.

where $\frac{d P}{d x}$ is a constant and

$$
\begin{aligned}
Q & =4 \int_{0}^{c} \int_{0}^{b} u d Y d X \\
& =-\frac{2}{\mu} \frac{d P}{d X} \int_{0}^{c}\left[b^{2} Y-\frac{Y^{3}}{3}\right]_{0}^{b} d X \\
& =-\left.\frac{4 b^{3}}{3 \mu} \frac{d P}{d X} x\right|_{0} ^{c} \\
& =-\frac{4}{3} \frac{b^{3} c}{\mu} \frac{d P}{d X} .
\end{aligned}
$$

$Q$ is also related to an average velucity across the channel which is set equal to the total velocity vector, $V$, which is the sum of the " $Y$ " and " $Z$ " direction components of velocity

$$
Q=4 \text { bc } V \text {. }
$$

Equating Eqs. (A-55) and $A-56)$

$$
-\frac{d P}{d x}=\frac{3 \mu V}{b^{2}}=\frac{3 \mu V}{\left(d_{h} / 4\right)^{2}}=\frac{48 \mu V}{d_{h}^{2}}
$$


The pressure gradient is related by Ref. 10, p 561ff:

$$
-\frac{\mathrm{dP}}{\mathrm{dX}}=\frac{\lambda_{\ell}}{\mathrm{d}_{\mathrm{h}}} \frac{\rho \mathrm{V}^{2}}{2 \mathrm{~g}} .
$$

Combining Eqs. $(A-57)$ and $A-58)$

$$
\lambda_{\ell}=\frac{96 \mathrm{g \mu}}{\rho \mathrm{d}_{\mathrm{h}} \mathrm{V}}=\frac{96}{\mathrm{Re}}
$$

which gives an identical result to experimental data of Eq. (A-52). We note that for Hagen-Potseuflle flow through a circular pipe the value of the constant would be 64 rather than 96 .

The hydrodynamic theory of lubrication (Ref, 10, p $108 \mathrm{ff}$ ) is an extension to the above analysis for the case when the plates are not parallel. If the angle between the two plates is significant, then the acceleration term in the Navier Stokes equation, $u \frac{\partial \mu}{\partial X}$, becomes important and must be compared to the viscous term, $\mu \partial^{2} u / \partial y^{2}$, even though the velocity is small. In our case, this angle is negligible throughout the entire crack and the case of parallel plates applies.

For the turbulent frictional coefficient, $\lambda_{t}$, we utilize the extensive experimental results for fully developed turbulent flow (Ref. 10, Eq. 20.35) which relates $\lambda_{t}$ with relative roughness as

$$
\lambda_{t}=\frac{1}{\left(2 \log \frac{d_{h}}{k_{s}}+1.74\right)^{2}} .
$$

The value of relative roughness, $k_{s} / d_{h}$, is the average grain size of particles composing the crack boundary divided by the hydraulic diameter.

\section{alternate Means of Calculating THE "Y" AND "Z" DIRECTION MONENTUM EQUATIONS IN THE CRACK}

The momentum equations utilized for the " $\mathrm{Y}$ " and " $\mathrm{Z}$ " direction within the crack should include acceleration and transient terms to be complete. The method outlined below adds substantial complication to the analysis but 
does include these additional terms which were neglected earlier. Use of steady flow momentum equations in the " $Y$ " and " $Z$ " directions appears intuitively justified since the transit time in the crack is much less than for gas permeation in the solid.

Let us consider that the total velocity in the crack is nearly parallel to the " 2 " axis. This will simplify the analysis since $u_{y} \approx 0$. Extension to the more general case would follow the same outline. Neglecting body forces, the " $z$ " direction momentum equation is (Ref. 10, Chapter 3)

$$
\rho u_{z} \frac{\partial u z}{\partial z}+\rho \frac{\partial u}{\partial t} \ldots-\frac{\partial p}{\partial z}+\mu \frac{\partial^{2} u_{z}}{\partial x^{2}} \text {. }
$$

The terms $\partial^{2} u_{z} / \partial Y^{2}$ and $\partial^{2} u_{z} / \partial z^{2}$ are omitted since they are negligible when compared to $\partial^{2} u_{z} / \partial x^{2}$.

There is some question as to the form in which the last term of Eq. (A-6I) may be written for transient flow. This term relates to the viscous forces present and for steady flows is equated to a frictional coefficient, $\lambda$, (Ref. 10, Chapters 19 and 20) as follows.

$$
\begin{aligned}
\mu \frac{\partial^{2} u_{z}}{\partial x^{2}} & =\frac{\partial}{\partial x}\left[\left(\mu+\rho E_{t}\right) \frac{\partial u_{z}}{\partial x}\right] \\
& =\frac{\partial}{\partial x}\left[\tau_{\ell}+\tau_{t}\right] \\
& =\frac{\lambda \rho u_{z}^{2}}{4 g d_{c}}
\end{aligned}
$$

Here $\tau_{\ell}$ and $\tau_{t}$ are the laminar and turbulent shear stresses and $\varepsilon_{t}$ is the turbulent eddy viscosity. 
As explained in the main body of the report, Ginzberg ${ }^{28}$ and Petrova ${ }^{29}$ both assume that the resistance properties established for steady flow apply for transient conditions. Yeremenko and Markov ${ }^{30}$ develop a relationship between increases in frictional coefficient for accelerating flow and an unsteady flow parameter, $\delta_{0}$, but do not Indicate how to obtain $\delta_{0}$ without knowing the velocity distribution. Although this velocity distribution has been analyzed for laminar flow by Doughty ${ }^{31}$, it is uninown in general. Therefore we have used the frictional coefficient based on steady flow. Combining Eqs. $(A-61)$ and $(A-62)$ with the gas equation of state (Eq. A-18) gives

$$
\mathrm{P} u_{z} \frac{\partial u_{z}}{\partial z}+\mathrm{P} \frac{\partial u_{z}}{\partial t}=-R \mathrm{~T} \frac{\partial \mathrm{P}}{\partial z}+\frac{\lambda \mathrm{Pu}_{z}{ }^{2}}{4 \mathrm{~g} \mathrm{~d}_{\mathrm{c}}}
$$

We cannot use Eq. $(A-63)$ to eliminate $u_{z}$ in the continuity equation for flow in the crack (Eq. $A-28$ ) as we had done previously. Instead, Eq. (A-63) is used as one equation in a set of coupled equations which could be solved numerically to obtaln values of $u_{z}$ and $P$.

The second of the coupled equations is developed for the case when $u_{y} \approx 0$ by combining the continuity equation, Eq. (A-35), with the "X" direction momentum equation, Eq. $(A-36)$, and the ideal gas equation of state, Eq. $(A-18)$. This gives

$$
-\frac{2 P k_{x}}{d_{c} \mu} \frac{\partial P}{\partial X}+\frac{\partial\left(P_{z}\right)}{\partial z}+\frac{\partial P}{\partial t}=0 .
$$

It is needless to say that the coupling between Eqs. $(A-63)$ and $(A-64)$ results in substantial complication in obtalning a solution. Rather than attempt this form of solution we choose to use the simpler formulation that includes the momentum equations for fully developed flow in the " $Y$ " and " $Z$ " directions. We then checked the magnitude of the neglected transient and acceleration terms using results of the calculations with the momentum equations for fully developed flow. Fortunately we found that the transient and acceleration terms were less than $10 \%$ of the included terms in the momentum equations exc pt at times less than one eighth the rotal problem time. 
does include these additional terms which were neglected earlier. Use of steady flow momentum equations in the " $Y$ " and " $\mathrm{Z}$ " directions appears intuitively justified since the transit time in the crack is much less than for gas permeation in the solid.

Let us consider that the total velocity in the crack is nearly parallel to the " $Z$ " axis. This will simplify the analysis since $u_{y} \approx 0$. Extension to the more general case would follow the same outline. Neglecting body forces, the " $z$ " direction momentum equation is (Ref. 10, Chapter 3)

$$
\rho u_{z} \frac{\partial u_{z}}{\partial z}+\rho \frac{\partial u_{z}}{\partial t}=-\frac{\partial P}{\partial z}+\mu \frac{\partial^{2} u_{z}}{\partial x^{2}}
$$

The terms $\partial^{2} u_{z} / \partial Y^{2}$ and $\partial^{2} u_{z} / \partial z^{2}$ are omitted since they are negligible when compared to $\partial^{2} u_{z} / \partial x^{2}$.

There is some question as to the form in which the last term of .Eq. (A-61) may be written for transient flow. This term relates to the viscous forces present and for steady flows is equated to a frlctional coefficient, $\lambda$, (Ref. 10, Chapters 19 and 20) as follows.

$$
\begin{aligned}
\mu \frac{\partial^{2} u_{z}}{\partial x^{2}} & =\frac{\partial}{\partial x}\left[\left(\mu+\rho \varepsilon_{t}\right) \frac{\partial u_{z}}{\partial x}\right] \\
& =\frac{\partial}{\partial x}\left[\tau_{\ell}+\tau_{t}\right] \\
& =\frac{\lambda \rho u_{z}}{4 g d_{c}}
\end{aligned}
$$

Here $\tau_{\ell}$ and $\tau_{t}$ are the laminar and turbulent shear stresses and $\varepsilon_{t}$ is the turbulent eddy viscosity. 
As explained in the main body of the report, Ginzberg ${ }^{28}$ and Petrova 29 both assume that the resistance properties established for steady flow apply for transient conditions. Yeremenko and Markov ${ }^{30}$ develop a relationship between increases in frictional coefficient for accelerating flow and an unsteady flow parameter, $\delta_{0}$, but do not indicate how to obtain $\delta_{0}$ without knowing the velocity diatribution. Although this velocity distribution has been analyzed for laminar flow by Doughty ${ }^{3 l}$, it is unknown in general. Therefore we have used the frictional coefficient based on steady flow. Combining Eqs. $(A-61)$ and $(A-62)$ with the gas equation of state (Eq. A-18) gives

$$
P u_{z} \frac{\partial u_{z}}{\partial z}+P \frac{\partial u_{z}}{\partial t}=-R T \frac{\partial p}{\partial z}+\frac{\lambda P u_{z}{ }^{2}}{4 g d_{c}}
$$

We cannot use Eq. (A-63) to ellminate $u_{z}$ in the continulty equation for flow in the crack (Eq. A-28) as we had dona previously, Instead, Eq. (A-63) is used as one equation in a set of coupled equations which could be solved numerically to obtain values of $u_{z}$ and $P$.

The second of the coupled equations is developed for the case when $u_{y} \approx 0$ by combining the continulty equation, Eq. (A-35), with the " $X$ " direction momentum equation, Eq. (A-36), and the 1deal gas equation of state, Eq. (A-18). This gives

$$
-\frac{2 P k_{x}}{d_{c} \mu} \frac{\partial p}{\partial X}+\frac{\partial\left(P u_{z}\right)}{\partial z}+\frac{\partial P}{\partial t}=0 .
$$

It is needless to say that the coupling between Eqs. (A-63) and (A-64) results in substantial complication in obtaining a solution. Rather than at tempt this form of solution we choose to use the simpler formulation that includes the momentum equations for fully developed flow in the " $Y$ " and " $Z$ " directions. We then checked the magnitude of the neglected transient and acceleration terms using results of the calculations with the momentum equations for fully developed flow. Fortunately we found that the transient and acceleration terms were less than $10 \%$ of the Included terms in the momentum equations except at times less than one eighth the total problem time. 
Even at these early times we felt the transient and acceleration terms could be neglected for two reasons. First, the actual application of applied pressure appears over a short period of time rather than the mathematical step change we had used in the analysis. Second, the effect of any error included by neglecting the transient and acceleration terms at early times has little effect on the overall solution since most changes in gas pressure occurred after the time when the transient and acceleration terms were important.

\section{References for Appendix A}

A-1 J. Boussjinesq, "Application des Potentials a l'Etude de Z'Equilibre et du Mouvement des Solides Elastiques," (Gauthfer-Villars, Paris, 1885).

A-2 J. C. Holden, Stresses and Strains in a Sand Mass Subjected to a Uniform Circular Load, Ph.D. Thesis, University of Melbourne, 1967.

A-3 Waterways Experiment Station, Investigation of Pressures and Deflections for Flexible Pavements, Report No. 4, Homogeneous Sand Test Section, Technical Memorandum No. 3-323 (1954).

A-4 M. K. Hubbert, "Darcy's Law and the Field Equations of the Flow of Underground Flulds," Trans. Soc. Petrol. Eng. AIME, Vo1. 207 (1956), PP 222-239.

A-5 P. Forcheimer, "Wasserbewegung durch Boden," Zeitschrift des Vereines Deutscher Ingenteure, Vol. 45 (1901), pp 1781-1788.

A-6 F. A. Morrison Jr., Transient Compressible Flows In Porous Media, Final Report (UILU Eng-75 4004) Dept. of Mechanical and Industrial Engineering, University of Illinois at Urbana-Champalgn (1975). 


\section{Appendix B - Development of the Equations Used for Computation}

This append $1 \mathrm{x}$ converts the governing equations into the difference equations used for numerical computation in the computer code CHASM. If feasible, the difference equations also are written in terms of the varlables used In the computer code.

The arrangement of this appendix follows the logic of the computations which 1 shown on the flow chart of Fig. B-1. After input, calculation of constants, and Initialization, we iterate with time through a main computational loop. Within the main computational loop we first calculate the crack wall deflection based on the known values of pressure at $t$ ime, $n$. We next calculate the frictional coefficlent and values of the coefficients used in the crack-flow equations. Lastly we simultaneously calculate the pressures at a new time, $n+1$, throughout the solid and crack. If desired, we print out results before repeating the calculations in the main computational loop for the next time step.

The problem is considered complete if the tip of the crack reaches the maximum node in the " $\mathrm{"} \mathrm{direction} \mathrm{which} \mathrm{normally} \mathrm{represents} \mathrm{the} \mathrm{surface} \mathrm{of} \mathrm{the}$ earth or if it reaches the maximum node in the " $Y$ " direction which Indicates additional nodes need to be added to obtain a proper solution.

Superscripts are used for time variations and subscripts are used for spatial variations as Indicated in Table B-1.

Table B-1 - Subscripts and Superscripts used in the Difference Equations

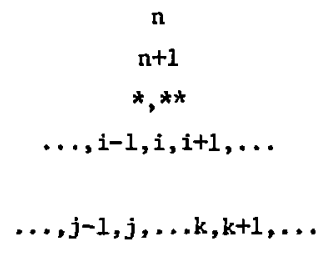

$\mathbf{n}$

*, **

Table B-1 - Subscripts and Superscripts used in the Difference Equations

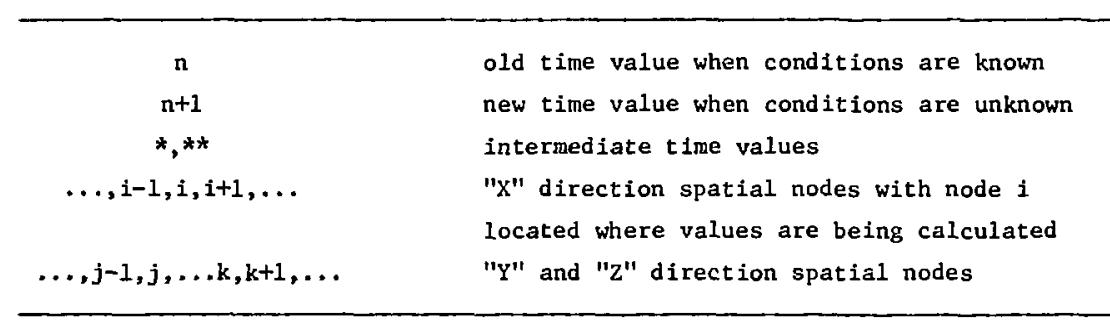



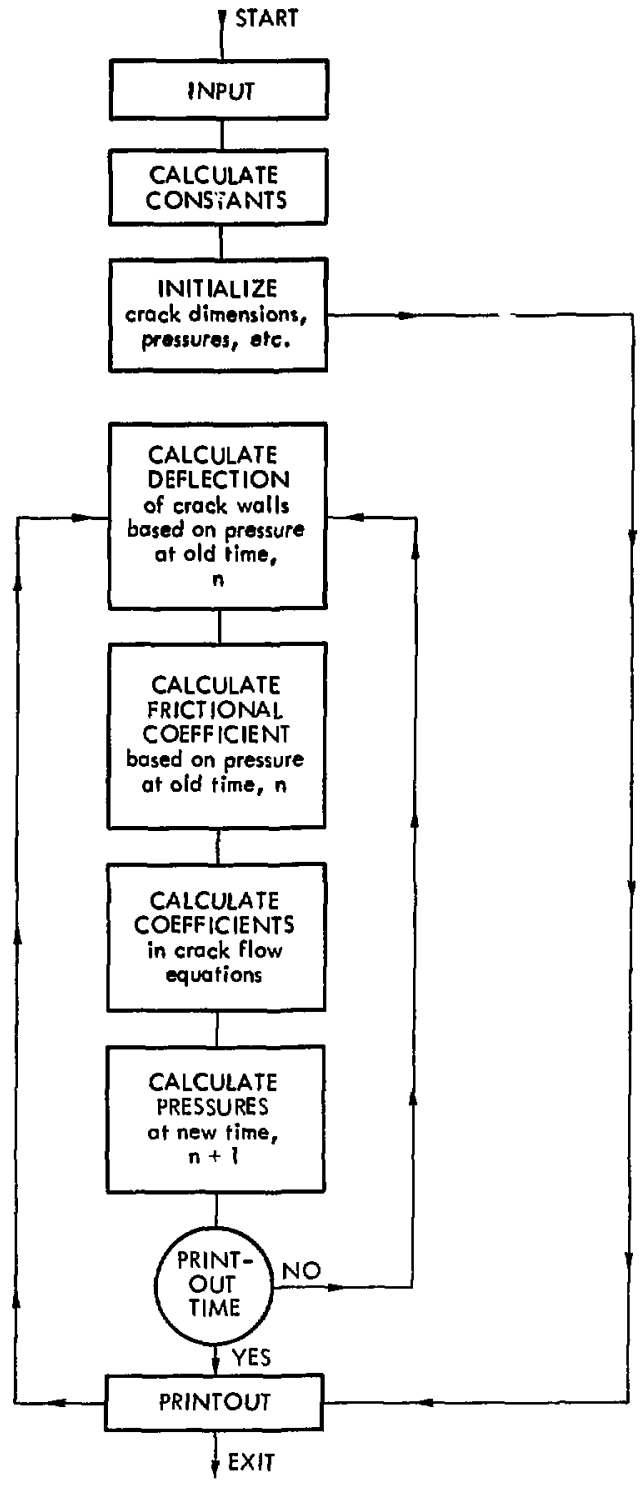

Fig. B-1. Flow chart of computations in the CHASM computer code. 
Deflections are calculated in dimensional form using $\mathrm{Eq}$. (A-7) multiplied by the reference length, $L$.

$$
\begin{aligned}
& \bar{D}(\bar{Y}, \bar{Z})=\sum C_{G} \frac{\left(1-v^{2}\right)}{\bar{E}}\left(\overline{\mathrm{P}}-\overline{\mathrm{P}}_{\mathrm{r}}\right)\left(\Delta \overline{\mathrm{Y}}^{\prime} \Delta \overline{\mathrm{Z}}^{\prime}\right)^{\frac{1}{2}} \\
& D(\overline{\mathrm{Y}}, \overline{\mathrm{Z}})=\sum \mathrm{C}_{\mathrm{G}} \frac{\left(1-v^{2}\right) L}{\overline{\mathrm{E}}}\left(\overline{\mathrm{P}}-\overline{\mathrm{P}}_{\mathrm{r}}\right)\left(\Delta \overline{\mathrm{Y}}^{\prime} \Delta \overline{\mathrm{Z}}^{\prime}\right)^{\frac{1}{2}}
\end{aligned}
$$

Values of $C_{G}$ are established as input in the main computer program from Gerrard and Morgan ${ }^{\prime} s^{8}$ and Campen and Smith's ${ }^{13}$ deflection data. These coefficients account for the effect of distance between the point the deflection is being calculated and the area subjected to unfform pressure loading as shown in Table A-1. We sum the component deflections only over those areas where $C_{G}$ is non zero which in our analysis comprises the region within three nodes of the area subjected to uniform pressure loading. In the main computer program we define a term, CDEF, which contains all the constants in Eq. (B-1) and an array, $\operatorname{CSUBG}(j, k)$, of the Gerrard and Morgan deflection coefficlents as

$$
\begin{aligned}
\operatorname{CDEF} & =\frac{\left(1-v^{2}\right) L}{\bar{E}} \\
\operatorname{CsUBG}(j, k) & =C_{G}(\Delta \overline{\mathrm{Y}} \cdot \overline{\Delta \bar{Z}})^{\frac{1}{2}} \\
& =C_{G} / N M I .
\end{aligned}
$$

Here, NMI is the computer term for the number of " 2 " direction nodes minus one. Our mesh spacing over the $\mathrm{X}=0$ plane is composed of uniform squares and the values of $C_{G}$ are calculated for uniform square areas. If a difference mesh spacing such as a rectangle is incorporated, a new set of $C_{G}$ values in Table A-1 would need to be developed.

The summation in $\mathrm{Eq} .(\mathrm{B}-1)$ is accomplished in three parts in the computer program. First we sum over all areas which are at the same elevation as the point where deflection is being calculated. If the point is near a boundary 
and the circle of influence, where $C_{G}$ is greater than zero, extends beyond the plane $\bar{Y}=0$, we utilize a symetry condition to account for $\bar{Y}<0$. If the circle of influence extends beyond the maximus " $\overline{\mathrm{Y}}$ " plane we set those gas pressures equal to the value at the maximum " $\bar{Y}$ ". Th1s is consistent with the boundary

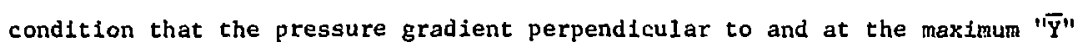
plane is zero.

Second we calculate the contribution due to nodes below the $\bar{z}=0$ plane if the circle of Influence extends that far. If the $\bar{Y}$ node is within the reglon of applied pressure at $\bar{z} \sim 0$ we utilize the applied pressure less the appropriate earth formation resistive pressure due to overburden as the net force tending to open the crack. If the $\vec{Y}$ node is outside the region of applied pressure we take the pore pressure to be a symmetric. 1mage of that above the $\bar{z}=0$ plane. Finally, we calculate the concribution of all nodes above the $\bar{z} \approx 0$ plane which have a non-zero $C_{G}$ and which have not been calculated previously. In all calculations, the approprlate Gerrard and Morgan deflection coefficient is chosen based on the number of nodes away from the point at which deflection is being calculated. We then multiply by the difference between the gas pressure in excess of the atmospheric pressure present at the node and the earthformation resistive pressure.

\section{FRICTIONAL COEFFICIENT}

The governing equation for a laminar flow frictional coefficient with a geometry of closely spaced parallel walls is

$$
\lambda_{\ell}=96 / R e
$$

where

$$
\operatorname{Re}=\frac{2 V d_{c} \rho}{\mu g}
$$


We first determine a relationship between the total velocity vector, $V$, and the pressure gradients in the " $Y$ " and " " direction. Recalling that in the crack

$$
\begin{aligned}
& \frac{\partial P}{\partial Y}=-\frac{\lambda}{2 d_{c}} \frac{\rho y^{2}}{2 g} \\
& \frac{\partial P}{\partial Z}=-\frac{\lambda}{2 d_{c}} \frac{\rho z^{2}}{2 g}
\end{aligned}
$$

we may establish the velocity vector relationship as

$$
\begin{aligned}
v^{2} & =u_{y}^{2}+u_{z}^{2} \\
& =\frac{4 g d_{c}}{\rho \lambda_{\ell}}\left(\left|\frac{\partial P}{\partial Y}\right|+\left|\frac{\partial P}{\partial Z}\right|\right) .
\end{aligned}
$$

The absolute value signs are necessary to assure $t$ it $u_{y}{ }^{2}$ and $u_{z}{ }^{2}$ are posttive for all values of pressure gradient as they must be. We take the values of $\lambda$ in Eqs. (A-41) and (A-42) to be for lamina. flow since we are calculating $\lambda_{\ell}$. If the flow is actually turbulent, then the calculated value of $\lambda_{\ell}$ will be discarded since the corresponding value calculated for $\lambda_{t}$ will be greater.

Combining equations we have

$$
\begin{aligned}
\lambda_{\ell}^{2} & =\frac{96^{2} \mu^{2} g^{2}}{4 V^{2} d_{c}^{2} \rho^{2}} \\
& =\frac{96^{2} \mu^{2} g \lambda_{\ell}}{16 d_{c}^{3} \rho\left(\left|\frac{\partial P}{\partial Y}\right|+\left|\frac{\partial P}{\partial Z}\right|\right)} .
\end{aligned}
$$


Eliminating the density by using the equation of state (Eq. A-18) ylelds

$$
\begin{aligned}
\lambda_{\ell} & =\frac{96^{2} \mu g R T}{16 d_{c}^{3} P\left(\left|\frac{\partial P}{\partial z}\right|+\left|\frac{\partial P}{\partial z}\right|\right)} \\
& =\frac{96^{2} \mu^{2} g k T}{8 d_{c}^{3}\left(\left|\frac{\partial P^{2}}{\partial Y}\right|+\left|\frac{\partial P^{2}}{\partial z}\right|\right)} .
\end{aligned}
$$

We wish to write Eq. (B-6) in terms of the pressure function, F. From the definitions

$$
\begin{aligned}
& \bar{P}=\frac{P-P_{0}}{P_{1}-P_{0}} \\
& F=\left(\bar{P}+\frac{1}{N-1}\right)^{2}
\end{aligned}
$$

we obtain

$$
\begin{aligned}
\mathrm{P}^{2} & =\left(\mathrm{P}_{1}-\mathrm{P}_{0}\right)^{2} \overrightarrow{\mathrm{P}}^{2}+2 \mathrm{P}_{0}\left(\mathrm{P}_{1}-\mathrm{P}_{0}\right) \overline{\mathrm{P}}+\mathrm{P}_{0}^{2} \\
& =\left(\mathrm{P}_{1}-\mathrm{P}_{0}\right)^{2}\left(\overline{\mathrm{P}}^{-2}+\frac{2 \mathrm{P}_{0}}{\mathrm{P}_{1}-\mathrm{P}_{0}} \overline{\mathrm{P}}+\frac{\mathrm{P}_{0}^{2}}{\left(\mathrm{P}_{1}-\mathrm{P}_{0}\right)^{2}}\right) \\
& =\left(\mathrm{P}_{1}-\mathrm{P}_{0}\right)^{2} \mathrm{~F}
\end{aligned}
$$

and

$$
\begin{aligned}
\frac{\partial P^{2}}{\partial Y} & =\frac{\partial P^{2}}{L \partial \bar{Y}} \\
& =\frac{\left(P_{1}-P_{0}\right)^{2}}{L} \frac{\partial F}{\partial \bar{Y}} . \\
-70- &
\end{aligned}
$$


Similarly

$$
\frac{\partial P^{2}}{\partial Z}=\frac{\left(P_{1}-F_{0}\right)^{2}}{L} \frac{\partial F}{\partial \bar{Z}}
$$

Combining Eq. $(B-6),(B-9)$, and $(B-10)$

$$
\lambda_{\ell}=\frac{96^{2} \mu^{2} g L R T}{8\left(\mathrm{P}_{1}-\mathrm{P}_{0}\right)^{2} \mathrm{~d}_{c}^{3}\left(\left|\frac{\partial F}{\partial \bar{Y}}\right|+\left|\frac{\partial F}{\partial \bar{Z}}\right|\right)} .
$$

The equation used for computation is written in terms of the crack half thickness rather than the crack thickness so that

$$
\lambda_{\ell}=\frac{144 \mu^{2} g L R T}{\left(P_{1}-P_{0}\right)^{2}\left(d_{c} / 2\right)^{3}\left(\left|\frac{\partial F}{\partial \bar{Y}}\right|+\left|\frac{\partial F}{\partial \bar{Z}}\right|\right)} .
$$

Care must be exerclsed to assure compatibility of units. We calculate all constants once in the first part of the main program as

$$
\text { CFRICT } 1=\frac{144 \mu^{2} g L R T}{\left(\mathrm{P}_{1}-\mathrm{P}_{0}\right)^{2}}
$$

The difference equations used along with Eqs. (B-12) and (B-13) are

$$
\begin{aligned}
& \left|\frac{\partial F}{\partial \bar{Y}}\right|=\left|F_{j+1, k}^{n}-F_{j-1, k}^{n}\right| / 2 \Delta \bar{Y} \\
& \left|\frac{\partial F}{\partial \bar{Z}}\right|=\left|F_{j, k+1}^{n}-F_{j, k-1}^{n}\right| / 2 \Delta \bar{Z}
\end{aligned}
$$

and

$$
d_{c} / 2=d_{c_{j, k}}^{n} / 2 .
$$


If the location at which the frictional coefficient is being calculated is on a boundary then the gradlents of the pressure function, F, are evaluated with either forward or backward differences rather than central differences. The value of the turbulent frictional coefficient is calculated directly as

$$
\lambda_{t}=\frac{1}{\left(2 \log \frac{d_{h}}{k_{s}}+1.74\right)^{2}}
$$

where $k_{s} / d_{h}$ is the relative roughness equal to the average diameter of the solid grains composing the crack wall divided by the hydraulic diameter, $d_{h}=2 d_{c}=4\left(d_{c} / 2\right)$.

We choose the greater of the laminar or turbulent frictional coefficlent for actual use. Because Inslgniflcant crack thicknesses can be obtalned mathematically, upper limits to the frictional coefficients are imposed to assure that reasonable values are not exceeded.

In the computer program, Reynolds number is calculated after the frictional cnefficients. For laminar flow

$$
\operatorname{Re}=\frac{96}{\lambda_{\ell}} .
$$

For turbulent flow we use Eq. $(A-53),(B-4),(B-9)$ and $(B-10)$. If we recall that the actual equation used for compucation is written in terms of the crack half thickness, then 


$$
\begin{aligned}
& \operatorname{Re}=\frac{|v| d_{h} \rho}{\mu g} \\
& \left.=\frac{2 d_{c}}{\mu}\left(\frac{4 d_{c} p}{\lambda_{t} B}\left(\left|\frac{\partial P}{\partial Y}\right|+\mid \frac{\partial P}{\partial Z}\right)\right)\right)^{\frac{1}{2}} \\
& =\frac{2 d_{c}\left(P_{1}-P_{0}\right)}{\mu}\left(\frac{2 d_{c}}{\lambda_{t} L R T}\left(\left|\frac{\partial F}{\partial \bar{Y}}\right|+\left|\frac{\partial F}{\partial \bar{Z}}\right|\right)\right)^{\frac{1}{L}} \\
& =\frac{8\left(d_{c} / 2\right)\left(P_{1}-P_{0}\right)}{H}\left(\frac{\left(d_{c} / 2\right)}{\lambda_{t} G L T T}\left(\left|\frac{\partial F}{\partial \vec{Y}}\right|+\left|\frac{\partial F}{\partial \bar{Z}}\right|\right)\right)^{\frac{1}{2}} \text {. }
\end{aligned}
$$

Again the constant values are cotbined into a single coefficient calculated in the main program which is

$$
\text { CFRIC2 }=\frac{B\left(\mathrm{P}_{1}-\mathrm{P}_{0}\right)}{\mu}\left(\frac{1}{\mathrm{BLRT}}\right)^{\frac{1}{2}}
$$

\section{IMPLICIT DIFFERENCING OF THE POROUS-SOLID FLOW EQUATIONS}

Above the crack tip but in the plane of the crack as well as througt ut the rest of the porous solid, the permeabilities in the spatial coordinaves are considered as constants so that the guverning equation is

$$
\frac{\bar{k}_{x}}{2} \frac{\partial^{2} F}{\partial \bar{x}^{2}}+\frac{\bar{l}_{y}}{2} \frac{\partial^{2} F}{\partial \bar{Y}^{2}}+\frac{\bar{k}}{2} \frac{\partial^{2} F}{\partial \bar{z}^{2}}=\frac{\partial \bar{P}}{\partial \tau}
$$

where

$$
F=\left(\bar{P}+\frac{1}{N-1}^{2}\right)
$$


We wish to difference Eq. $(A-31)$ in terms of the pressure function, F. Using Eq. $(B-20)$ we solve for $\bar{P}$ and $\partial \bar{P} / \partial \tau$ as

$$
\begin{aligned}
\bar{P} & =F^{\frac{3}{2}}-\frac{1}{N-I} \\
\frac{\partial \bar{P}}{\partial \tau} & =\frac{\partial \bar{P}}{\partial F} \frac{\partial F}{\partial T} \\
& =\frac{1}{2} F^{-\frac{1}{2}} \frac{\partial F}{\partial \tau}
\end{aligned}
$$

Substituting 1itco (A-31) we obtain

$$
k_{x} \frac{\partial^{2} F}{\partial \bar{X}^{2}}+k_{y} \frac{\partial^{2} F}{\partial \bar{Y}^{2}}+k_{z} \frac{\partial^{2} F}{\partial \bar{Z}^{2}}=F^{-\frac{l}{2}} \frac{\partial F}{\partial \tau}
$$

The coefficient of the time derivative is always finite since $F$ is 1 unded by $0 \leq F \leq N^{2} /(N-1)^{2}$. Each spatlal term taken separately with the time derivative forms a parabolic equation. We follow the procedure described by Carnahan, Luther, and Wilkes ${ }^{23}$ which ias originally developed by Brian ${ }^{25}$ since this reduces to the alternating direciton tmplictt method in two dimensions used in differencing the crack flow equations. Use of Douglas ${ }^{B-1}$ method described by Carnahan is an extension of the Crank-Nicolson method and as such would not be as compatible with the differencing chosen for the implicit solution of gas flow inside the crack in the " $y$ " and " $z$ " directions. 
The major advantage of the solution method chosen is the tri-diagonal form of the matrix which results. That 1s, the matrix has non-zero elements only along the diagonal and immediately adjacent elements as shown in $\mathrm{F} I \mathrm{~g}$. (B-2). A particularly efficient method to solve the matrix is available. Following Brian's ${ }^{23}$ method, the solution is broken into three parts as

$$
\begin{aligned}
& \bar{k}_{x} \delta_{x}^{2} F^{*}+\bar{k}_{y} \delta_{y}^{2} F^{n}+\bar{k}_{z} \delta_{z}^{2} F^{n}=\left(F^{n, *}\right)^{-\frac{1}{2}} \frac{F^{*}-F^{n}}{\Delta \tau / 2} \\
& \bar{k}_{x} \delta_{x}^{2} F^{*}+\bar{k}_{y} \delta_{y}^{2} F^{* *}+\bar{k}_{z} \delta_{z}^{2} F^{n}=\left(F^{n, * *}\right)^{-\frac{1}{2}} \frac{F^{* *}-F^{n}}{\Delta \tau / 2} \\
& \bar{k}_{x} \delta_{x}^{2} F^{*}+\bar{k}_{y} \delta_{y}^{2} i^{* *}+\bar{k}_{z} \delta_{z}^{2} F^{n+1}=\left(F^{* *, n+1}\right)^{-\frac{1}{2}} \frac{F^{n+1}-F^{* *}}{\Delta \tau / 2}
\end{aligned}
$$

Here $\delta_{x}^{2}, \delta_{y}^{2}$, and $\delta_{z}^{2}$ are finite difference forms of the second derivative acting on the pressure function at the time shown. The double superscripts indicate a value of $F$ between the times denoted by the superscripts.

The actual equations used for computations are developed following the solution method for tridiagonal matricles outlined by Roache. ${ }^{24}$ We let

$$
\begin{aligned}
& \alpha=\bar{k}_{x} \\
& \gamma=\bar{k}_{y} \\
& \xi=\bar{k}_{z}
\end{aligned}
$$




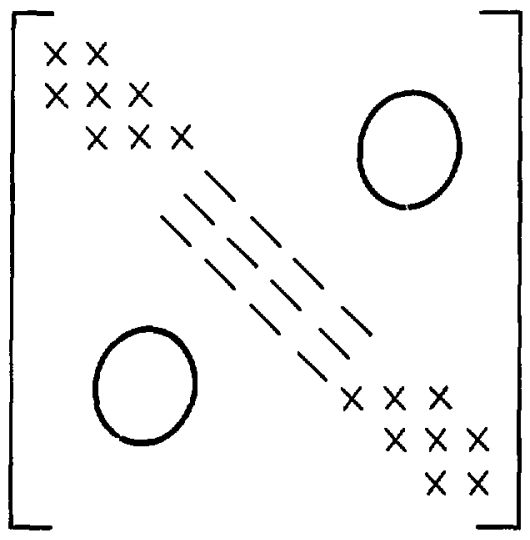

Zero elements

$X$ Nonzero elements

Fig. B-2. Form of a tri-diagonal matrix.

and

$$
\eta_{i, j, k}^{n, k}=\theta\left(F_{i, j, k}^{*}\right)^{-\frac{k}{2}}+(1-\theta)\left(F_{i, j, k}^{n}\right)^{-\frac{l}{2}}
$$

$(B-30)$

The coefficients $\alpha, \gamma$, and $\xi$ are taken to be independent of time and space. Time superscripts and spatial subscripts could also be included for generality if desired. The correct time value to use when calculating the value of $E_{i, j, k}$ in the $n_{i, j, k}$ coefficient is a matter at some debate. We include a weighting coefficient $\theta$ in the calculation of $\eta_{1, j, k}^{n, *}$ which may be varied depending on the specific problem. The superscript contains the two time values used in calculating the $n$ coefficient.

$-76-$ 
We use Blottner's grid stretching method 26 in the " $X$ " direction to increase the effectiveness of the number of grid points used. This makes the grid size varlable in the " $\mathrm{X}$ " direction. Substituting Eqs. (B-27) through (B-30) into (B-24) with the derivatives expanded into differences gives

$$
\frac{2 \alpha}{\left(\Delta \bar{x}_{i+1 / 2}+\Delta \bar{x}_{1-1 / 2}\right)}\left[\frac{\left(F_{i+1, j, k}^{*}-F_{i, j, k}^{*}\right)}{\Delta \bar{x}_{i+1 / 2}}-\frac{\left(F_{i, 1, k}^{*}-F_{1-1, j, k}^{*}\right)}{\Delta \bar{x}_{1-1 / 2}}\right]
$$

$$
\begin{aligned}
& +\gamma \frac{\left(F_{i, j+1, k}^{n}-2 F_{1, j, k}^{n}+F_{1, j-1, k}^{n}\right)}{(\Delta \bar{Y})^{2}} \\
& +\xi \frac{\left(F_{i, j, k+1}^{n}-2 F_{1, j, k}^{n}+F_{i, j, k-1}^{n}\right)}{(\Delta \bar{Z})^{2}}=n_{i, j, k}^{n, k} \frac{\left(F_{1, j, k}^{*}-F_{1, j, k}^{n}\right)}{\Delta \tau / 2}
\end{aligned}
$$

where

$$
\begin{aligned}
& \Delta \bar{x}_{i+1 / 2}=\bar{x}_{i+1}-\bar{x}_{i} \\
& \Delta \bar{x}_{i-1 / 2}=\bar{x}_{1}-\bar{x}_{i-1} .
\end{aligned}
$$

Values of the spatial derivatives at the boundaries would use either the Dirichlet condition where the boundary value is specified or the Neumann condition where the spatial derivative is equal to zero. Within the crack, over the portion of the lower surface where the pressure is specifled as Input, and over the total upper surface where the normalized pressure is zero, we use the Dirichlet condition. On all other portions of the boundary we use the Neumann condition. 


\section{"X"X" Direction Implicit Differencing}

Equation ( $B-31$ ) is written in the following form for use in the computer program when considering the " $\overline{\mathrm{X}}$ " direction implicit with the " $\overline{\mathrm{Y}}$ " and " $\mathrm{Z}$ " directions explicit.

$$
-A_{i, j, k} F_{i+1, j, k}^{*}+B_{i, j, k} F_{i, j, k}^{*}-C_{i, j, k} F_{i-1, j, k}^{*}=D_{i, j, k} \quad \text { (B-34) }
$$

where

$$
\begin{aligned}
& A_{i, j, k}=\frac{2 \alpha}{\Delta x_{i+1 / 2}\left(\Delta x_{i+1 / 2}+\Delta x_{i-1 / 2}\right)} \\
& B_{i, j, k}=\frac{2 \alpha}{\left(\Delta x_{i+1 / 2}+\Delta x_{i-1 / 2}\right)}\left[\frac{1}{\Delta x_{i+1 / 2}}+\frac{1}{\Delta x_{i-1 / 2}}\right]+\frac{n_{i, j, k}^{n, *}}{\Delta \tau / 2} \\
& =\frac{2 \alpha}{\Delta x_{i+1 / 2} \Delta x_{i-1 / 2}}+\frac{n_{i, j, k}^{n, *}}{\Delta \tau / 2} \\
& c_{i, j, k}=\frac{2 \alpha}{\Delta x_{i-1 / 2}\left(\Delta x_{i+1 / 2}+\Delta x_{i-1 / 2}\right)} \\
& D_{i, j, k}=r \frac{\left(F_{i, j+1, k}^{n}-2 F_{i, j, k}^{n}+F_{i, j-1, k}^{n}\right)}{(\Delta \bar{Y})^{2}} \\
& +\xi \frac{\left(F_{i, j, k+1}^{n}-2 F_{i, j, k}^{n}+F_{i, j, k-1}^{n}\right)}{(\Delta \bar{z})^{2}}+\frac{\eta_{i, j, k}^{n, *} F_{i, j, k}^{n}}{\Delta \tau / 2} .
\end{aligned}
$$

In turn we have

$$
F_{i, j, k}^{*}=E_{i, j, k} F_{i+1, j, k}^{*}+\tilde{F}_{i, j, k}
$$


where

$$
\begin{aligned}
& E_{1, j, k}=\frac{A_{i, j, k}}{B_{1, j, k}-C_{1, j, k} E_{1-1, j, k}} \\
& \tilde{F}_{1, j, k}=\frac{D_{1, j, k}+C_{1, j, k} \tilde{F}_{i-1, j, k}}{B_{1, j, k}-C_{1, j, k} E_{1-1, j, k}} .
\end{aligned}
$$

At the left boundary, the subscript $1=1$, and from Eq. (B-39)

$$
F_{1, j, k}^{*}=E_{1, j, k} F_{2, j, k}^{*}+\tilde{F}_{1, j, k}
$$

For a Dirichlet boundary condition where the value of $F_{1, j, k}^{*}$ is specified

$$
\left.\begin{array}{l}
E_{1, j, k}=0 \\
\tilde{F}_{1, j, k}=\text { specified value }
\end{array}\right\} \begin{aligned}
& \text { Dirichlet } \\
& \text { condition } .
\end{aligned}
$$

For a Newmann boundary condition where the derivative is zero

$$
\left.\begin{array}{l}
E_{1, j, k}=1 \\
\tilde{F}_{1, j, k}=0
\end{array}\right\} \begin{aligned}
& \text { Neumann } \\
& \text { condition } .
\end{aligned}
$$

Using the boundary conditions above and the recursion relationship of Eqs. (B-40) and (B-41) we may calculate all the values of $E_{1, j, k}$ and $\tilde{F}_{1, j, k}$. At the right hand boundary, where the subscript, 1 , has 1 ts maximum value we use either the Dirichlet condition to specify the value of $F_{L, j, k}^{*}$ or the Neumann condition which gives from Eq. (B-39) that

$$
F_{L, j, k}^{*}=\frac{\tilde{F}_{L-1, j, k}}{1-E_{L-1, j, k}}
$$


where the subscript, $L$, indicates the maximum " $\bar{X}$ " direction node. We may then use the recursion relation, Eq. (B-39) to calculate all other values of $F_{i, j, k}^{*}$ starting with the maximum " $\bar{X} "$ direction node.

"Y"' Direction Implicit Differencing

Working with the "To" direction implicit portion of the calculation, we have from Eq. (B-25)

$$
\begin{aligned}
& \frac{2 a}{\left(\Delta \bar{x}_{1+1 / 2}+\Delta \bar{x}_{1-1 / 2}\right)}\left[\frac{\left.F_{i+1, j, k}^{*}-F_{1, j, k}^{*}\right)}{\Delta \bar{x}_{1+1 / 2}}-\frac{\left(F_{i, j, k}^{*}-F_{i-1, j, k}^{*}\right)}{\Delta \bar{x}_{i-1 / 2}}\right] \\
& +\gamma \frac{\left(F_{i, j+1, k}^{* *}-2 F_{i, j, k}^{* *}+F_{i, j-1, k}^{* *}\right)}{(\Delta \bar{y})^{2}} \cdot \\
& +\xi \frac{\left(F_{1, j, k+1}^{n}-2 F_{i, j, k}^{n}+F_{i, j, k-1}^{n}\right)}{(\Delta \bar{z})^{2}} \\
& =n_{i, j, k}^{n, * *} \frac{\left(F_{i, j, k}^{* *}-F_{i, j, k}^{n}\right)}{\Delta \tau / 2}
\end{aligned}
$$

or

$$
-A_{i, j, k} F_{1, j+1, k}^{* *}+B_{i, j, k} F_{1, j, k}^{* *}-C_{i, j, k} F_{i, j-1, k}^{* *}=D_{1, j, k}
$$

with

$$
A_{i, j, k}=Y
$$

$$
\begin{gathered}
B_{i, j, k}=2 \gamma+\frac{(\Delta \bar{Y})^{2}}{\Delta \tau / 2} \eta_{i, j, k}^{n, \star *} \\
c_{i, j, k}=\gamma
\end{gathered}
$$

$-37$. 
and

$$
\begin{aligned}
D_{1, j, k} & =\frac{2 \alpha}{\left(\Delta \bar{x}_{1+1 / 2}+\Delta \bar{x}_{1-1 / 2}\right)}\left(\frac{\left(F_{1+1, j, k}^{*}-F_{i, j, k}^{*}\right)}{\Delta \bar{x}_{1+1 / 2}}-\frac{\left(F_{1, j, k}^{*}-F_{i-1, j, k}^{*}\right)}{\Delta \bar{x}_{i-1 / 2}}\right) \\
& +\xi \frac{\left(F_{1, j, k+1}^{n}-2 F_{i, j, k}^{n}+F_{1, j, k-1}^{n}\right)}{(\Delta \bar{z})^{2}} \\
& \left.+\frac{n_{i, j, k}^{n, * k} F_{1, j, k}^{n}}{\Delta \tau / 2}\right](\Delta \bar{Y})^{2}
\end{aligned}
$$

Rewriting Eq. (B-46)

$$
E_{1, j, k}^{* *}=E_{i, j, k} F_{i, j+1, k}^{* k}+\tilde{F}_{i, j, k}
$$

with

$$
\begin{aligned}
& E_{i, j, k}=\frac{A_{1, j, k}}{B_{i, j, k}-C_{i, j, k} E_{i, j-1, k}} \\
& \tilde{E}_{1, j, k}=\frac{D_{i, j, k}+C_{1, j, k} \tilde{F}_{i, j-1, k}}{B_{i, j, k}-C_{i, j, k} E_{1, j-1, k}} .
\end{aligned}
$$

As before we use both Dirichlet and Neumann boundary conditions as appropriate for calculating first the vilues of $E_{i, j, k}$ and $\tilde{F}_{1, j, k}$, and then the values of $F_{i, j, k}^{* *}$ 
"Z" Direction Implicit Differencing

For the " $\overline{\mathrm{Z}}$ " direction implicit portion, the difference equations used are developed from Eq. $(B-26)$ as

$$
\begin{aligned}
& \frac{2 \alpha}{\left(\Delta \overline{\mathrm{x}}_{i+1 / 2}+\Delta \overline{\mathrm{x}}_{1-1 / 2}\right)}\left[\frac{\left(F_{i+1, j, k}^{*}-F_{i, j, k}^{*}\right)}{\Delta \overline{\mathrm{x}}_{i+1 / 2}}-\frac{\left(F_{i, j, k}^{*}-F_{k-1, j, k}^{*}\right)}{\Delta \overline{\mathrm{x}}_{i-1 / 2}}\right] \\
& +\gamma \frac{\left(F_{i, j+1, k}^{* *}-2 F_{i, j, k}^{* *}+F_{1, j-1, k}^{k *}\right)}{(\Delta \bar{y})^{2}} \\
& +\xi \frac{\left(F_{i, j, k+1}^{n+1}-2 F_{i, j, k}^{n+1}+F_{1, j, k-1}^{n+1}\right)}{(\Delta \bar{z})^{2}} \\
& =n_{i, j, k}^{* *, n+1} \frac{\left(F_{i, j, k}^{n+1}-F_{1, j, k}^{* *}\right)}{\Delta \tau / 2}
\end{aligned}
$$

or

$$
-A_{i, j, k} F_{i, j, k+1}^{n+1}+B_{i, j, k} F_{i, j, k}^{n+1}-C_{i, j, k} F_{i, j, k-1}^{n+1}=D_{i, j, k}
$$

with

$$
A_{i, j, k}=\xi
$$

$$
\begin{gathered}
B_{1, j, k}=2 \xi+\frac{(\Delta \bar{z})^{2}}{\Delta \tau / 2} n_{i, j, k}^{\star *, n+1} \\
c_{i, j, k}=\xi
\end{gathered}
$$

$-82-$ 


$$
\begin{aligned}
D_{1, j, k} & =\left[\frac{2 \alpha}{\left(\Delta \bar{x}_{1+1 / 2}+\Delta \bar{x}_{1-1 / 2}\right)}\left(\frac{\left(F_{i+1, j, k}^{*}-F_{i, j, k}^{*}\right)}{\Delta \bar{x}_{i+1 / 2}}-\frac{\left(F_{i, j, k}^{*}-F_{i-1, j, k}^{*}\right)}{\Delta \bar{x}_{i-1 / 2}}\right)\right. \\
& \left.+\gamma \frac{\left(F_{1, j+1, k}^{* *}-2 F_{i, j, k}^{* *}+F_{1, j-1, k}^{* *}\right)}{(\Delta \bar{Y})^{2}}+\frac{n_{i, j, k}^{* *, n+1} F_{i, j, k}^{* *}}{\Delta \tau / 2}\right]_{(\Delta \bar{z})^{2}}
\end{aligned}
$$

In turn,

$$
F_{i, j, k}^{n+1}=E_{i, j, k} F_{i, j, k+1}^{n+1}+\tilde{F}_{i, j, k}
$$

with

$$
\begin{aligned}
& E_{i, j, k}=\frac{A_{i, j, k}}{B_{i, j, k}-C_{i, j, k} E_{i, j, k-1}} \\
& \tilde{F}_{i, j, k}=\frac{D_{i, j, k}+C_{1, j, k} \tilde{F}_{i, j, k-1}}{B_{i, j, k}-C_{1, j, k} E_{1, j, k-1}}
\end{aligned}
$$

Maps outlining the calculations for all the spatial locations in each step are shown in Figs. B-3 through B-5 since there are a number of regions with different boundary condittons. The circled numbers outline the sequence of steps in the computer program.

\section{IMPLICIT DIFFERENCING OF THE CRACK-FLOW EQUATIONS}

We explored two ways of differencing the crack flow equations both of which are related here. Each method of differencing is satisfactory and result in nearly identical answers when compared in a sample problem. The method described first was used for all the calculations documented because there appears to be an advantage in stability. The alternate method has the possible advantage of being more accurate for the same spatial griu size. 


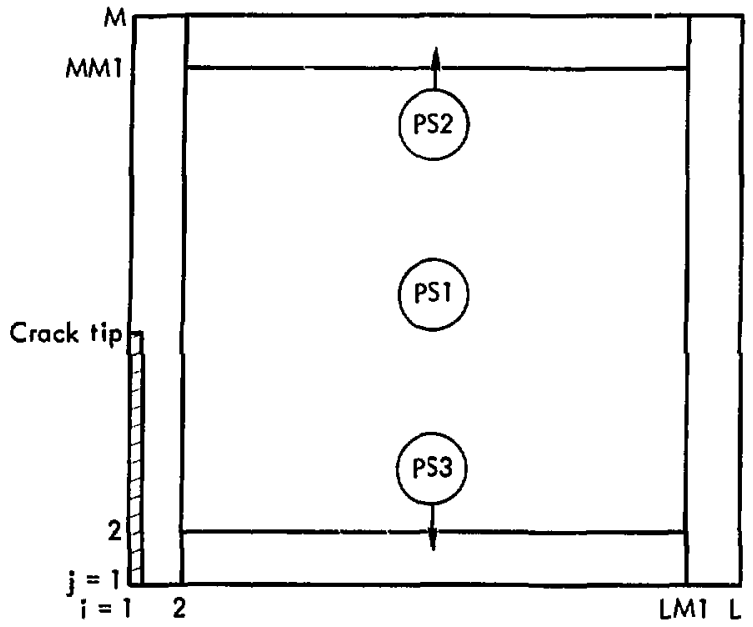

$$
2 \leq Z \leq N M 1
$$

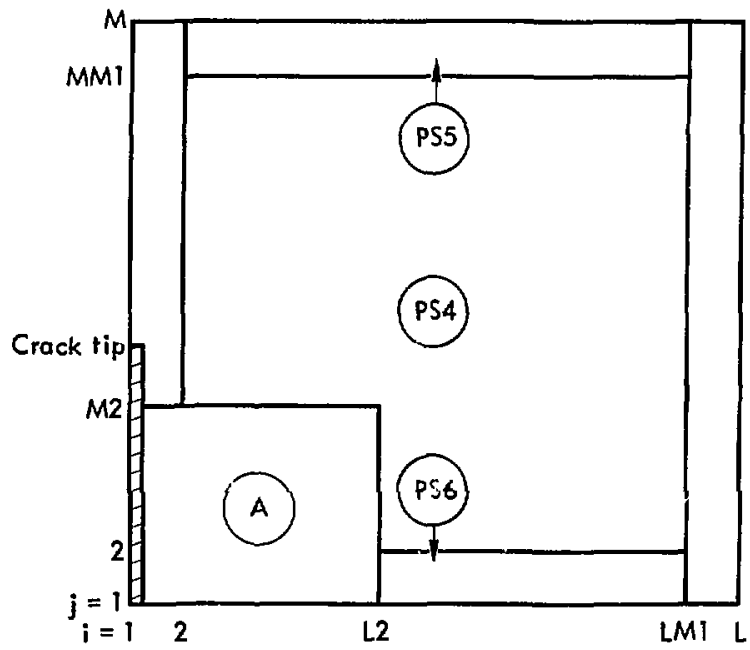

$Z=1$

Values in area $A$ specified as a function of time by input

Fig. B-3. Calculational steps for the $\overrightarrow{\mathrm{X}}$-direction implicit calculations for the porous solfd. 


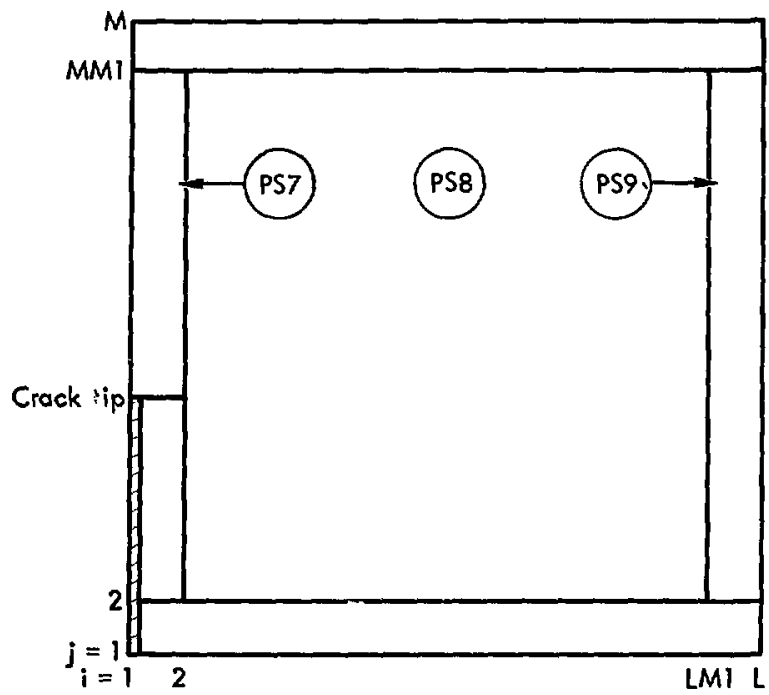

$$
2 \leq \mathrm{Z} \leq \mathrm{NM1}
$$

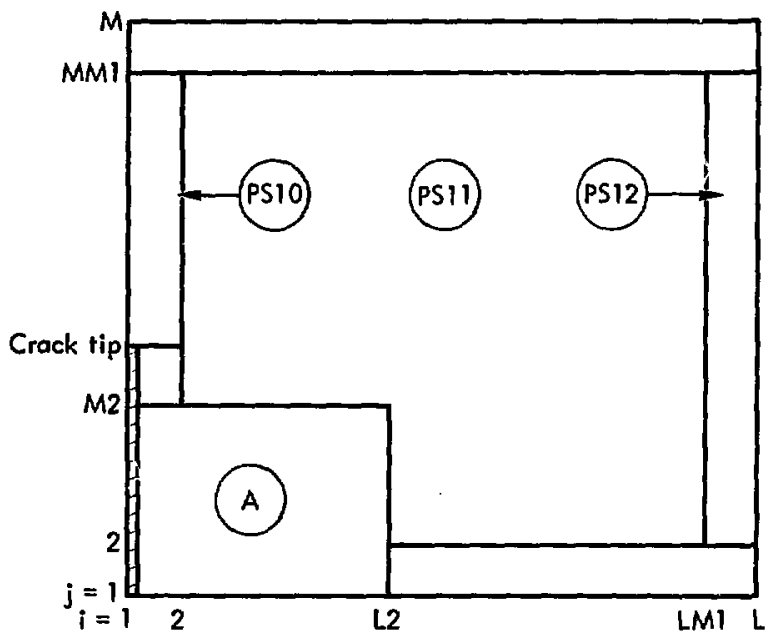

$z=1$

Valves in area $A$ are specified as a function of time by input

Fig. B-4. Calculational steps for the $\bar{Y}$-direction implicit calculations for the porous solit. 


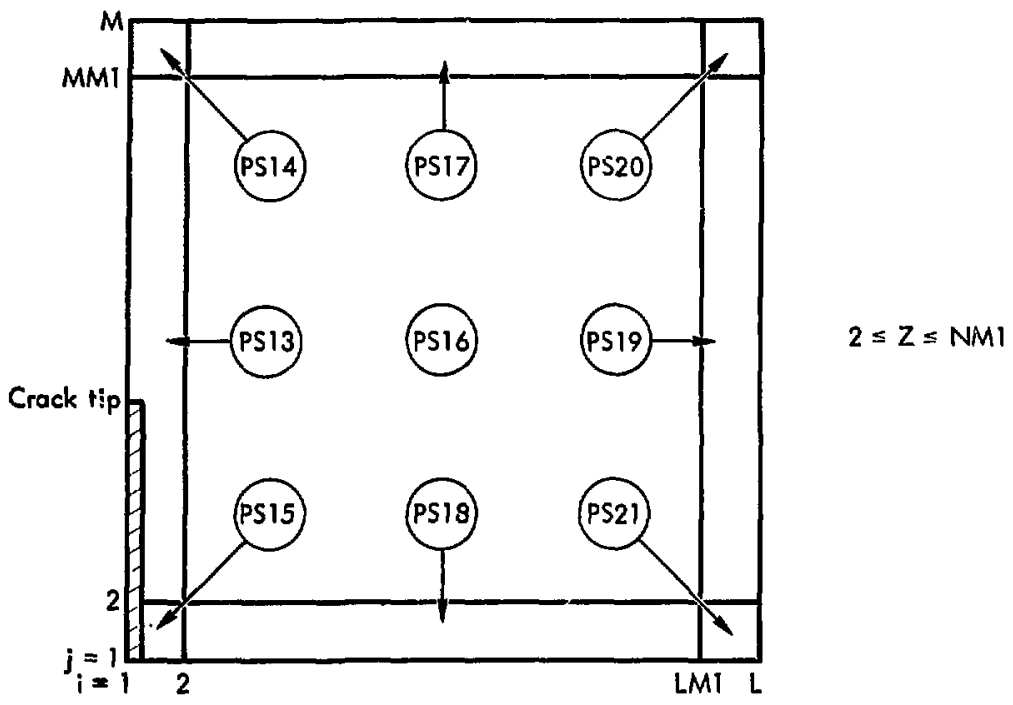

F1g. B-5. Calculational steps for the $\bar{Z}$-direction Implicit calculations for the porous solid.

The governing equation for flow within the crack is

$$
-\bar{k}_{c x} \frac{\partial F}{\partial \bar{X}} \pm \frac{\partial}{\partial \bar{Y}}\left(\bar{k}_{c y z}\left(\left|\frac{\partial F}{\partial \bar{Y}}\right|\right)^{\frac{1}{2}}\right) \pm \frac{\partial}{\partial \bar{Z}}\left(\bar{k}_{c y z}\left(\left|\frac{\partial F}{\partial \bar{z}}\right|\right)^{\frac{1}{2}}\right)+\frac{\partial \bar{P}}{\partial \tau}=0 . \quad(A-50)
$$

We replace the temporal derivative of pressure with a derivative of the pressure function using $E q .(B-22)$ which results in

$$
\begin{gathered}
-\bar{k}_{c x} \frac{\partial F}{\partial \bar{X}} \pm \frac{\partial}{\partial \bar{Y}}\left(\bar{k}_{c y z}\left(\left|\frac{\partial F}{\partial \bar{Y}}\right|\right)^{\frac{1}{2}}\right) \pm \frac{\partial}{\partial \bar{Z}}\left(\bar{k}_{c y z}\left(\frac{\partial F}{\partial \bar{Z}}\right)^{\frac{1}{2}}\right) \\
+\frac{1}{2} F^{-\frac{1}{2}} \frac{\partial F}{\partial \tau}=0 .
\end{gathered}
$$


In the first method of differencing, we differentiate the second and third terms from the left in closed form to obtain

$$
\begin{aligned}
& -\bar{k}_{c x} \frac{\partial F}{\partial \bar{X}} \pm\left(\frac{\partial F}{\partial \bar{Y}} \mid\right)^{\frac{1}{2}} \frac{\partial \bar{k}_{c y z}}{\partial \bar{Y}} \pm \frac{\bar{k}_{c y z}}{2\left(\left|\frac{\partial F}{\partial \bar{Y}}\right|\right)^{\frac{1}{2}} \frac{\partial}{\partial \bar{Y}}\left|\frac{\partial F}{\partial \bar{Y}}\right|} \\
& \pm\left(\left|\frac{\partial F}{\partial \bar{Z}}\right|\right)^{\frac{1}{2}} \frac{\partial \bar{k}_{c y z}}{\partial \bar{Z}} \pm \frac{\bar{k}_{c y z}}{\left.2\left(\mid \frac{\partial F}{\partial \bar{Z}}\right)\right)^{\frac{1}{z}} \frac{\partial}{\partial \bar{Z}}\left|\frac{\partial F}{\partial \bar{Z}}\right|+\frac{1}{2} F^{-\frac{1}{2}} \frac{\partial F}{\partial \tau}=0}
\end{aligned}
$$

The value of $F$ is bounded by $0 \leq F \leq N^{2} /(N-1)^{2}$ so that the coefficient of the right hand term is always finite. On the other hand, it is possible for singularities to occur numerically in the third or fifth term from the left if $\partial F / \partial \bar{Y}$ or $\partial F / \partial \bar{Z}$ approach zero. One means of avoiding such difficulties is to multiply through by these values. However this yields an equation which In the limit does not conform to the physics of the problem. For example, if $\partial F / \partial \bar{Y} \rightarrow 0$, only the second and third terms from the left in Eq. (B-65) should approach zero. Yet if we multiply Eq. $(B-65)$ by $(\partial F / \partial \bar{Y})^{\frac{1}{2}}$ we find that all terms approach zero as $\partial F / \partial \bar{Y} \rightarrow 0$ leaving us with a trivial result. A better way of eliminating the possible singularity is to set the second and third terms from the right equal to pero if $|\partial F / \partial \bar{Y}|$ is less than some small value. Similarly, we would set the fourth and fifth terms from the right equal to zero if $|\partial F / \partial \bar{z}|$ is less chan some small value.

The plus signs in the second and third terms from the ieft in Eq. (B-65) are used if $\partial F / \partial \bar{Y}<0$ and the minus signs are used if $\partial F / \partial \bar{Y}>0$. If we multiply the numerator and denominator of the second cerm by $(|\partial F / \partial \bar{Y}|)^{\frac{1}{2}}$ and remove the absolute value sigrs in the numerator, then the minus sign should be used regardless of the magnitude of $\partial F / \partial \bar{Y}$. In the third term we may 
eliminate the absolute value signs in the numerator if the minus sign is used. Similar arguments may be made for the fourth and fifth terms from the left. This gives, after rearranglng,

$$
\begin{aligned}
& \left.\bar{k}_{c x} \frac{\partial F}{\partial \bar{X}}+\left(\frac{\partial F}{\partial \bar{Y}} /\left(\mid \frac{\partial F}{\partial \bar{Y}}\right)\right)^{\frac{1}{2}}\right) \frac{\partial \bar{k}_{c y z}}{\partial \bar{Y}}+\left(\bar{k}_{c y z} / 2\left(\mid \frac{\partial F}{\partial \bar{Y}}\right)^{\frac{I_{F}}{2}}\right) \frac{\partial^{2} F}{\partial \bar{Y}^{2}} \\
& +\left(\frac{\partial F}{\partial \bar{z}} /\left(\left|\frac{\partial F}{\partial \bar{z}}\right|\right)^{\frac{L}{z}}\right) \frac{\partial \bar{k}_{c y z}}{\partial \bar{z}}+\left(\bar{k}_{c y z} / 2\left(\left|\frac{\partial F}{\partial \bar{z}}\right|\right)^{\frac{1}{2}}\right) \frac{\partial^{2} \bar{F}}{\partial \bar{z}^{2}} \\
& =\frac{1}{2} \mathrm{~F}^{-\frac{1}{2}} \frac{\partial F}{\partial \tau}
\end{aligned}
$$

In Eq. (B-66), the te:ms containing $\partial F / \partial \bar{Y}$ are set equal to zero in the computer program, CHASN, if $|\partial F / \partial \vec{Y}|$ is less than $10^{-25}$. Simflarly, terms containing $\partial F / \partial \bar{Z}$ are set equal to zero if $|\partial F / \partial \bar{Z}|<10^{-25}$.

The " $\overline{\mathrm{X}}$ " direction term taken separately with the temporal term forms a hyperbollc equation whereas efther the "Y" or " $\bar{Z}$ " direction second derivative terms taken individually with the temporal term form parabolic equations. Accordingly, we retain an explicit differenclng scheme in the " $\mathrm{X}$ " direction to prevent artificial numerical damping. In the " $\bar{Y}$ " and "Һ" directions we retain an implicit differencing scheme because of its inherently better stability. We use an operator splitting technique (Ref. 33 and B-2) where Eq. (B-66) is broken into two parts which are

$$
\bar{k}_{c x} \frac{\partial F}{\partial \bar{X}}=\frac{1}{2} F^{-\frac{1}{2}} \frac{\partial F}{\partial \tau}
$$


and

$$
\begin{gathered}
\left.\left(\frac{\partial F}{\partial \bar{Y}} /\left(\mid \frac{\partial F}{\partial \bar{Y}}\right)\right)^{\frac{1}{2}}\right) \frac{\partial \bar{k} c y z}{\partial \bar{Y}}+\left(\bar{k}_{c y z} / 2\left(\left|\frac{\partial F}{\partial \bar{Y}}\right|\right)^{\frac{1}{2}}\right) \frac{\partial^{2} F}{\partial \bar{Y}^{2}} \\
+\left(\frac{\partial F}{\partial \bar{Z}} /\left(\mid \frac{\partial \bar{F}}{\partial \bar{Z}}\right)^{\frac{1}{2}}\right) \frac{\partial \bar{k} c y z}{\partial \bar{Z}}+\left(\bar{k}_{c y z} / 2\left(\left|\frac{\partial \bar{F}}{\partial \bar{Z}}\right|\right)^{\frac{1}{2}}\right) \frac{\partial^{2} F}{\partial \bar{Z}^{2}} \\
=\frac{1}{2} F^{-\frac{1}{2}} \frac{\partial \bar{F}}{\partial \tau} .
\end{gathered}
$$

In using Eqs. $(B-67)$ and $(B-68)$ as an alternate to Eq. (B-66) we are determining first the effect of the " $\bar{X}$ " direction spatial component throughout a given time to find a hypothetical value of the pressuie function from $\mathrm{Eq}$. $(B-67)$. Then we use this hypothetical pressure function over the same time period to calculate the actual pressure function at the new tine using $\mathrm{Eq}$. (B-68).

Since we explicitly difference Eq. (B-67), the value of the time step must be less than the " $\bar{X}$ " direction spatial step slze divided by the equivalent velocity if stability is to exist. This time step would be

$$
\Delta \tau \leq \frac{\Delta \bar{x}}{2 \bar{k}_{c x} F^{\frac{1}{2}}}
$$

We repeat the explicit " $\bar{X}$ " direction calculation using Eq. (B-S7) a number of times unt 11 we have advanced from time $\tau^{n}$ totime $\tau^{*}$. The time $\tau^{*}$ is a hypothet ical time value which occurs after completion of the " $\bar{X}$ " direction calculations. Next we use an licersating direction implicit scheme 23,24 for the "Ȳ" and " $\mathrm{Z}$ " directions in two rime steps from time $\tau^{\mathrm{n}}$ to time $\tau^{\mathrm{n}+1}$. In the first step 
the "Y" direction spatial second derivative is differenced implicitly and in the second time step the " $\bar{Z}$ " direction spatiai second derivative is differenced implicitly. In the alternating direction inplicit calculations, all coefficients are evaluated using some average value of the pressure function, $F$, between the hypothetical time, $\tau^{*}$, and the new time $\tau^{n+1}$. The total time dirference in the explicit calculation, $\tau^{*}-\tau^{n}$, must be identical to the total time difference in the implicit calculations, $\tau^{n+1}-\tau^{n}$, if the solution we obtain from Eqs. (B-67 and B-68) is to be equivalent to a solution to Eq. (B-66).

Use of an alternating direction implicit scheme is unconditionaliy stable for any time step if Eq. (B-68) is linear. Because Eq. (B-68) is nonlinear, stability must still be considered in selecting a time step. We approached the time step selection on a trial basis. We found the results were independent of variations in time step by over a factor sf 100 as 1 ong as stability was maintained.

The best means of differencing the coefficiencs of Eqs. (B-67) and (B-68) depend on the problem and it is not clear which values of time should be used in evaluating the pressure function, $F$. We use a weighting factor, $\theta$, for all implicit calculations which may be varied and which is a fraction used to multiply the new time value of $F$. The following coefficients are defined for use in the "Y"' direction implicit portion of the calculation:

$$
\begin{aligned}
\alpha_{1, j, k} & =\bar{k}_{c x_{j, k}} \\
\beta_{1, j, k}^{*, * *} & =\theta\left(F_{1, j+1, k}^{* *}-F_{1, j-1, k}^{* *}\right) /\left(2 \Delta \bar{Y}\left(\left|F_{1, j+1, k}^{* *}-F_{1, j-1, k}^{* *}\right|\right)\right)^{\frac{1}{2}} \\
& +(1-\theta)\left(F_{1, j+1, k}^{*}-F_{1, j-1, k}^{*}\right) /\left(2 \Delta \bar{Y}\left(\left|F_{I, j+1, k}^{*}-F_{1, j-1, k}^{*}\right|\right)\right)^{\frac{1}{2}}
\end{aligned}
$$




$$
\begin{aligned}
& \gamma_{1, j, k}^{*, * i k}=\bar{k}_{c y z, j, k}\left[\theta /\left(2\left(\mid F_{1, j+1, k}^{* *}-F_{1, j-1, k}^{* *}\right)\right) / \Delta \bar{Y}\right)^{\frac{1}{2}} \\
& +(1-\theta) /\left(2\left(\left|F_{1, j+1, k}^{*}-F_{1, j-1, k}^{* *}\right|\right) / \Delta \bar{Y},{ }^{\frac{1}{2}}\right] \\
& \delta_{1, j, k}^{*, * *}=\theta\left(F_{1, j, k+1}^{* k}-F_{1, j, k-1}^{* *}\right) /\left(2 \Delta \bar{Z}\left(\left|F_{1, j, k+1}^{* *}-F_{1, j, k-1}^{* *}\right|\right)\right)^{\frac{1}{2}} \\
& +(1-\theta)\left(F_{1, j, k+1}^{*}-F_{1, j, k-1}^{*}\right)\left(2 \Delta \bar{z}\left(\left|F_{1, j, k+1}^{*}-{ }_{1, j, k-1}^{*}\right|\right)\right)^{1 / 2} \\
& \underset{\xi_{1, j, k}^{*, * *}}{*}=k_{c y z j, k}\left[\theta /\left(2\left(\left|F_{1, j, k+1}^{* *}-F_{1, j, k-1}^{* *}\right|\right) / \Delta \bar{z}\right)^{\frac{1}{2}}\right. \\
& \left.+(1-\theta)\left(2\left(\mid F_{1, j, k+1}^{*}-F_{1, j, k-1}^{*}\right) / \Delta \bar{z}\right)^{\frac{1}{2}}\right] \\
& n_{1, j, k}^{*, * *}=0.5\left[\theta /\left(F_{1, j, k}^{* *}\right)^{\frac{1}{2}}+(1-\theta) /\left(F_{1, j, k}^{*}\right)^{\frac{3 / 2}{2}}\right]
\end{aligned}
$$

with

$$
\begin{aligned}
& \beta_{1, j, k}^{*, * *}=\gamma_{1, j, k}^{*, * *}=0 \text { if } F_{1, j+1, k}^{*} \approx F_{1, j-1, k}^{*} \\
& \delta_{1, j, k}^{*, * *}=\xi_{1, j, k}^{*, * *}=0 \text { if } F_{1, j, k-1}^{*} \approx F_{1, j, k-1}^{*}
\end{aligned}
$$

Similar values of the coefficients are defined between the times, $\tau^{* *}$ and $\tau^{n+1}$ for use during the " $\bar{Z}$ "-direction-implcit portion of the calculations. The values of $\overline{\mathrm{k}}_{\mathrm{cx}}$ are considered to be time independent. 
In the first step of the operator splitting scheme the difference equation for the " $\overline{\mathrm{X}}$ " direction is utilized.

$$
\alpha_{1, j, k} \frac{\left(F_{2, j, k}^{n}-F_{1, j, k}^{n}\right)}{\Delta \bar{x}}=n_{1, j, k}^{n, *} \frac{\left(F_{1, j, k}^{*}-F_{1, j, k}^{n}\right)}{\Delta t}
$$

The difference equations for the second step uses an alternating direction implicit scheme fot the " $\overline{\mathrm{Y}}$ " and " $\overline{\mathrm{Z}}$ " directions.

$$
\begin{aligned}
& \beta_{1, j, k}^{*, * *} \frac{\left(\bar{k}_{c y z}, 1+1, k-\bar{k}_{c y z}, j-1, k\right)}{2 \Delta \bar{Y}}+r_{1, j, k}^{*, * *} \frac{\left(F_{1, j+1, k}^{* *}-2 F_{1, j, k}^{* *}+F_{1, j-1, k}^{* *}\right)}{(\Delta Y)^{2}} \\
& +\delta_{1, j, k}^{*, * *} \frac{\left(\bar{k}_{c y z_{j, k+1}}-\bar{k}_{c y z}, k\right)}{2 \Delta \bar{z}}+\xi_{1, j, k}^{*, * k} \frac{\left(F_{1, j, k+1}^{*}-2 F_{1, j, k}^{*}+F_{1, j, k-1}^{*}\right)}{(\Delta \bar{z})^{2}} \\
& =\eta_{1, j, k}^{*, * *} \frac{\left(F_{1, j, k}^{* *}-F_{1, j, k}^{*}\right)}{\Delta \tau / 2}
\end{aligned}
$$

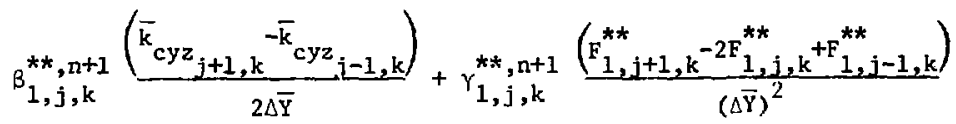

$$
\begin{aligned}
& +\delta_{1, j, k}^{* *, n+1} \frac{\left(\bar{k}_{c y z} j_{j, k+1}^{-\bar{k}} c y z_{j, k-1}\right.}{2 \Delta \bar{z}}+\xi_{1, j, k}^{* *, n+1} \frac{\left(F_{1, j, k+1}^{n+1}-2 F_{1, j, k}^{n+1}+F_{1, j, k-1}^{n+1}\right)}{(\Delta \bar{z})^{2}} \\
& \left.=\eta_{1, j, k}^{* *}, \frac{\left(F_{1, j, k}^{n+1}-F_{1, j, k}^{* *}\right.}{\Delta \tau / 2}\right)
\end{aligned}
$$

Eq. (B-78) is solved for each new value of pressure function directly withcut iteration and the process is repeated until the total time difference equal to $\tau^{n+1}-\tau^{n}$ is reached. We rewrite Eq. (B-79) to obtain a standard algorithm form for solving a tri-diagonal matrix as follows:

$$
-A_{1, j, k} F_{i, j+1, k}^{* *}+B_{1, j, k} F_{1, j, k}^{* j}-C_{1, j, k} F_{1, j-1, k}^{* *}=D_{1, j, k}
$$


where

$$
\begin{aligned}
& A_{1, j, k}=r_{1, j, k}^{k, t k} \\
& B_{1, j, k}=2 r_{1, j, k}^{*}+\frac{(i \bar{i})^{2}}{i, T / 2} r_{1, j, k}^{k, k} \\
& c_{1, j, k}=i_{1, j, k}^{n}
\end{aligned}
$$

and

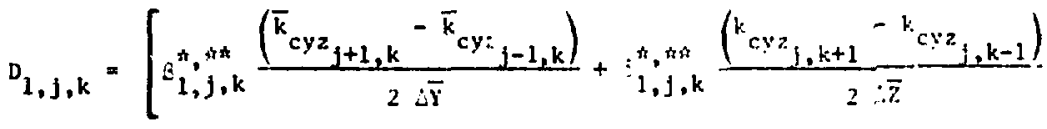

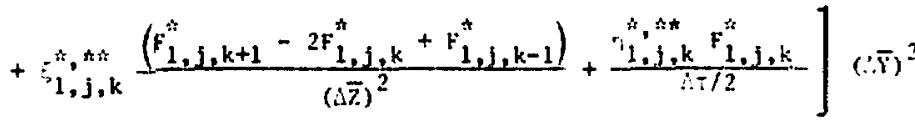

in turn, for the "Y" direction we site

$$
F_{l, j, k}^{* k}=E_{1, j, k} F_{1, j+1, k}^{* k}+\vec{F}_{1, j, k}
$$

with

$$
\begin{aligned}
& E_{1, j, k}=\frac{A_{1, j, k}}{B_{1, j, k}-C_{1, j, k} F_{1, j-1, k}} \\
& \vec{F}_{1, j, k}=\frac{D_{1, j, k}+C_{1, j, k} F_{1, j-1, k}}{B_{1, j, k}-C_{1, j, k} E_{1, j-1, k}}
\end{aligned}
$$

At the boundaries we use conditions identical with those mentioned previously for flow in the porous solid. That is

$$
\begin{aligned}
& \text { Dirichlet condicion: } E_{1, j, k}=0 \text { and } \bar{F}_{1, j, k}=F_{1, j, k} \\
& \text { (boundary value } \\
& \text { speciffed) }
\end{aligned}
$$




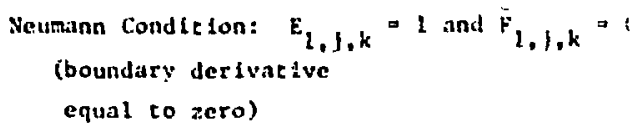

for the "T" direction we write Eq. (11-80) as

$$
-\lambda_{1,1, k} F_{1, j, k+1}^{n+1}+n_{1, j, k} F_{1, j, k}^{n+1}-c_{1,1, k} F_{1,1, k-1}^{n+1}+1,1, k
$$

where

$$
\begin{aligned}
& \lambda_{1, j, k}=\sum_{1, j, k}^{n+1}
\end{aligned}
$$

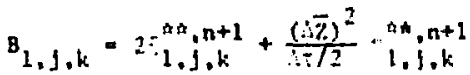

$$
\begin{aligned}
& c_{1, j, k}=\sum_{i, j, k}^{n+1}
\end{aligned}
$$

and

$$
\begin{aligned}
& 0_{1,1, k}=\left[s_{1, j, k}^{k \hbar, n+1} \frac{\left(\bar{k}_{c y z}+1, k-\bar{k}_{c y z} j-1, k\right)}{2 . \bar{Y}}\right. \\
& +v_{l, j, k} \frac{\left(F_{1, j+1, k}^{* \hbar}-2 F_{1, j, k}^{k s} \pm F_{1, j-1, k}^{* k}\right)}{(\Delta \bar{Y})^{2}}
\end{aligned}
$$

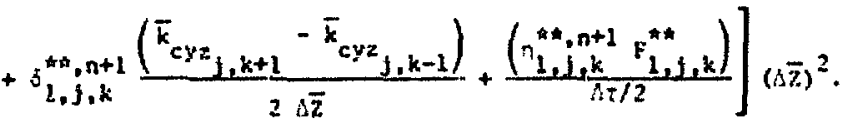

In turn, for the "7" direction

$$
F_{1, j, k}^{n+1}=E_{1,1, k} F_{1, j, k+1}^{n+1}+\vec{F}_{1,1, k}
$$

$-94-$ 
where

$$
\begin{aligned}
& E_{1, j, k}=\frac{A_{1, j, k}}{B_{1, j, k}-C_{1, j, k} F_{1, j, k-1}} \\
& F_{1, j, k}=\frac{D_{1, j, k}+C_{1, j, k} F_{1, j, k-1}}{B_{1, j, k}-C_{1, j, k} E_{1, j, k-1}} .
\end{aligned}
$$

In all Implicit calculations we iterate to updace those coeffictents which vary with time. The equations for the flow inside the crack are coupled with the equations for the porous solid in the $\bar{Y}$ and $\bar{\gamma}$ dfrections so that a single matrlx is formed that covers all nodes in the problem. That is we calculate changes in tive $\bar{x}$ direction for all nodes efther within che crack or in the solld icerating as necessary for the implicit calculations. Then we calculate changes and lterace in the $\bar{Y}$ direction for all nodes. The $\overline{7}$ direction calculations and iterations for all nodes are performed rext. A final fteration loop over the cotal implicit calculations in the $\bar{x}, \bar{Y}$, plus $\vec{z}$ directions is included to assure convergence.

\section{AL.TEHNATE METHOD FOK DIFFERENCING THE CRACK-FLOW EQUATIONS}

he again start with the governing equation for flow inside the crack, wich is

$$
-\bar{k}_{c x} \frac{\partial F}{\partial \bar{x}} \pm \frac{\partial}{\partial \bar{r}}\left(\bar{k}_{c y z}\left(\mid \frac{\partial F}{\partial \bar{r}}\right)^{\frac{b}{2}}\right)=\frac{\partial}{\partial \bar{z}}\left(\bar{k}_{c y z}\left(\left|\frac{\partial F}{\partial \bar{z}}\right|\right)^{\frac{j}{z}}\right)+\frac{1}{2} F^{-\frac{j}{\partial}} \frac{\partial F}{\partial \tau}=0
$$

Ratier than differentiating in closed form. Winslow ${ }^{\mathrm{B}-3}$ has suggested incorporacing inco che coefficient $\bar{k}_{c y z}$ the necessary mulciple of $\partial F / \partial \bar{Y}$ or $\partial F / \partial \bar{z}$ to eliminate the square roots. That is, since the coefficients $\vec{k}_{\text {cyz }}$ are variable we could add such a mulciple to the coeffictents without appreciable complication and obtain a form of Eq. (B-64) that may be directly applied to the tri-diagonal matrix solution algorthm. We obtain the following form of the equacion: 
$\bar{k}_{c x} \frac{\partial F}{\partial \bar{X}}+\frac{\partial}{\partial \bar{Y}}\left(\frac{\bar{k}_{c y z}}{\left(\frac{\partial F}{\partial \bar{Y}}\right)^{\frac{1}{2}}} \frac{\partial F}{\partial \bar{Y}}\right)+\frac{\partial}{\partial Z}\left(\frac{\bar{k}}{\left(\frac{\partial \bar{F}}{\partial \bar{Z}}\right)^{\frac{1}{2}}} \frac{\partial F}{\partial \bar{Z}}\right)=\frac{1}{2} E^{-\frac{1}{Z}} \frac{\partial F}{\partial \tau}$.

In differencing Eq. (B-97) we define the following.

$$
\begin{aligned}
& \alpha_{1, j, k}=\bar{k}_{c x_{j, k}}
\end{aligned}
$$

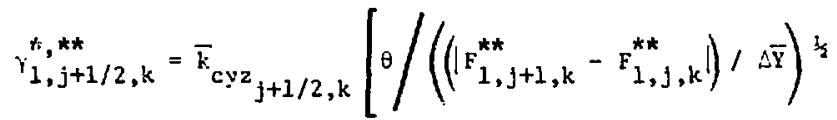

$$
\begin{aligned}
& \left.+(1-\theta) /\left(\left(\mid F_{1, j+1, k}^{*}-F_{1, j, k}^{*}\right) / \Delta \vec{Y}\right)^{\frac{1}{2}}\right] \\
& \xi_{1, j, k+1 / 2}^{*, k+}=\bar{k}_{c y z}{ }_{j+1 / 2, k}\left[\theta /\left(\left|F_{1, j, k+2}^{* \star}-F_{1, j, k}^{* *}\right|\right) / \Delta \bar{z}\right)^{\frac{k}{2}} \\
& \left.+(1-\theta) \int\left(\left(\mid F_{-, j, k+1}^{*}-E_{1, j, k}^{*}\right) / \Delta \bar{z}\right)^{\frac{1}{2}}\right] \\
& n_{1, j, k}^{*, * *}=0.5\left[\theta /\left(F_{1, j \cdot k}^{* *}\right)^{\frac{1}{2}}+(1-\theta) /\left(F_{1, j, k}^{*}\right)^{\frac{1}{2}}\right]
\end{aligned}
$$

where

$$
\bar{k}_{c y z_{j+1 / 2, k}}=\left(\bar{k}_{c y z_{j, k}}+\bar{k}_{c y z}{ }_{j+1, k}\right) / 2 .
$$

We retain the operator splitting technique using the " $\overline{\mathrm{X}}$ " direction as explicit and an aiternating direction implicit scheme in the " $\overline{\mathrm{Y}}$ " and " $\overline{\mathrm{Z}}$ " directions. 
In the " $\mathrm{X}$ " direction the difference equation is

$$
\alpha_{1, j, k}\left(\frac{F_{2, j, k}^{n}-F_{1, j, k}^{n}}{\Delta \bar{x}}\right)=n_{1, j, k}^{n, *}\left(\frac{F_{1, j, k}^{*}-F_{1, j, k}^{n}}{\Delta \tau}\right) .
$$

In the " $\bar{Y} "$ and " $\bar{Z}$ " directions the difference equations are

$$
\begin{aligned}
& \frac{1}{(\Delta \bar{Y})^{2}}\left[r_{1, j+1 / 2, k}^{*, * *}\left(F_{1, j+1, k}^{* *}-r_{1, j, k}^{* *}\right)-r_{1, j-1 / 2, k}^{*}\left(F_{1, j, k}^{* *}-F_{1, j-1, k}^{* *}\right)\right] \\
& +\frac{1}{\left\langle(\bar{Z})^{2}\right.}\left[\xi_{1, j, k+1 / 2}^{*, *}\left(F_{1, j, k+1}^{*}-F_{1, j, k}^{*}\right)-\xi_{1, j, k-1 / 2}^{*, \star *}\left(F_{1, j, k}^{*}-F_{1, j, k-1}^{*}\right)\right] \\
& =\eta_{1, j, k}^{\star, \star *}\left(\frac{F_{1, j, k}^{* *}-F_{1, j, k}^{*}}{\Delta \tau / 2}\right)
\end{aligned}
$$

and

$\frac{1}{(\Delta \bar{Y})^{2}}\left[r_{1, j+1 / 2, k}^{* *, n+1}\left(F_{1, j+1, k}^{* *}-F_{1, j, k}^{* *}\right)-r_{1, j-1 / 2, k}^{* *, n+1}\left(F_{1, j, k}^{* *}-F_{1, j-1, k}^{* *}\right)\right]$

$+\frac{1}{(i \bar{z})^{2}}\left[\xi_{1, j, k+1 / 2}^{\star \star}\left(F_{1, j, k+1}^{n+1}-F_{1, j, k}^{n+1}\right)-\xi_{1, j, k-1 / 2}^{* \star, n+1}\left(F_{1, j, k}^{n+i}-F_{1, j, k-1}^{n+1}\right)\right]$

$$
=\eta_{1, j, k}^{* \star, n+1} \frac{\left(F_{1, j, k}^{n+1}-F_{1, j, k}^{\star *}\right)}{\Delta \tau / 2} \text {. }
$$

This alternate formulation of the difference equations contains less terms and conservation of the pressure function flux across an elemental control volume is more apparent than in the method we used to obtain results. However, the alternate formulation was discarded because we found the stability limiss to be more severe. Both formulations gave the same results on sample problems. 
If the alternate method were to be utilized we would write Eq. (B-104) for the "Ti" direction as

$-A_{i, j, k} F_{1, j+1, k}^{* k}+B_{1, j, k} F_{1, j, k}^{* k}-c_{1, j, k} F_{1, j-1, k}^{* *}=D_{1, j, k}$

where

$$
\begin{aligned}
& A_{1, j, k}=\gamma_{1, j+1 / 2, k}^{\star, \hbar \star} \\
& B_{1, j, k}=\left(\gamma_{1, j+1 / 2, k}^{*, \star k}+\gamma_{1, j-1 / 2, k}^{\star, \star k}\right)+\eta_{1, j, k}^{\star, \star \star} \frac{(\Delta \bar{\gamma})^{2}}{\Delta \tau / 2} \\
& c_{1, j, k}=\gamma_{1, j,-1 / 2, k}^{\star k} \\
& D_{1, j, k}=\left[\frac{1}{(\Delta \bar{z})^{2}}\left|\xi_{1, j, k+1 / 2}^{*, k *}\left(F_{1, j, k+1}^{*}-F_{1, j, k}^{*}\right)-\xi_{1, j, k-1 / 2}^{*, * k}\left(F_{1, j, k}^{*}-F_{1, j, k-1}\right)\right|\right. \\
& \left.+\frac{\pi_{1, j, k}^{*, k}}{\Delta \tau / 2} \mathrm{~F}_{1, j, k}^{*}\right](\Delta \overline{\mathrm{y}})^{2}
\end{aligned}
$$

This gives

$$
F_{1, j, k}^{* k}=E_{1, j, k} F_{1, j+1, k}^{* a}+F_{1, j, k}
$$

where $E_{1, j, k}$ and $F_{1, j, k}$ are defined by Eqs. (B-87) and (B-88). We write Eq. (B-105) for the "z" direction as

$-A_{1, j, k} F_{1, j, k+1}^{n+1}+B_{1, j, k} F_{1, j, k}^{n+1}-C_{1, j, k} F_{1, j, k-1}^{n+1}=D_{1, j, k}$ 
where

$$
\begin{aligned}
& A_{1, k, j}=\xi_{1, j, k+1 / 2}^{* \star}
\end{aligned}
$$

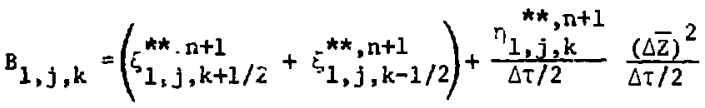

$$
\begin{aligned}
& c_{1, j, k}=\xi_{1, j, k-1 / 2}^{* k, n+1} \\
& D_{1, j, k}=\left[\frac{1}{(\Delta \bar{Y})^{2}}\left\{\begin{array}{l}
\gamma_{1, j+1 / 2, k}^{* *}\left(F_{1, j+1, k}^{* *}-F_{1, j, k}^{* *}\right. \\
--\gamma_{1, j-1 / 2, k}^{* *, n+1}
\end{array}\left(F_{1, j, k}^{* *}-F_{1, j-1, k}^{* *}\right)\right\}\right. \\
& \left.+\frac{\eta_{1, j, k}^{* *, n+1}}{\Delta \tau / 2} F_{1, j, k}^{* *}\right] \quad(\Delta \bar{z})^{2}
\end{aligned}
$$

which in turn we write as

$$
F_{1, j, k}^{n+1}=E_{1, j, k} F_{1, j, k+1}^{n+1}+F_{1, j, k}
$$

We use the definition of $E_{1, j, k}$ and $F_{1, j, k}$ in Eqs. (B-95) and (B-96) for use " $z$ " direction. Boundary conditions are identical to those described earlier.

EVALUATION OF AN EFFECTIVE ZRACK THICKNESS AT THE TIP OF THE CRACK at the crack tip there is a control volume which is represented half as a ciack and half as a porous solid as shown in Fig. B-6. The crack thickness diminishes to zero at the central node location so that flow in the lower half of the control volume is governed by the crack-flow equations. In the upper half the porous soldd flow equations apply. Our calculations consider that the control volume has a single gas pressure and a single effective crack thickness. 


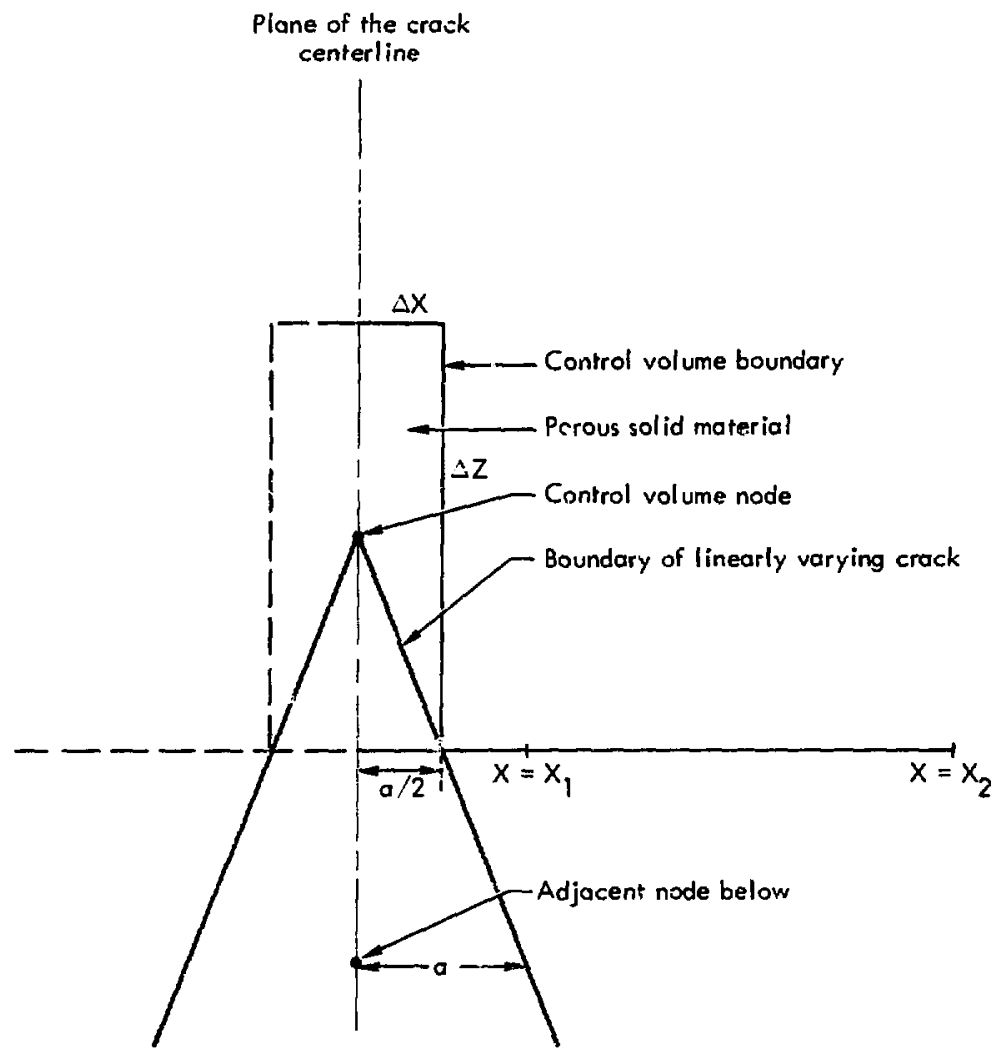

Fig. B-6. Crack-tip control volume at a region on top of the crack where no Y-direction variation, exists. 
If the crack boundary varles in a linear fashion over the localized region, then the crack thickness at the lower surtace of the control volume would be one half the value at the adjacent node below. The average thickness of the crack in the lower half of control voiuse would be one fourth that of the adjazent node below.

Since the reststance to flow in the porous solid is generally much greater than that the resistance to flow inside the crack, the pressure at the node of interest would be approximately equal to that determined by che gas flow in the crack portion of the control volume. It could be argued that the average crack thickness represents an effective value to be used for calculating the average pressure over the control volume.

Normally the shape of the crack wall is convex outward so that the thickness remains large over most of its length and diminishes rapidly near the tip. This characteristic suggests that the effective crack thickness would be more than $1 / 4$ that of the adjacent node below. On tlie other hand, any pressures calculated using the crack-flow equations apply only to the lower portion of the control volume so that the average pressure over the entire control volume would be less. We have varied the effective chickness between $1 / 4$ and $1 / 2$ that $r f$ the adjacent ncde below and find less than $5 \%$ difference in the results of sample probiems. This effective thickress is ifft as an input variable with the recommendation that is value equal to about $1 / 4$ that of the adjacent node below be utilized. 


\section{References for Appendix B}

B-1 J., Douglas, "Alternating Direction Methods for Three Space Variables", Numerische Mathematik, Vol. 4, (1962), pp 41-63.

B-2 R. D., Richtmyer, and K. W., Morton, Difference Methods for InitialValue Problems (Incerscience Publishers, New York, 2nd Edition, 1967), PP 216-217.

B-3 A., Winslow, Lawrence Livermore Laboratory, Private Communication, (1974-1975). 


\section{Appendix C - The Computer Code CHASM}

Included in this appendix is a listing of the computer code, CHASM, which was used to generate all results of this research on a CDC 7600 computer, a sample input for one of the problems, and a portion of the output.

The computer code consists of a main program and three subroutines. The main program is used to calculate constants, initjalize variables, call the subroutines during each time iteration, and priatout the results. The first subroutine, DEFL, determines the deflection of the crack walls due to gas pressure inside the crack. The second subroutine, FRICT, salculaces frictional coefficients for use in the last subroutine, FLOW. All calculations for gas flow in the crack and in the porous solid are performed within subroutine FLOW. Comment cards are included to describe each set of calculations. Also included is a listing of the nomenclature. The definition of the pressure function, $F$, in this report is revised from that used in the computer program. This revision results in simplification of some equations in the report. The definttion in the computer program differs by a constant factor $(1 / N-1)^{2}$ and is consistent with all calculations performed.

The sample input shows the format for those varlables called for on iines 198 to 200 and line 423 of the computer code. Although results are presented in metric units in the body of this report, English units were used for the computer input and output.

The output shown includes only th? first portion and a representative portion toward the end of the problem. The first portion lists the input variables and some calculated constants. The representative portion gives the output at one specific time in the problem. Simllar portions for all other printout times are found in a complete output. 
I.ISTING OF CONPUTER CODE, CHASM

PRUGLAM CHASM(TAPE59, INPUT, TAPEL= INPUT, ANSWER, TAPE 3 ANSWER )

G: S-INITIATED CRACK PROPAGATION IN A POROUS SOL ID--A COMPUTER CODE IN THREE DIMENSIONS WHICH USES AN IDEAL GAS AS A FLUID. THE PROGRAM CALCULATE? THE CRACK WALL DEFLECTION, FRICTIONAL COEFFICIENTS. AND GAS FLOW BOTH IN THE CRACK AND IN THE POROUS SOL ID. THE FORTRAN PROGRAMMING USES MIXED MODE ARITHMETIC. INITIALIZATION OF ALL VARIABLES TO ZERO BY THE COMPILER IS REQUIRED.

COMMON /CRACK) AF $(10,15,20), A F F(10,15,20), B B(10,15,20), B E T A 11,15,2$ 10), CDEF, CFR IC 1, CFRIC2, CKX 1 15, 20), CKYZ (15,20), CSUBG $(3,3), D(15,20), D$ ZD(10,15,20),DELTA $1,15,20), D T, D T O T(15,20), D T 2, D X(10), D Y, D Y 2, D Z, D Z 2$ 3.EE $(10,15,20)$,EFFTIP,ETA $10,15,20), F(10,15,20), F F(10,15,20), F M A:, F$ 4STAR (10,:5,20),FSSTAR( $10,15,20)$, GAMMA $(1,15,20), 10$, JSTOP (20),L.LMI,

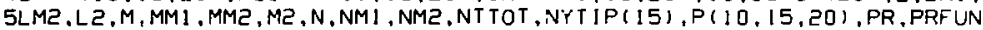
$6, P S(60)$, REYNC $(15,20)$, SIZE, SPACE $(15,20)$, THETA, THETA $1, X(10), X K X, X L A M$ $7 B(20,30), Y K Y, Z E T A(1,15,20), Z K, Z$

CALL DEVICE (GHCREATE, GHANSWER, 110000 )

NOMENCLATURE

AAF--PREVIOUS VALUE OF THE PRESSURE FUNCTION AF $(1, \mathrm{~J}, \mathrm{~K})$ USED IN $\square \mathrm{Z}$ DIRECTION FLOW CALCULATION ITERATION

AF $(1, J, K)--V A L U E$ OF THE PRESSURE FUNCTION $F(I, J, K)$ AT ADVANCED TIME AFTER COMPLETION OF QZL DIRECTION FLOW CALCULATIONS

AFF $(1, J, K)-$-VALUE OF THE PRESSURE FUNCT!ON F $(1, J, K)$ AFTER aX口, $\square Y \square$, AND IZI DIRECTION FLOW CALCULATION ITERATIONS

AJ, AK--VARIABLES USED IN CALCULATING THE INIIIAL CRACK THICKNESS

ARS--ARGUMENT IN LOG BASE 10 FUNCTION FOR CALCULATING TURBULENT FRICTION FACTOR, SUBROUT INE FRICT

BB(I.J.K)--VARIABLE USED FOR INVERSION OF THE TRI-DIAGONAL MATRIX, SUBROUT INE FLOW

BETA $(1, U, K)-$-VARIABLE COEFF ICIENT IN THE CRACK FLOW CALCULATIONS BLOTK--VALUE OF KAPPA IN BLOTTNER'S GRID STRETCHING METHOD

BLOTN-VARIABLE IN THE EXPONENT GF BLOTTNER'S GRID STRETCHING METHOD (EQUATION 13)

B1 .BZ--VARIAGLES USED IN CALCULATING BETAII.J.KI WITHIN SUBROUT INE FLOW

COEF--CONSTANT USED IN SUBROUTINE DEFL (EQUATION B-Z)

CFRICI--CONSTANT USED TO CALCULATE XLLAM IN SUBROUTINE FRICT (EQUATION B- 13)

CFRIC2--CONSTANT USED TO CALCULATE. TURBULENT REYNC (J,K) IN SUBROUT INE FRICT (EQUATION B-19)

CKX(J.K)-DNORALIZFD aXI DIRECTION PERMEABILITY THROUGH THE CRACK WALL

CKYZ (J.K) - NORMAL IZED EFFECTIVE PERMEABILITY IN THE aYa aZם DIRECTIONS WITHIN THE CRACK

COMPARE--DIFFERENCE BETWEEN OLD AND NEW VALUES OF FSTAR $(1, J, K)$, FSSTAR $(I, J, K)$, AF $(I, J, K), \operatorname{OR} \operatorname{AFF}(i, J, K)$ USED TO CHECK CONVERGENCE IN SUBROUT INE FLOW

CONCKX--CONSTANT USED IN CALCULATING CKX $(J, K)$

CSUBG $(J, K)$--GERRARO AND MORGAN DEFLECTION COEFFICIENT ACCOUNTING FOR THE DISTANCE AWAY FROM THE POINT OF PRESSURE APPLICATION DURING THE CALCULATION OF THE DEFLECTION OF THE CRACK WALL

D(J.K)--DEFLECTION OF THE CRACK WALL IN EXI DIRECTION (FEET)

DBLOTN-DIFFERENTIAL SPACING IN BLOTINER'S GRID STRETCHING METHOD (EQUATION 13 )

DO $(1, J, K)-$-VARIABLE USED FOR INVERSION OF THE TRI-DIAGONAL MATRIX, SUBROUTINE FLOW 


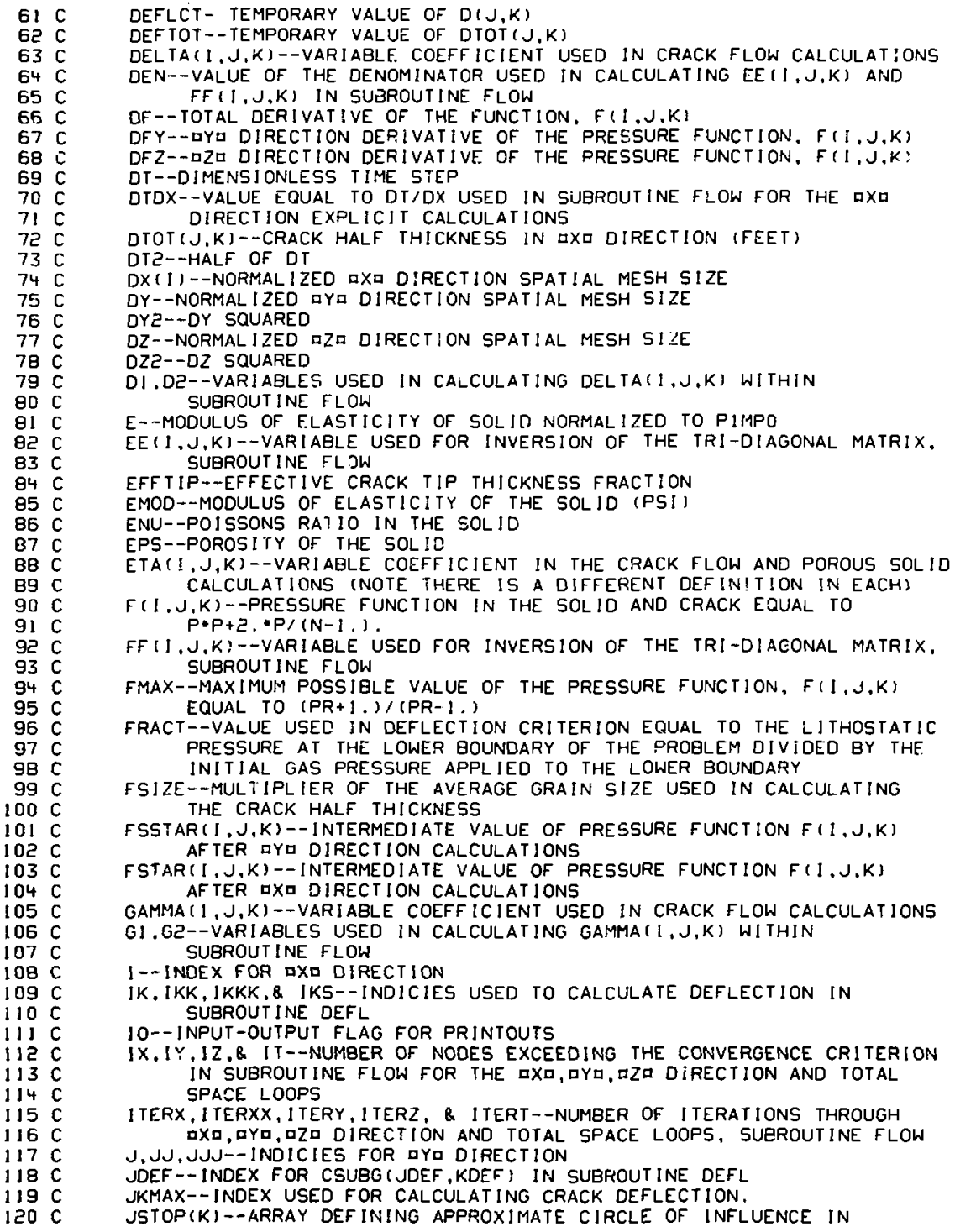




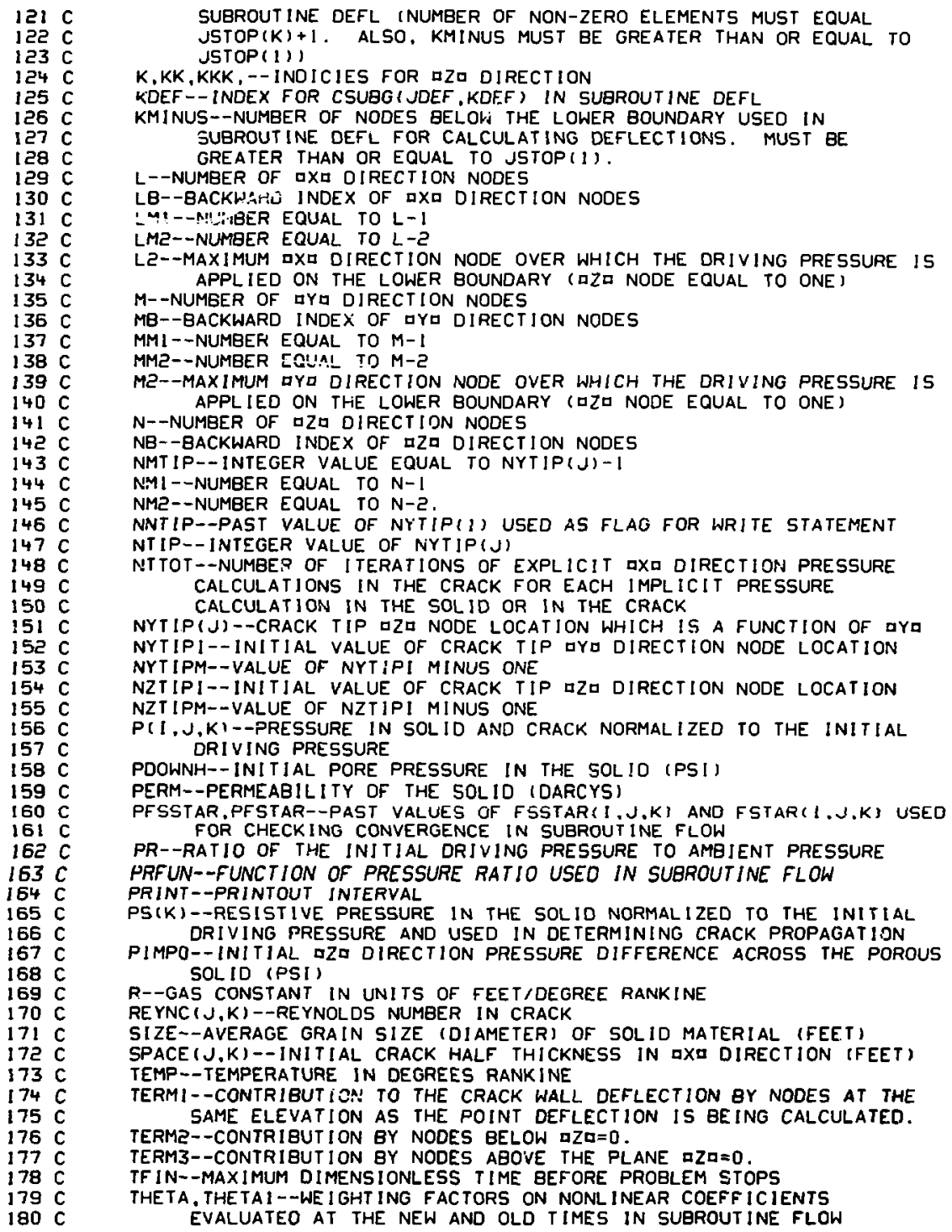




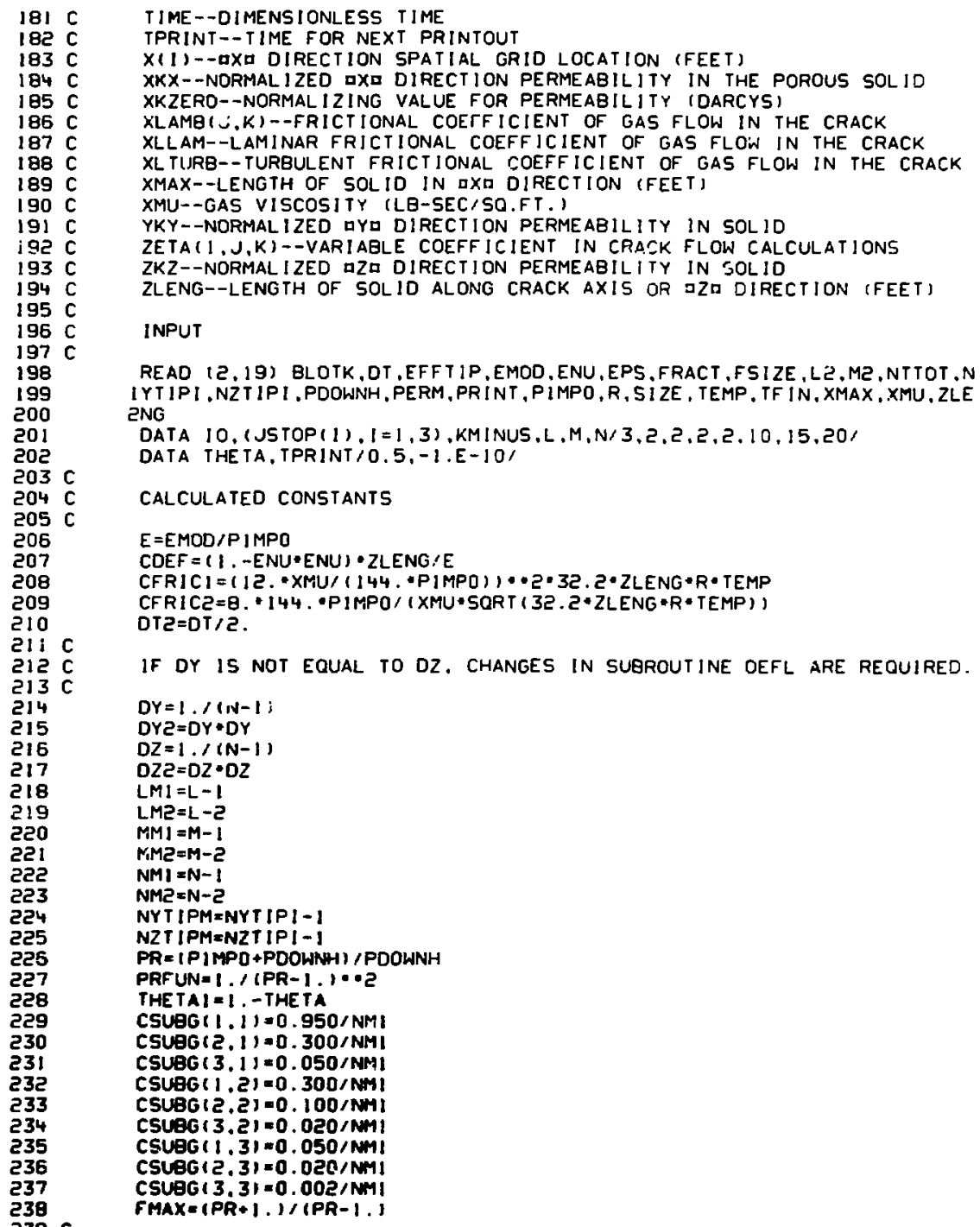

$239 \mathrm{C}$

$240 \mathrm{C}$

calculate $\times(\|)$ and oxil using blottner's equation number 9. comp. 


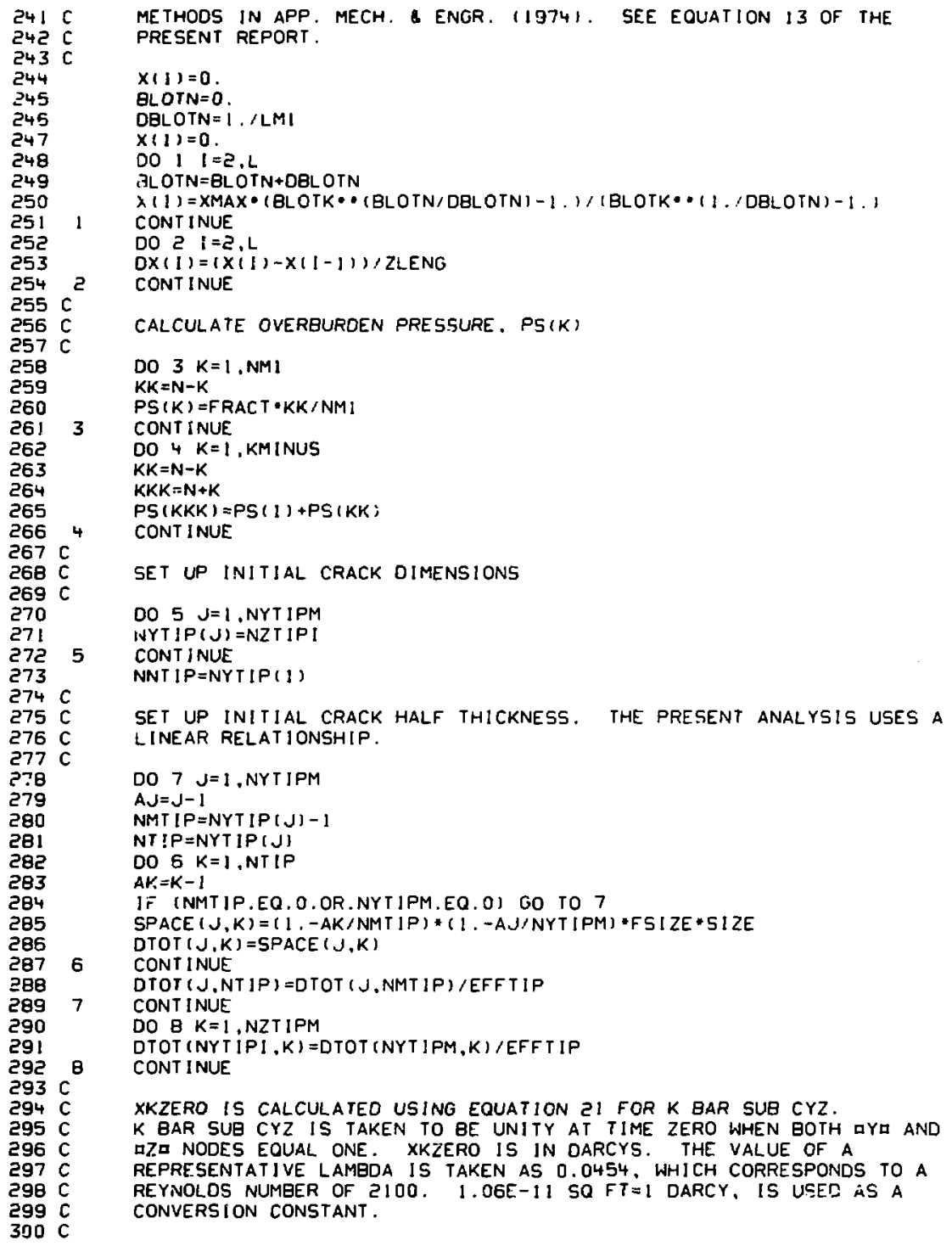


XKZERO=EPS •XMU -SORT $(E 4.4 \cdot 2 . \cdot S P A C E(1,1) \cdot R \cdot T E M P \cdot Z L E N G / 0.04541 / 11.0 E-$ $111 \bullet P I M P 0 \cdot 144.1$

SET DIRECTIONAL PERMEABILITIES IN THE S*LID

$X K X=P E R M / X K Z E R O$

$Y K Y=P E R M, X K Z E R O$

$Z K Z=P E R M / X K Z E R O$

COINCKX $=X K X+E P S \cdot Z L E N G / 2$.

INITIALIZE THE DRIVING PRESSURE OVER THE APPROPRIATE PART OF THE PLANE hHERE the aZt nODE EQUALS ONE.

DO $91=1$, LC

00 $9 \mathrm{~J}=1 . M 2$

$P(1, J, 1)=1$.

F(1.J. I I = FMAX

CONTINUE

WRITE OUT INPUT VALUES

WRITE (10.20) BLOTK,DT,EFFTIP.EMOD, ENU, EPS,FRACT,FSIZE, 10.KMINUS,L 1.M,N,LZ,MZ, NT TOT, NYT IPI , NZTIPI ,PDOWNH, PERM, PRINT, FIMPO,R, SIZE. TEMP Z. IF IN, XMAX, XMU, ZLENG, E, XKX, XKZERO, $(X(1), I=1,10)$

GO TO 16

MAIN CALCULATIONAL LOOPS

UPOATE CRACK HALF THICKNESS AND EFFECTIVE PERMEABILITY IN THE DZD DIRECTION DUE TO CRACK OIMENSION CHANGES.

CALL DEFL

DO $13 \mathrm{~J}=1, \mathrm{M}$

DO $11 K=1, N$

CALCULATE FRICTION COEFFICIENTS

IF (OTOT $(J, K)$.LE.O.) GO TO IZ

CALL FRICT $(J, K)$

CALCIJLATE CRACK EFFECTIVE PERMEAGILITIES FROM EQUATIONS 20 AND 21. NOTE THAT INITIALLY CKYZ(I.1)=1.0

CKX $(J, K)=$ CONCKX $/ D T O T(J, K)$

IF (XLAME (J,K).LE.O.) GO TO la

CKYZ $(J, K)=$ SORT $(D T O T(J . K) \cdot 0.0454 /($ SPACE $(1.1) * X L A M B(J . K))$

11 CONTINUE

IL IF IOTOT (J.I).LE.D.J J=M

13 CONT INUE

CALL FLOW

$T I M E=T I M E+D T$

IF IOTOTII.N).GT.O..OR.OTOT(M.1).GT.O.I GO TO 16

REOLICE THE DRIVING PRESSURE WITH TIME. INCLUDE A MATHEMATICAL RELATIONSHIP HERE OR DELETE THE LOOP IF THE DRIVING PRESSURE IS CONSTANT.

DO $14 \quad 1=1$, L.

DO $14 \quad J=1, M 2$

$P(1 . J .11=(1472 . / E X P(0.034422 \cdot T$ IME $)+29) /$.1501 . 


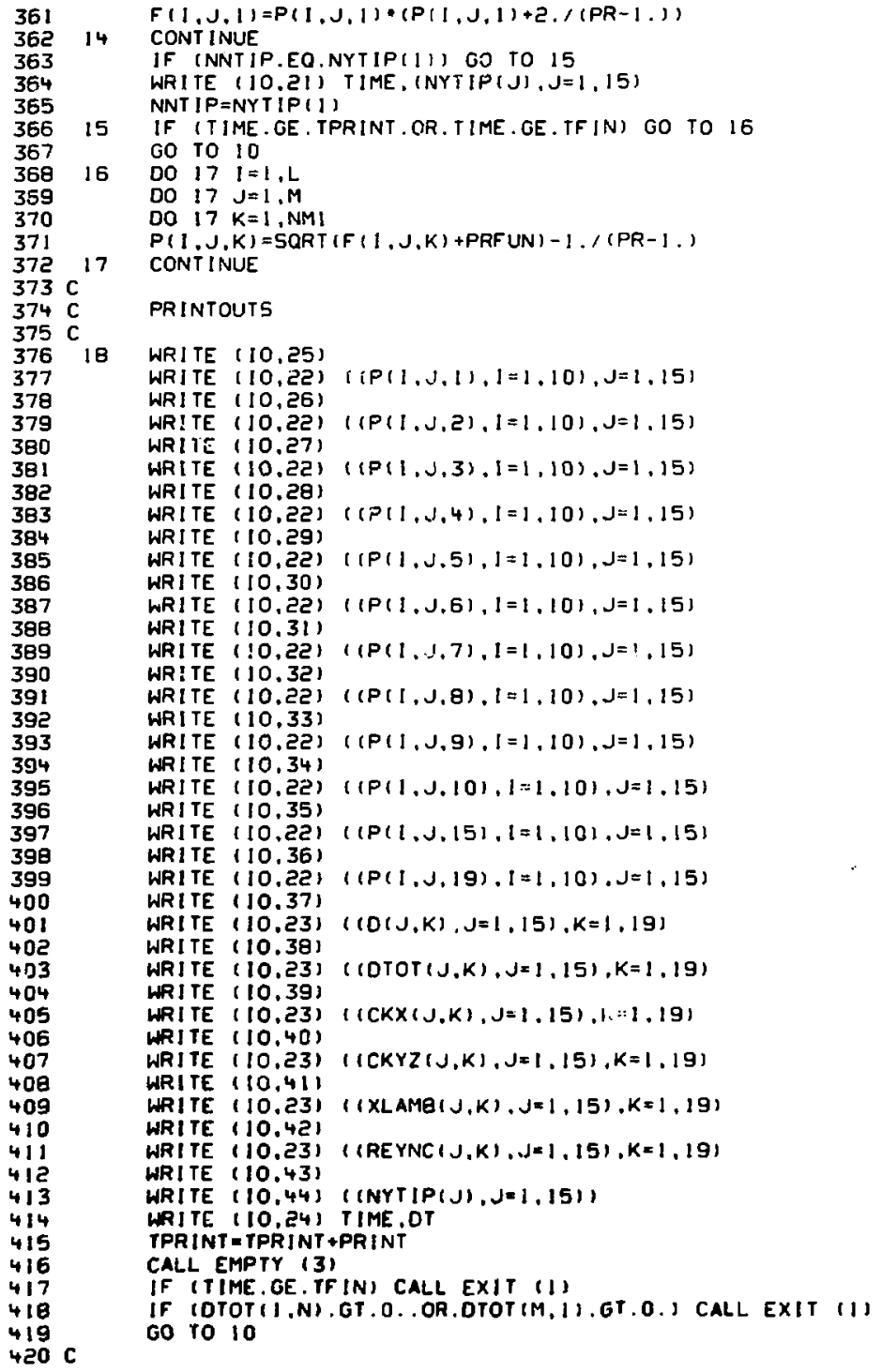




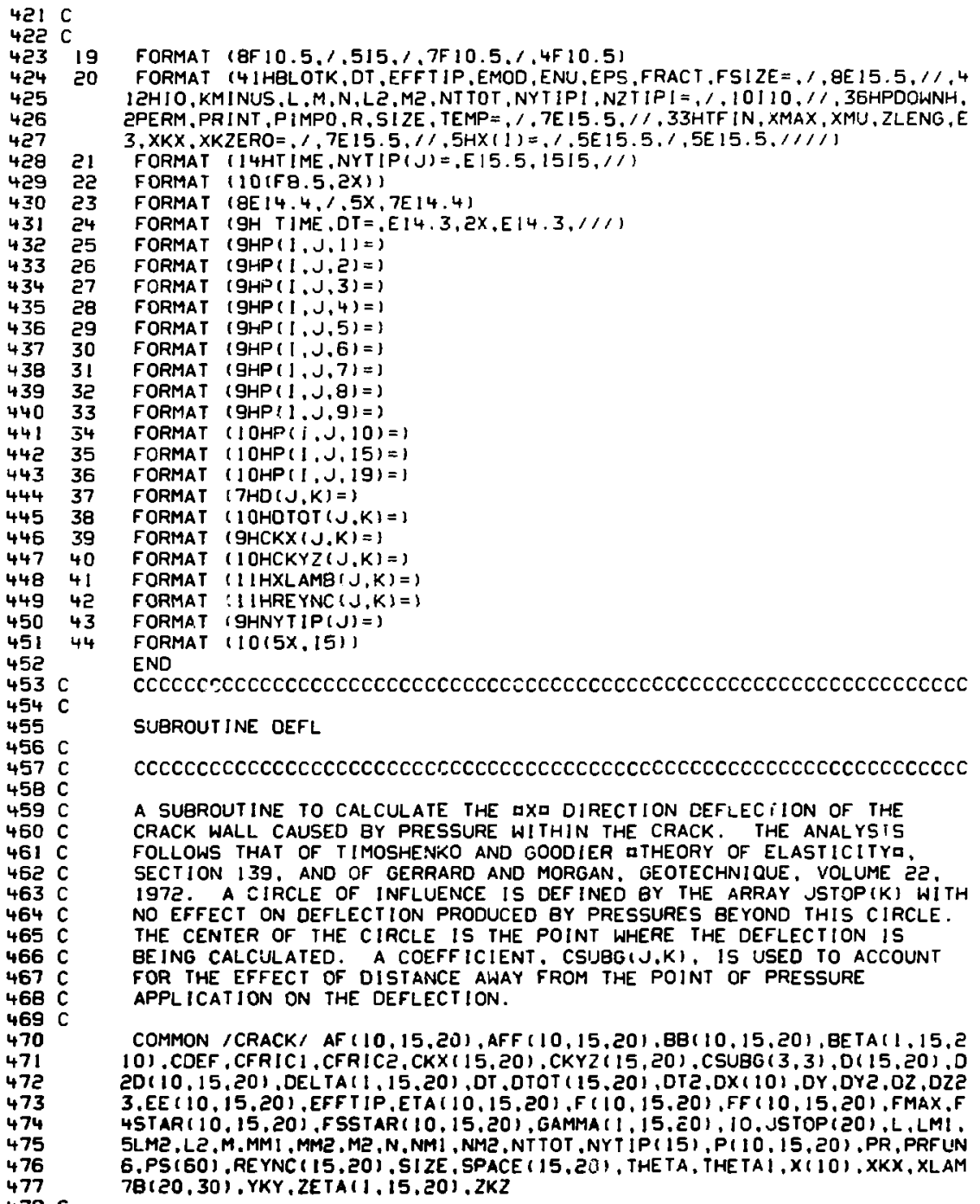

calculate values of pressure from the pressure function. 


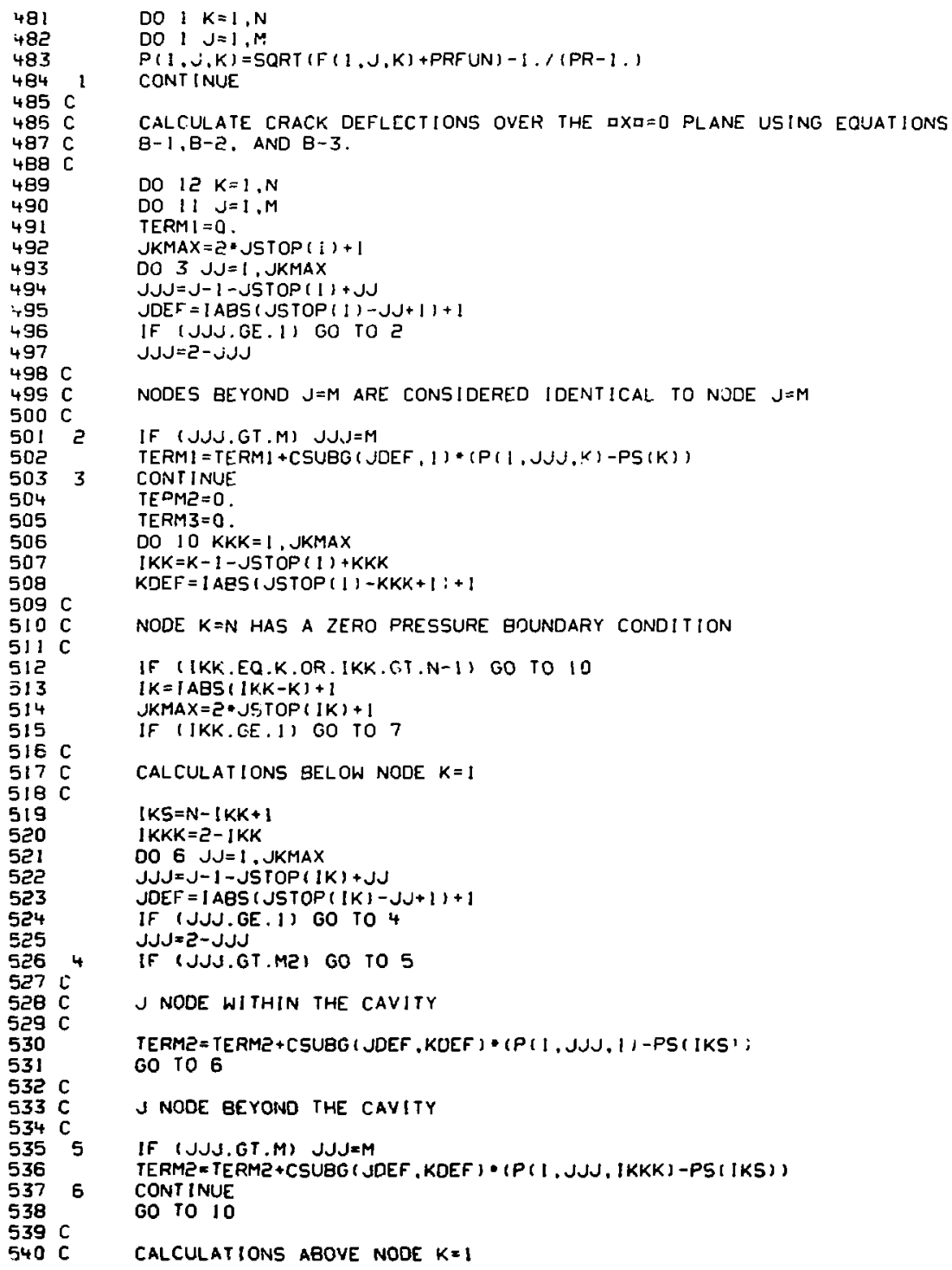




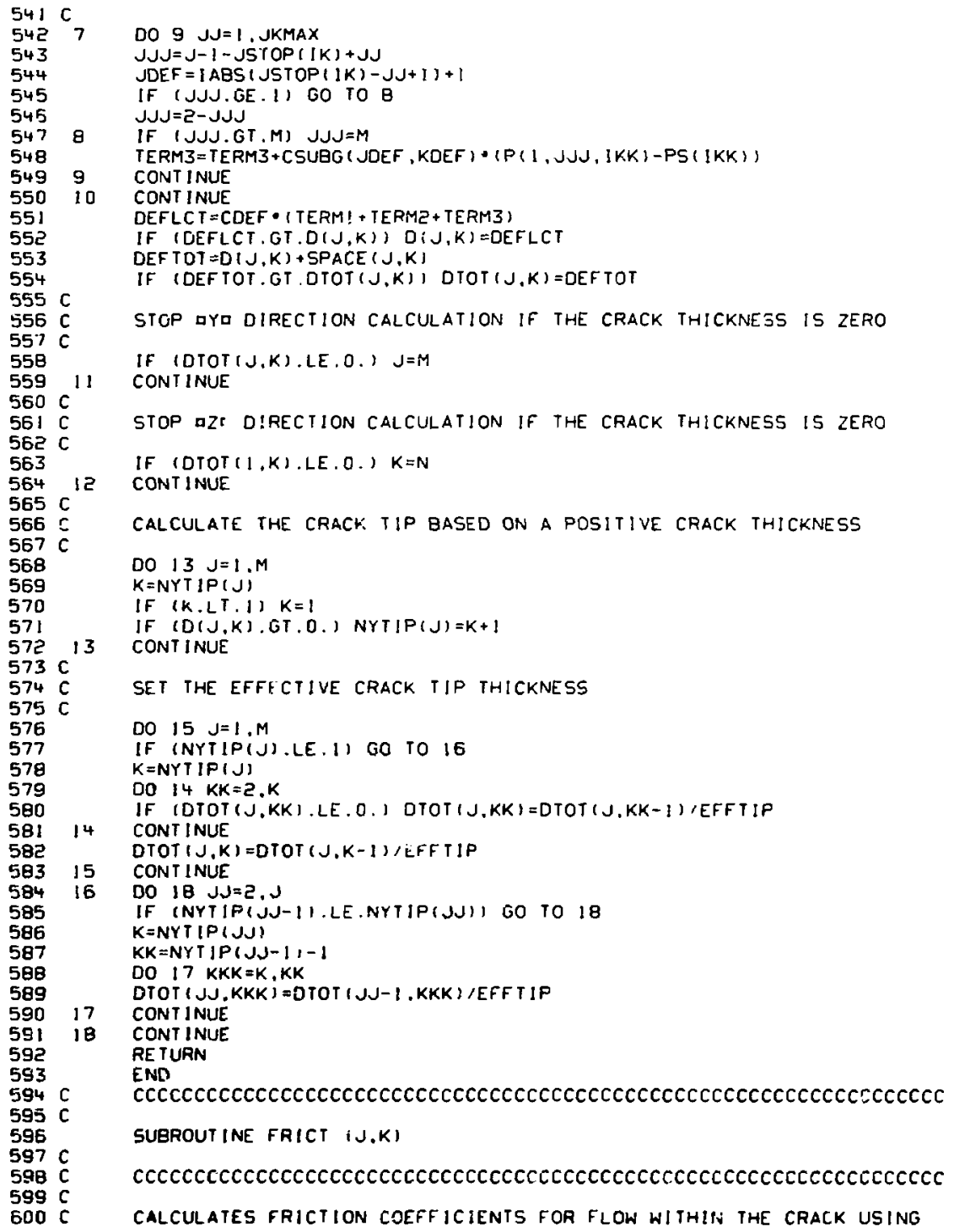




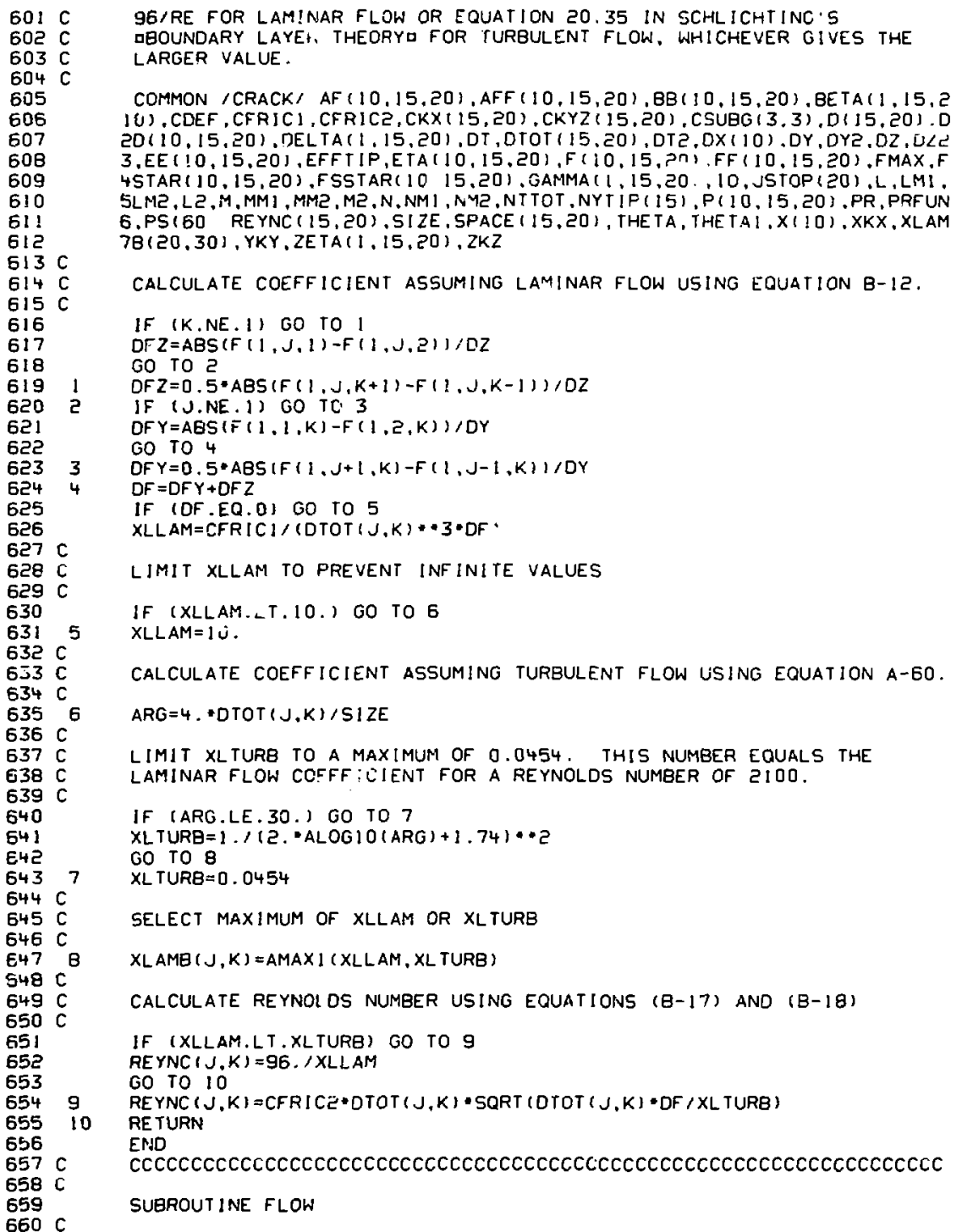


56! C

$662 \mathrm{C}$

$663 \mathrm{C}$

$664 \mathrm{C}$

$655 \mathrm{C}$

$665 \mathrm{C}$

$667 \mathrm{C}$

$668 \mathrm{C}$

$669 \mathrm{C}$

$670 \mathrm{C}$

$671 \mathrm{C}$

$672 \mathrm{C}$

673

674

675

676

677

678

679

680

$68 I \mathrm{C}$

$682 \mathrm{C}$

$683 \mathrm{C}$

684

685

686

587

686

684

690

691

692

693

$694 \mathrm{C}$

$695 \mathrm{C}$

$696 \mathrm{C}$

$697 \mathrm{C}$

$698 \mathrm{C}$

$699 \mathrm{C}$

$700 \mathrm{C}$

$701 \mathrm{C}$

$702 \mathrm{C}$

$703 \mathrm{C}$

$704 \mathrm{C}$

705

706

707

708

709

710

711

$71 \bar{c}$

713

714

715

716

717

718

719

720

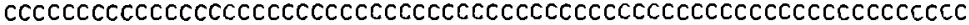

THIS SUBROU'INE DETERMINES THE PRESSURE AT EACH NODE IN THE POROUS SOL ID ANO WITHIN THE CPACK DUE TO THE GAS FLOW. FIRST FLOW IN THE QXI OIRECTION IS CALCULATED EXPLICITLY WITHIN THE CRACK AND IMPLICITLY OUTSIOE OF THE CRACK. NEXT THE aYa AND THEN THE $\square Z \square$ DIRECTION FLOW IS FOUND IMPLICITLY. WITHIN THE. CRACK AN OPERATOR SPLITTING METHOD IS USED BECAUSE THE GOVERNING EQUATION IS HYPERBOL IC IN EXI AND PARABOLIC IN IYE AND DZD. AN ALTERNATING DIRECTION IMPLICIT ME THOD IS USED HIHFA THF R.OVERNING F.QUATION I S PAKABOL IC.

COMP1ON /CRACK: AF I 10,15.20),AFF $110,15,20), B 8(10,15.20), B E T A 11,15 . ?$ 10), COEF.CFRIC ? .CFRIC2,CKX $(15,20), C$ CYZ $(15,20), C S U B G(3,3), 0(15,20), D$ $2 D(10,15,20)$,DELTA $(1,15,20), D T$. DTOT $(15,20), D T 2 . D X(101, D Y, D Y 2, D Z, D Z 2$ 3,EE $(10,15,20)$, EFF T IP.ETA $(10,15,20), F(10,15, \cdots), F F(10,15,20), F M A X . F$

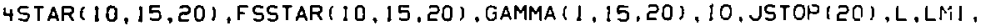
5LMP,L2,MI,MMI, MMI, M2,N,NMI, NME, NTTOT, NYTIP(15;,P(10,15,20),PR, PRF UN 6.PS $160 ;,$ REYNC $(15.20)$,SIZE, SPACE $(15,20)$. THETA, THETA , X 110$), X K X$. XLAM $78(20.30)$, YKY, ZETAII. 15.20), ZKZ

INITIALIZE VALUES

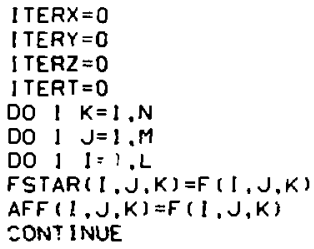

DXa DIRECTION EXPLIC!T -- USED FOR aXa NODE EOUAL TO ONE AND INSIJE THE CRACK. AN OPTRATOR SPLITTING METHOD IS USED WHERE IN THE IXI DIRECTION ONLY TIAE QXI COMPONENT EXPLICIT SPATIAL DERI:ATIVE AND THE TIME OERIVATIVE ARE CONSIDERED IN THE GOVERNING EOUATION. LATER IN THE GYO ANO GZ口 OIRECTIONS AN ALTERNATING DIRECTION IMPLICIT METHOD IS USED WHERE NO IXI DIRECTION SPATIAL DERIVATIVES ARE PRESENT IN THE EASIC GOVERNING EQUATION. THE EXPLICIT TIME STEP IS SET EQUAL TO THE IMPLICIT TIME STEP DIVIDED 8Y NTTOT .

DTOX $=D T /(D X(5) * N T$ TOT $)$

DO 5 ITIME $=1$, NTTOT

DO $4 \quad K=1, N M 1$

DO $3 \mathrm{~J}=1, M$

IF (DTOT (J,K).LE.O.) GO TO 3

IF (J.LE.MZ.AND.K.EO.1) GO TO 3

$F(1, J, K)=F S T A R(1, J, K)$

1 TERXX $=0$

ETA $(I, J, K)=0,5 *($ THE TA / SORT (FSTAR ( ) , J,K) +PRFUN ) + THE TA I/SQRT (F ( $1, J, K$ 1) +PRF UN)?

FSTAR $(1, J, K)=C K X(J, K) * D T D X *(F(2, J, K)-F(1, J, K)) / E T A(1, J, K)+F(1, J, K)$ 1 TERXX $=$ ITERXX+1

3 COR:T INUE COR:T INUE IF (DTOT $(1, K)$.LE.O., $K=N$

4 CONT INUE 


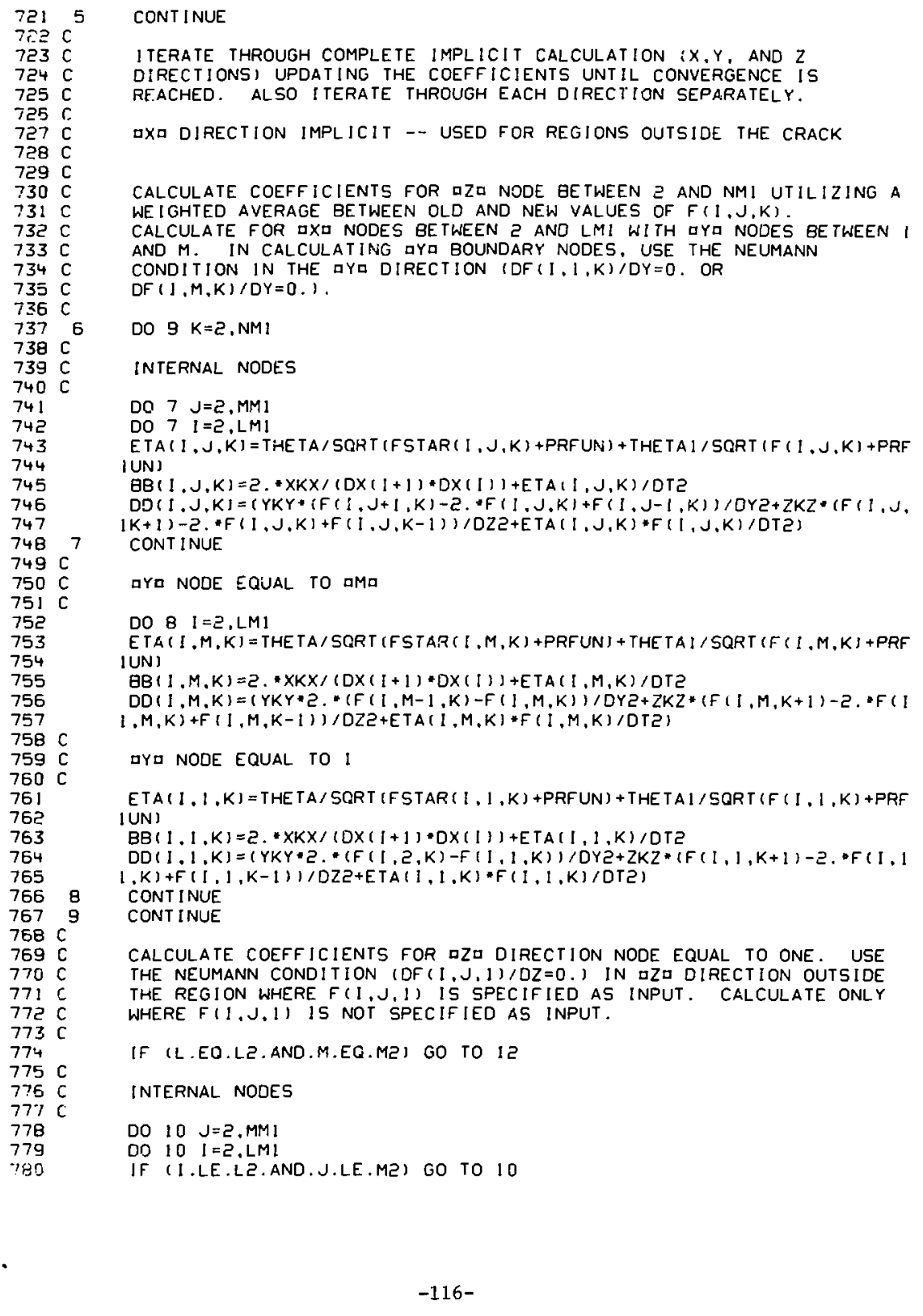


ETA $1, J, \mid$ l = THE TA/SORT (FSTAR $(1, J, 1)+P R F U N)+T H E T A \mid / S O R T(F(I, J, 1)+P R \Gamma$

B日( $1,7,1)=5 .+X K X /(D X(1+1)+D X(1))+E T A(1, J, 1) / D T 2$

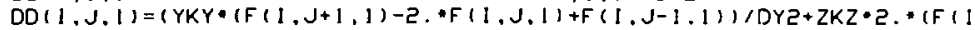

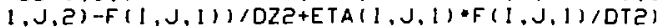

10 CONT INUE

口Ya NODE EOUAL TO DME

DO I! $I=2, L M I$

IF (I.LE.LZ.AND.M.EO.MZ) GO TO II

ETA $(1, M, 1)=$ THE TA/SORT (FSTAR $(I, M, 1)+P R F U N)+T H E T A \mid / S O R T(F(I, M, l)+P F:$ IUN)

$\mathrm{BB}(1, M, 1)=2, * X K X /(D X i 1+1, * \mathrm{XX}(1))+E T A(1, M, 1) / D T 2$

$D D(1, M, 1)=(Y K Y * 2 . *(F(1, M-1,1)-F(1, M, 1)) / D Y Z+Z K Z * 2, *(F(1, M, 2)-F \mid 1, M$ $1,1) / D Z 2+E T A(\mathbf{i}, M, 1) * F(1, M, 1) / D T 2)$

口YL NODE EQUAL TO 1

IF I I.LE.LZJ GO TO I!

ETA $(1,1,1)=$ THE TA /SORT (FSTAR $(1,1,1)+P R F U N)+$ THE TA / SORT $(F(1,1,1)+P R F$ IUN!

B日( $1,1,1)=5 . \times K X / 1 D X(1+1) * D X(1) 1+E T A(1,1,1) / D T 2$

$\mathrm{DO}(1,1,1)=(Y K Y * 2 . \bullet(F(1,2,1)-F(1,1,1)) / D Y 2+Z K Z \bullet 2,(F(1,1,2)-F(1,1,1$ $111 / D Z 2+E T A(1,1,1) \bullet F(1,1,1) / D T 2)$

CONT INUE

CALCULATE EE $(I, J, K)$ AND FF $(I, J, K)$ FOR IXI NODES BETWEEN $I$ AND LM!. USE THE DIRICHLET CONDITION (FSTAR $(1, J, K$ ) IS OBTAINED FROM THE EXPLICIT CALCULATIONS) FOR $[=1$ IF INSIDE THE CRACK, USE THE NEUMANN CONDITION FOR $l=1$ OUTSIDE THE CRACK (DF $(1, J, K) / D X=0$.$) .$ USE THE RECURSION RELATIONSHIP FOR ALL OTHER 口XI NODES. IF THE 口Z NODE EQUALS i. VALUES ARE CALCULATED ONLY OUTSIDE THE PEGION WHERE F (I,J,I) IS SPECIFIED AS INPUT.

CALCULATIONS FOR aZa NODE GETWEEN 2 AND NMI

DO $16 K=2, N M 1$

$00 \quad 16 \quad J=1, M$

INSIDE THE CRACK

IF (DTOT (J.K).LE.O.) GO TO :3

$E E(1, J, K)=0$

$F F(1, J, K)=F \operatorname{STAR}(1, J, K)$

GO TO 14

OUTSIDE THE CRACK W] TH $[=1$

$E E(1, J, K)=1$.

$F F(1, J, K)=0$.

ALL OTHER REGIONS

DO $15 \quad l=2, L M !$

$\mathrm{DEN}=\mathrm{BQ}(1, \mathrm{~J}, \mathrm{~K})-5, \mathrm{XKX} * \mathrm{EE}(1-1, J, K, /(\mathrm{DX}(1) *(\mathrm{DX}(1+1)+\mathrm{DX}(1)))$

$E E(], J, K)=5 .+X K X)(D X(1+1) *(D X i I+1)+D X(1)) * D E N i$

$F F(J, J, K)=(D D(I, J, K)+2, * X K X * F F(I-1, J, K) /(D \times(I) *(D X(I+1)+D \times(1))) / D$ IEN CONT JNUE 


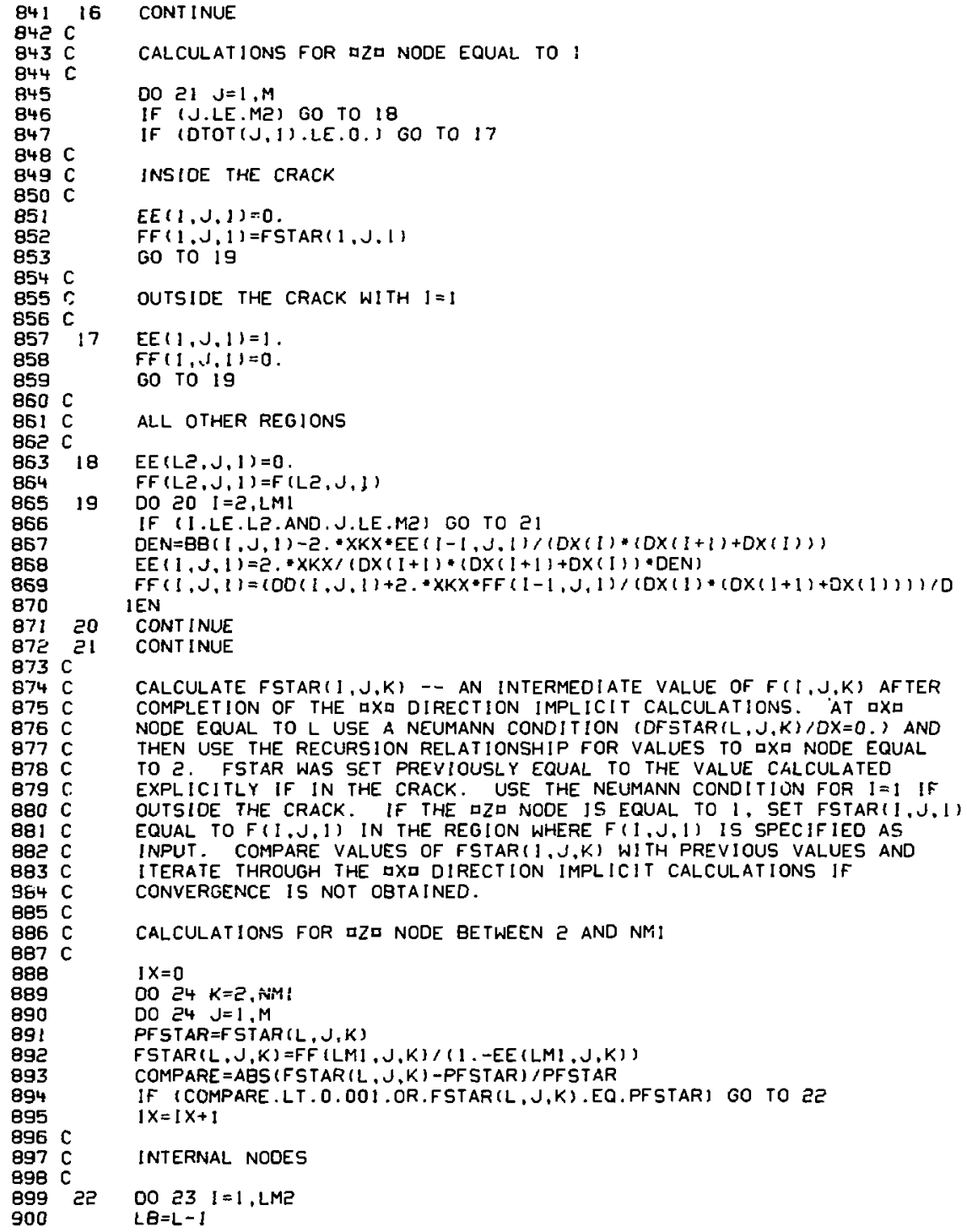

INTERNAL NOOES

DO $23 \quad I=1$, LMP

LB $=L-1$ 


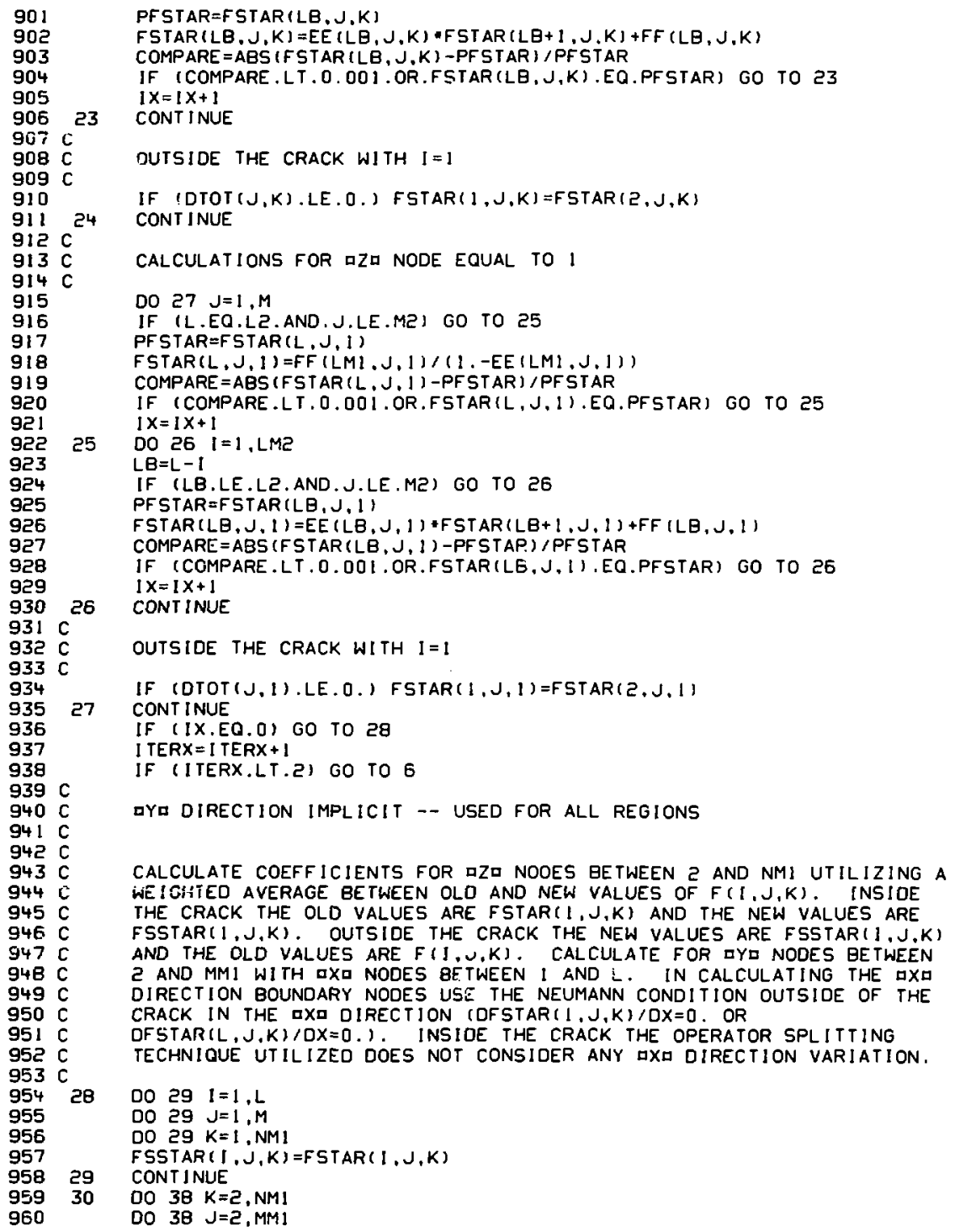




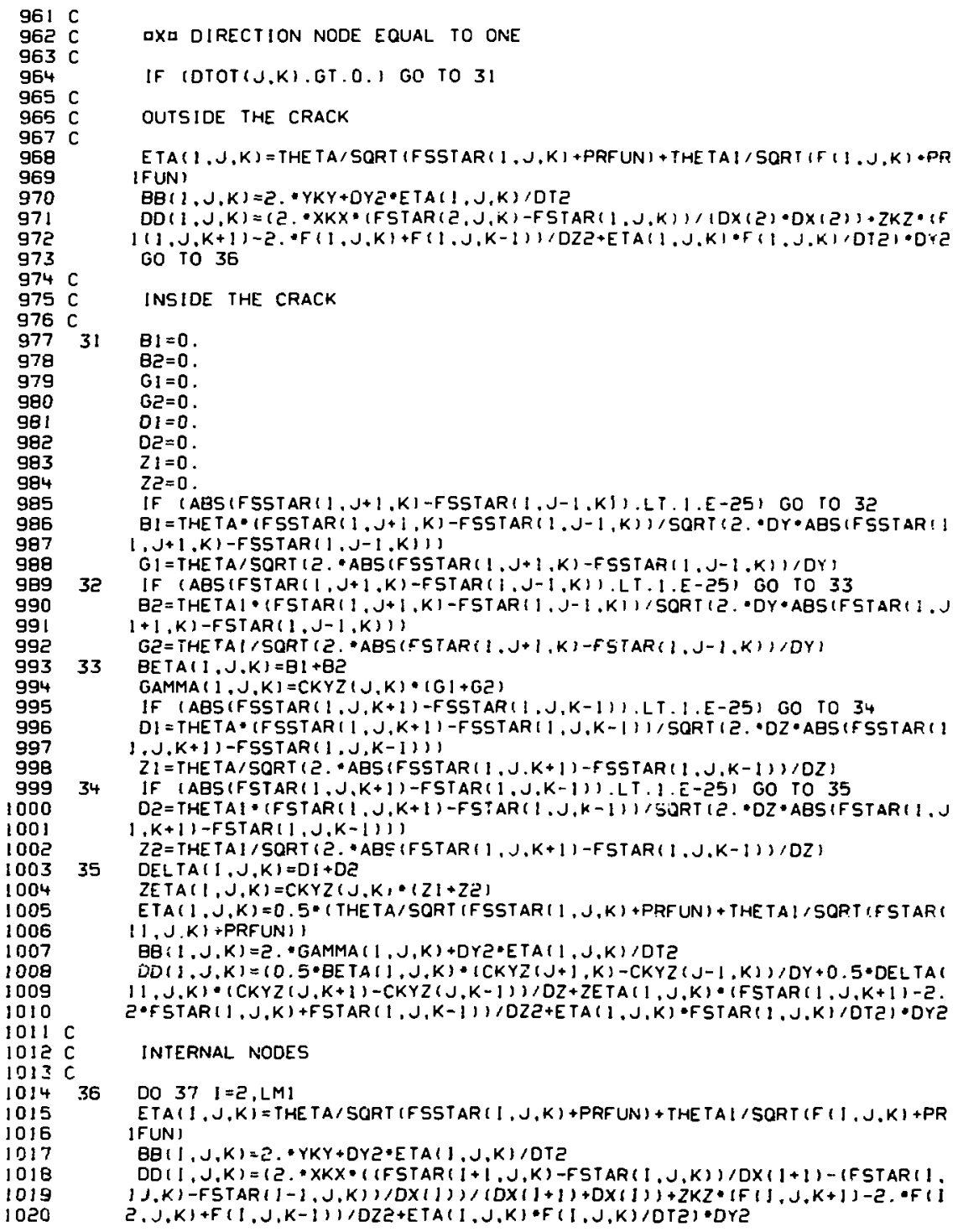




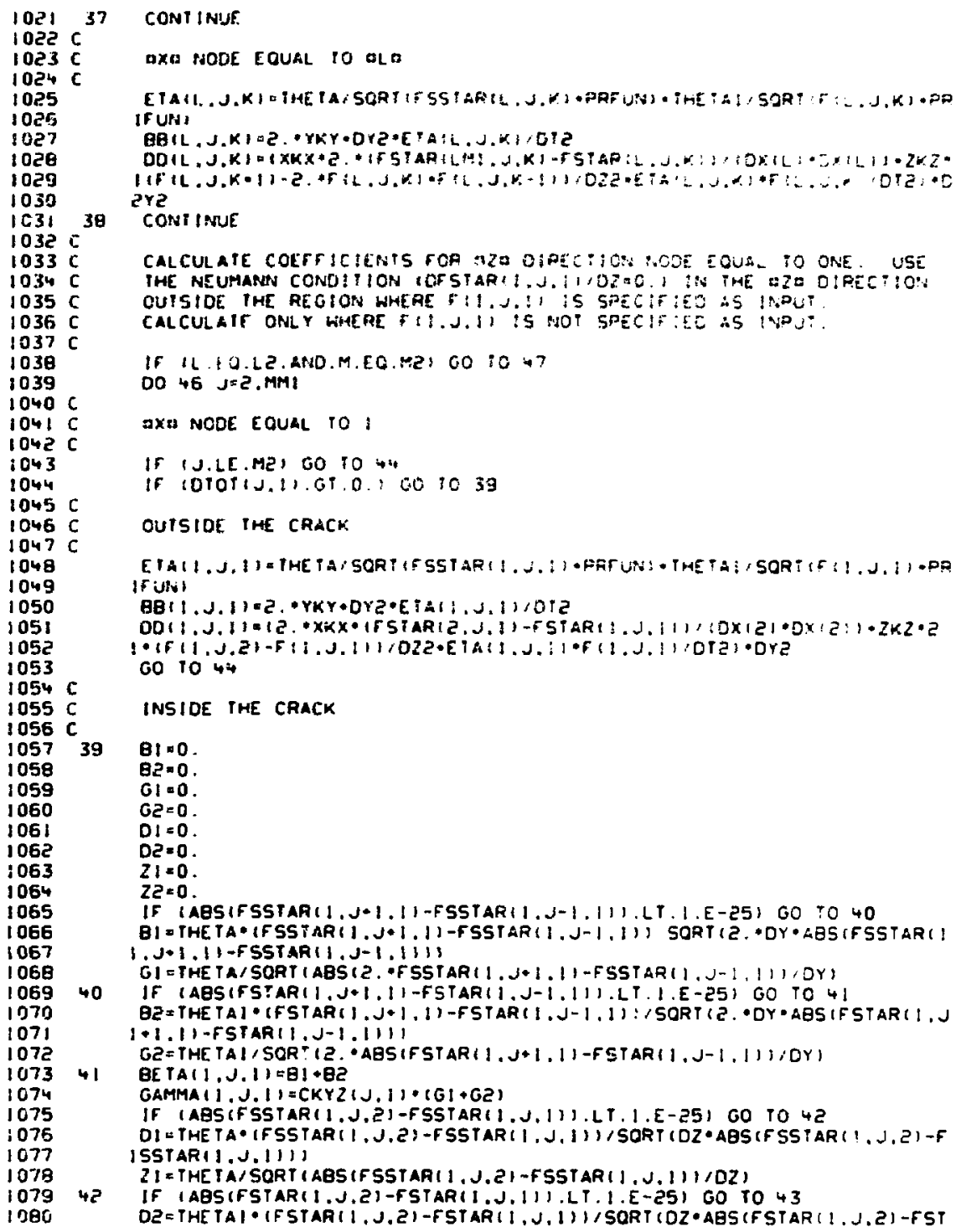




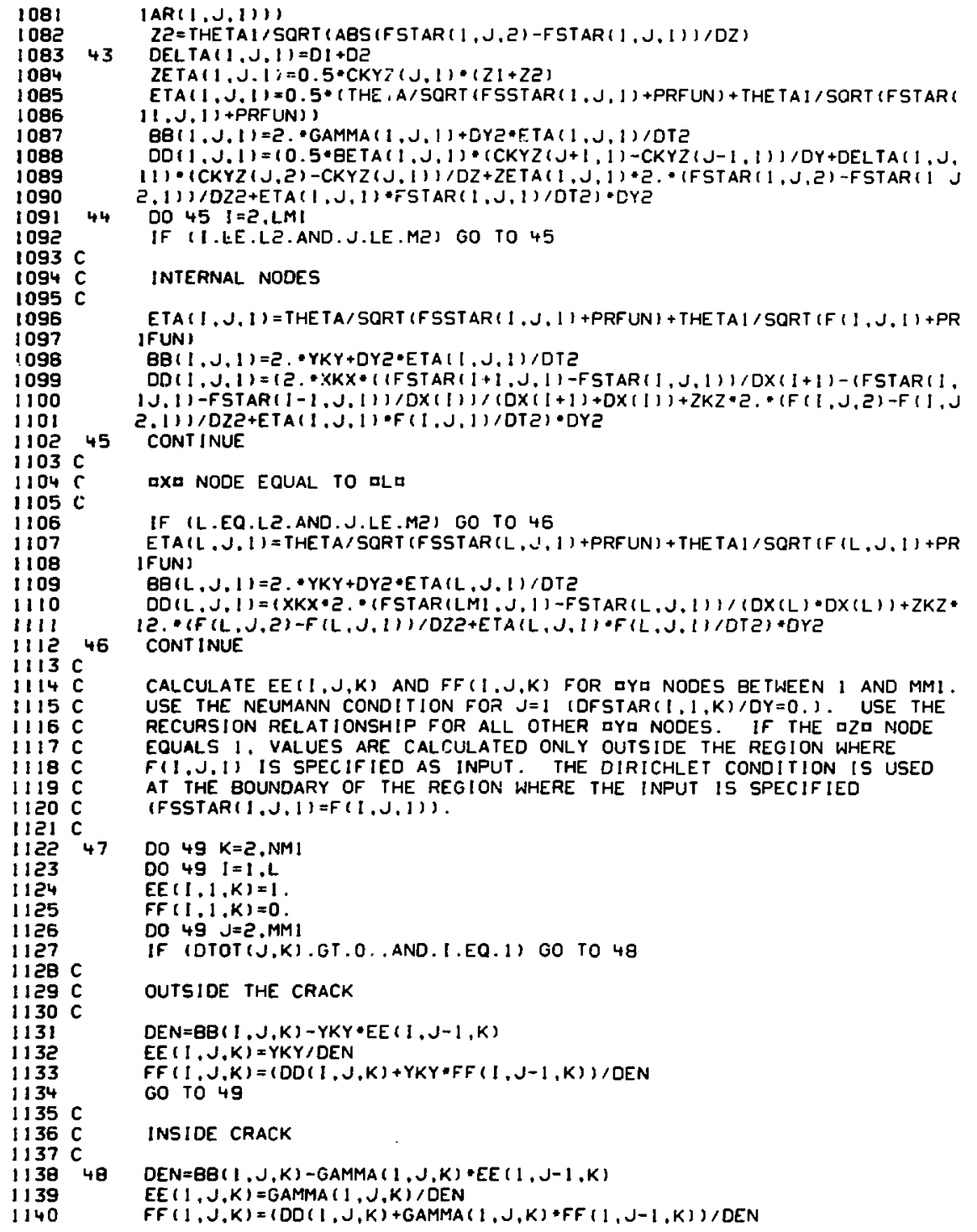




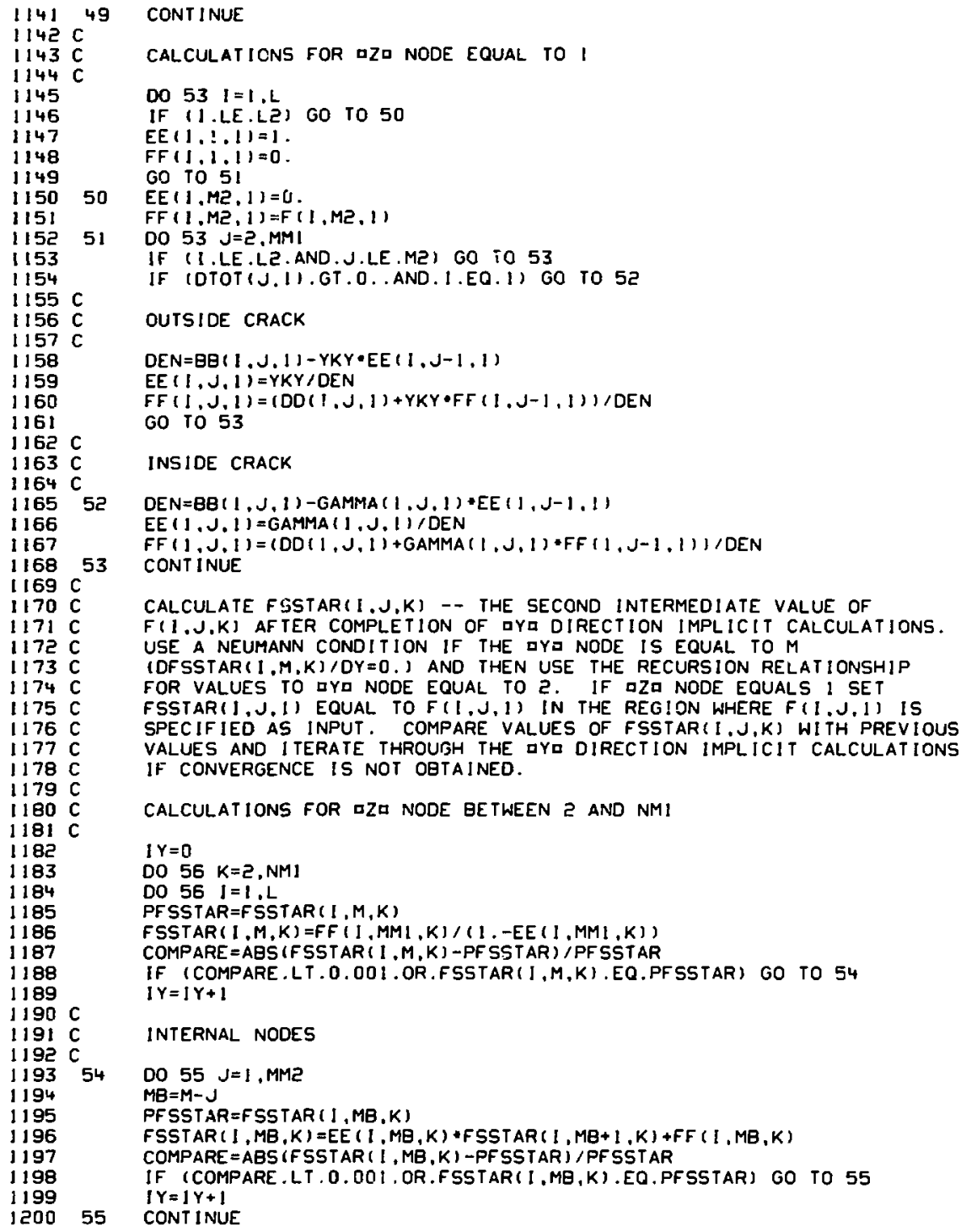




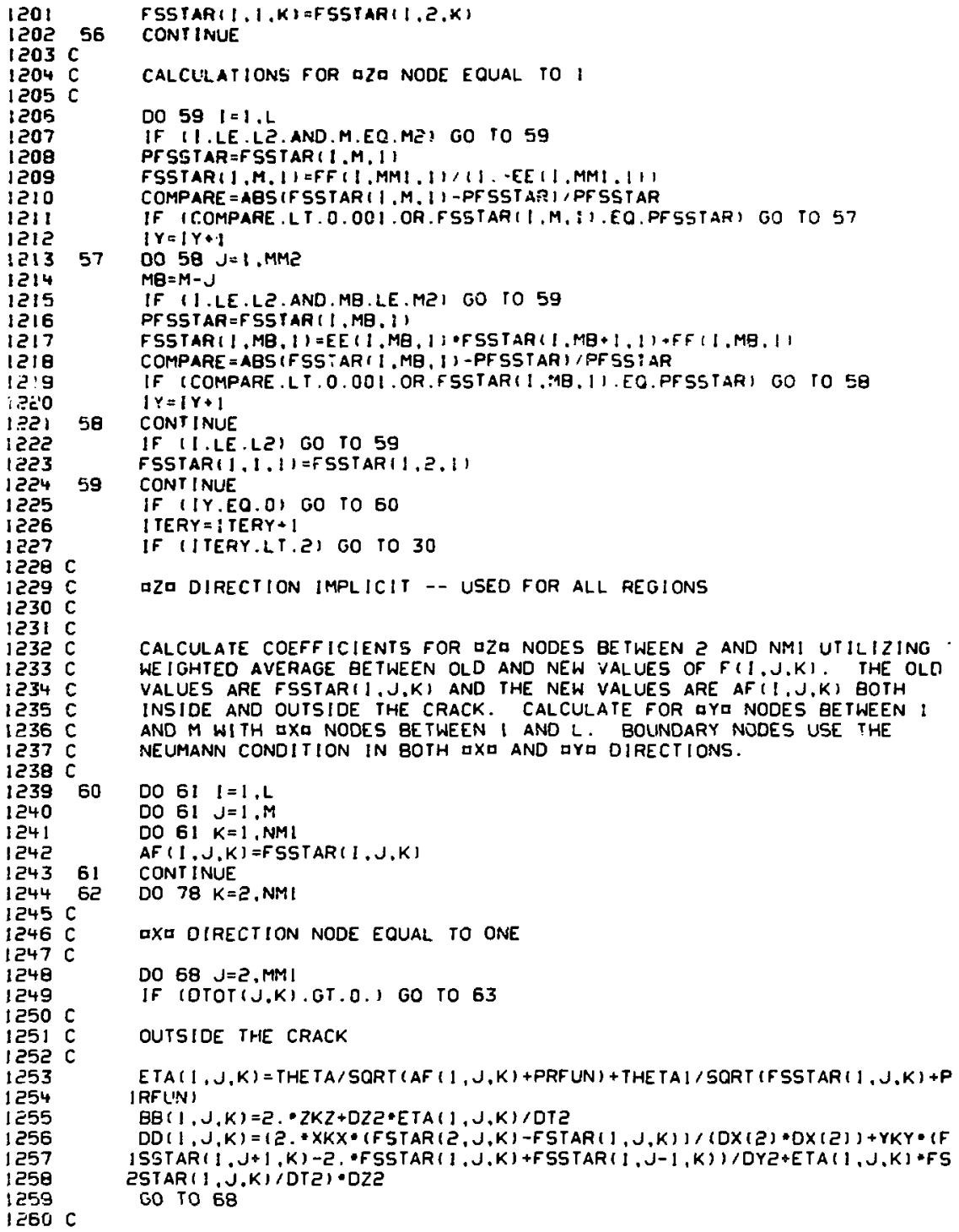




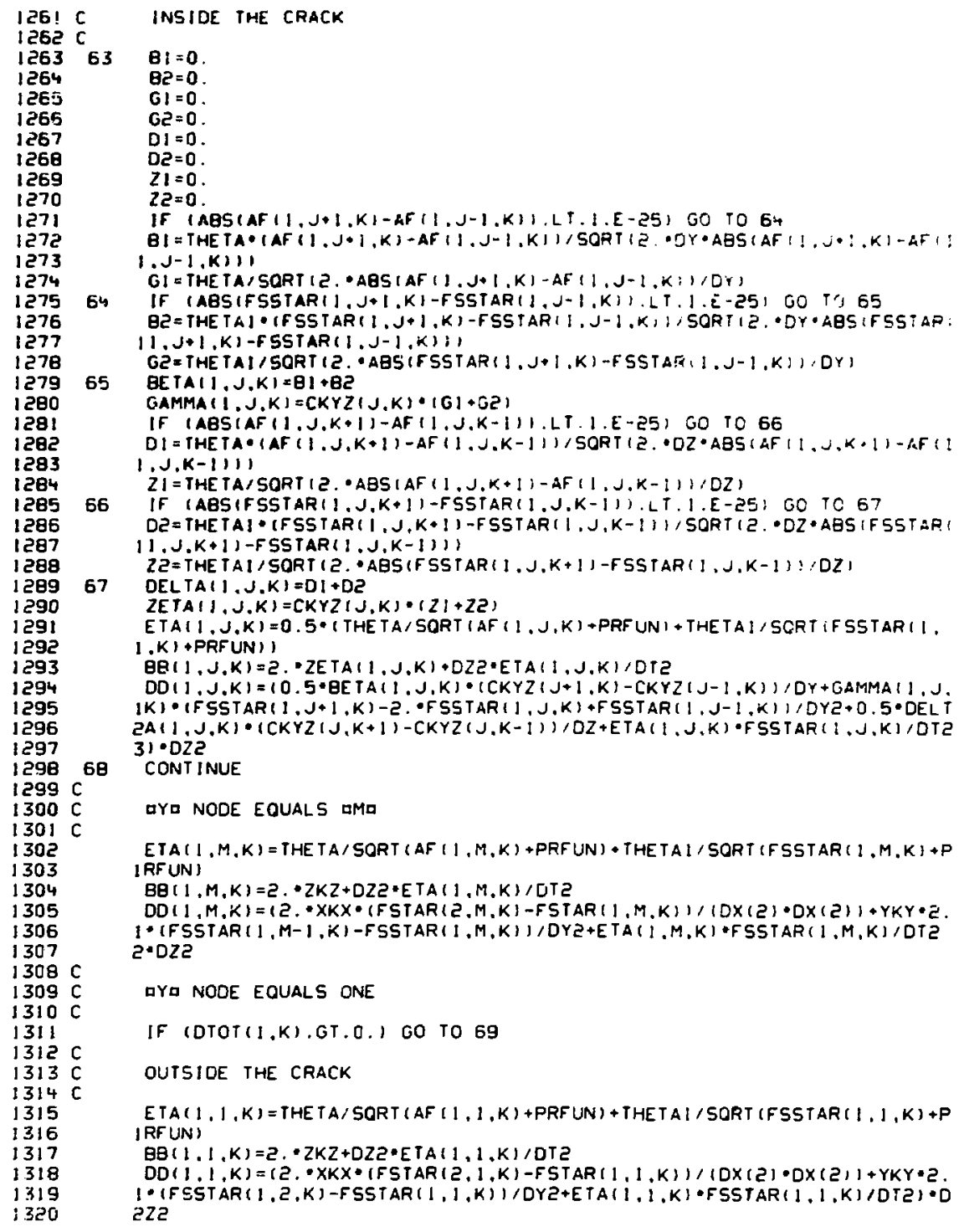




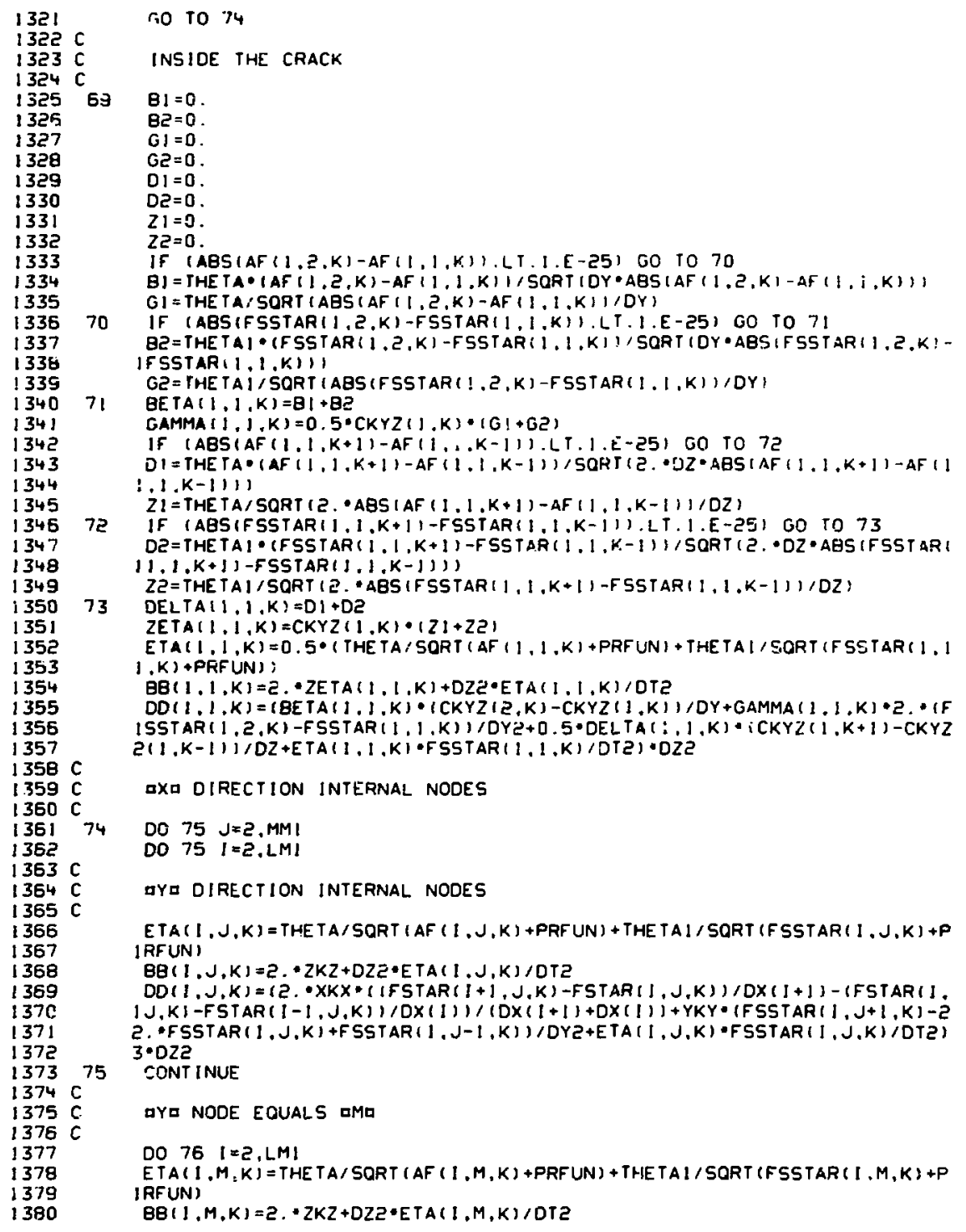


$D D(1, M, K)=\{2 . \cdot X K X+1(F S T A R(1+1, M, K)-F S T A R I), M, K))(D X(1+i)-(F S T A R(1$,

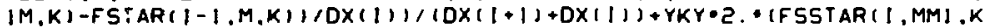
2) -FSSTAR ( I.M.K) I/DYZ+ETA ( , M,K) FSSTAR I , M,K)/OTZ)・DZZ

\section{DYO NODE EQUALS I}

ETA $(I, 1, K)=$ THETA SORT (AF $(I, 1, K)+P R F U N)+\operatorname{THETA}$ I/SORT (FSSTAR $(1,1, K)+P$ IRFUNI

$\mathrm{aB}(1,1, K)=2 . \cdot 2 K Z \cdot D Z 2 \cdot E T A 11,1, K) / D T 2$

DD $(1,1, K)=(2, \cdot x K X+1$ FSTAR $11+1,1, K)-F S T A R(1,1, K) / D X(1+1)-(F S T A R(1)$ 11.K)-FSTAR $(1-1,1 . K)) / D X(1),(D X(1+1)+D X(1))+Y K Y \cdot 2 .=(F S S T A R(1,2, K)-$ EFSSTAR $(1, l, K)$ )/DVZ+ETA $(1,1, K) \cdot F S S T A R(1,1, K) / O T 2) \cdot D Z 2$ CONTINUL

aXa NODE EQUAL TO IL口

DO $77 \mathrm{~J}=5, \mathrm{MMI}$

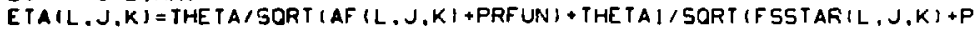
IRFUN,

$B B(L, J, K)=5 . \cdot Z K Z+D Z 5 \cdot E T A(L, J, K) / D T 2$

$D D(L, J, K)=(X K X \bullet Z$. (FSTAR $(L M !, J, K)-F S T A R(L, J, K)), D X(L) * D X(L))+Y K Y *$ I (FSSTARIL, J+1,K)-2. -FSSTAR $(L, J, K)+F S S T A R(L, J-1, K)$ ) /DYZ+ETA(L.J.K)

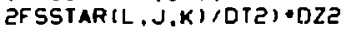

CONT INUE

aXa NODE EQUAL aLa AND aYa NODE EQUAL

$E T A(L, M, K)=T H E T A / S Q R T$ ( AF $(L, M, K)+P R F U N)+T H E T A$ I SORT (FSSTAR $(L, M, K)+P$ (RFUN)

$B B(L, M, K)=2 \cdot-Z K Z+D Z 2 \cdot E T A(L, M, K) / D T 2$

$D D(L, M, K)=(X K X \bullet 2$. (FSTAR $(L M), M, K)-F S T A R(L, M, K)) /(D X(L)+D X(L))+Y K Y *$ 12.-(FSSTAR $(L, M M), K)$-FSSTAR $(L, M, K)$ ) DVE+ETA $(L, M, K) \cdot F S S T A R(L, M, K) / D T$ $251 \cdot 0 Z 2$

aXa NODE EQUALS ILI AND aYI NODE EQUALS ONE

ETA $(L, 1, K)=T H E T A / S O R T(A F(L, 1, K)+P R F U N)+T H E T A) / S O R T(F S S T A R(L, 1, K)+P$ (RFUN)

$B B(L, 1, K)=2 \cdot Z K Z+D Z 2+E T A(L, 1, K) / D T 2$

$D D(L, 1, K)=(X K X+2 . *(F S T A R(L M), 1, K)-F S T A R(L, 1, K)) /(D X(L) * D X(L))+Y K Y *$ 12. (FSSTAR (L , 2,K) -FSSTAR $(L, 1, K)$ ) DYR+ETA $(L, 1, K)+F S S T A R(L, 1, K) / D T 2)$ $5 \cdot 0 Z 2$

78 CONT INUE

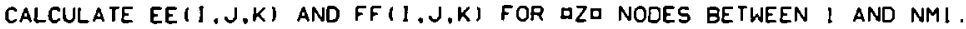
USE NEUMANN CONDITION FOR $K=I$ (DFSSTARIDZ=0.) IN REGION INHERE AF $(1, J, 1)$ IS NOT SPECIFIED AS INPUT AND DIRICHLET CONDITION WHERE AF $(1, J, 1)$ IS SPECIFIED EOUAL TO FSSTAR $(1, J, 1)$, USE THE RECURSION RELATIONSHIP FOR ALL OTHER QZD NODES.

DO $83 \mathrm{~J}=1 . M$

DO $83 \quad J=1.2$

IF (I.LE.L2.AND.J.LE.MZ) GO TO 79

$E E(1, J, 1)=1$.

$F F(1, J, 1)=0$.

GO TO BO

$79 \quad \mathrm{EE}(1, \mathrm{~J}, 1\}=0$.

80 DO $B$ E $K=5, N M I$

IF (DTOT (J.K).GT.O..AND. I.EQ.1) GO TO BI 


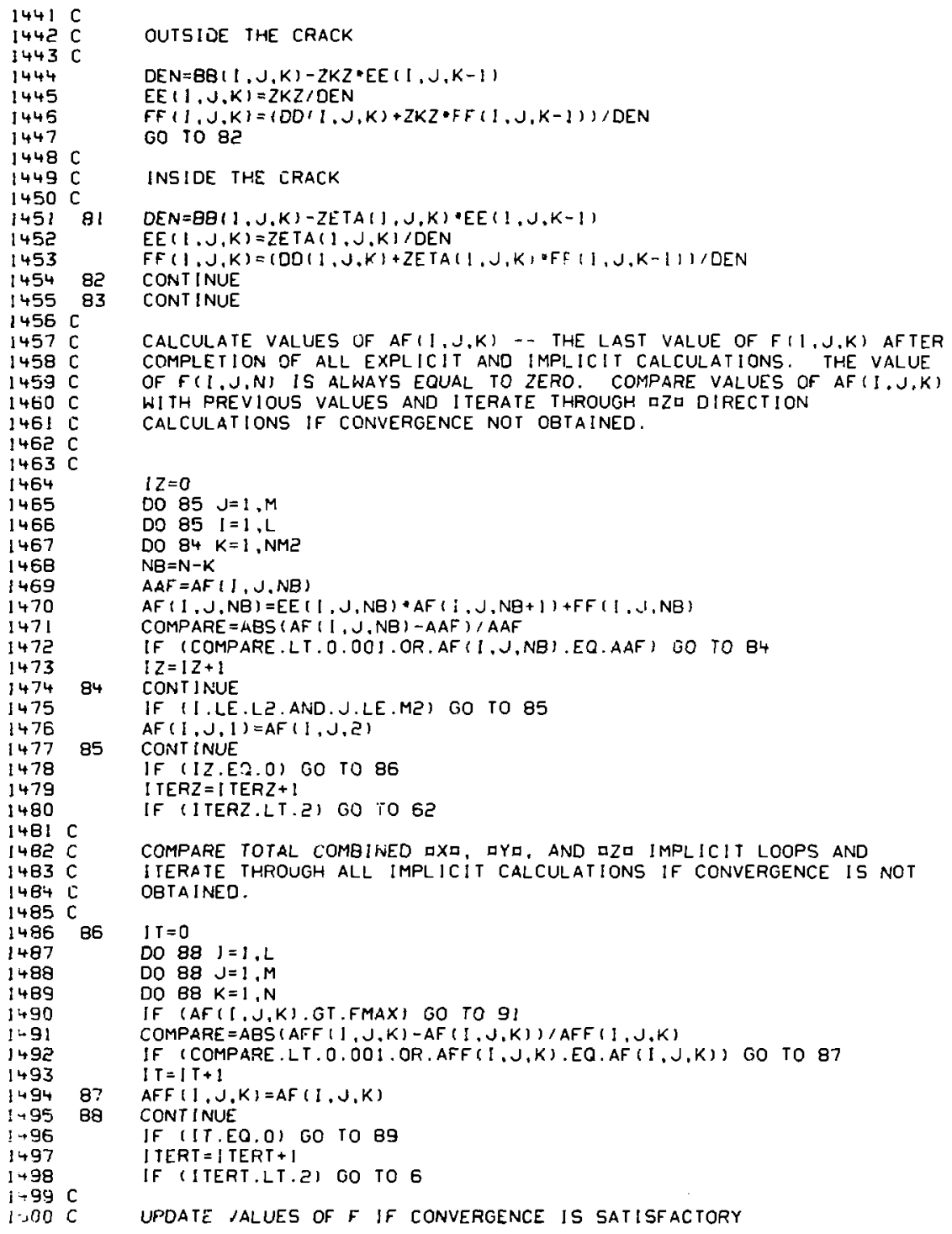


$1501 \mathrm{C}$

150289 DO $90 \mathrm{~J}=1 . \mathrm{M}$

1503 DO $90 \quad I=I . L$

$1504 \quad 0090 \mathrm{~K}=1 . \mathrm{NM} 1$

$1505 \quad F(I, J, K)=A F^{*}(I, J, K)$

150590 CONTINUE

1507 RE TURN

(508 91 WRITE (59,92) I,J.K

1509 CALL EXIT(1)

$1510 \mathrm{C}$

151192 FORMAT IG5HCONVERGENCE FAILURE IN SUBROUTINE FI.OW, REDUCE TIME STE

1512

1513 IP, $1, J, K=, 3151$ END 


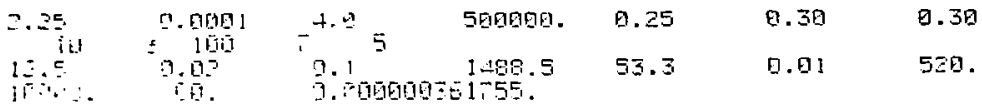

\section{SAMPLE OUTPUT}

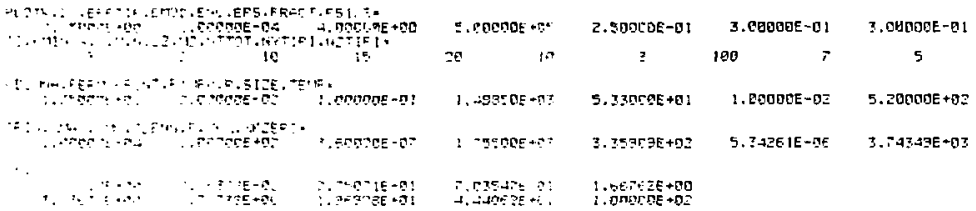

\begin{tabular}{|c|c|c|}
\hline$=$ & $.77^{\circ}=$ & 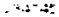 \\
\hline$\therefore$ & $26^{2}=8$ & $.7:^{-}$ \\
\hline 7 & ש2. & $\because 4=$ \\
\hline & $\because, \cdots$ & 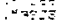 \\
\hline & $\because=$ & -7 \\
\hline & $\because \cdots$ & : \\
\hline & 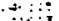 & ניבד \\
\hline & 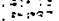 & 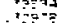 \\
\hline - & $1+x=$ & 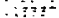 \\
\hline$\rightarrow$ & יזיחדידים & תפומלחה \\
\hline הי:ים & 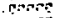 & 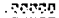 \\
\hline$\because \cdots$ & 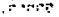 & 79? \\
\hline & דים ידידים & זהיםיה .. \\
\hline & . 苛 等 & $3611=$ \\
\hline & 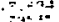 & $\begin{array}{c}30: 24 \\
0\end{array}$ \\
\hline$n, i^{*}=$ & הדים - & $\therefore-\theta$ \\
\hline$\therefore:$ & $\therefore !=\div$ & 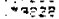 \\
\hline & $-6 t^{60}$ & $x \times=$ \\
\hline$"$ & $\therefore n+\infty$ ! & . \\
\hline &.$+\div::$ & 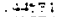 \\
\hline & $.+0^{-}: I$ & 1 : \\
\hline.$r$ & 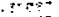 & t ton-6 \\
\hline & $10+4$ & .13325 \\
\hline$\because 3$ & - anons & - \\
\hline 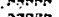 & c nrane & - Tegng \\
\hline 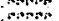 & - Desto & אית \\
\hline . : : & & \\
\hline & & 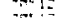 \\
\hline$"$ & $+2 \div$ & $=04$ \\
\hline & $c+.93$ & ו \\
\hline & 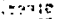 & 3.65 \\
\hline & $x: 2=3$ & $\because 305$ \\
\hline 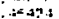 & $=3:=$ & - \\
\hline & $\rightarrow-x^{2}$ & 33558 \\
\hline$\ldots$ & 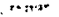 & 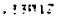 \\
\hline . : & $\because=$ & $i+3$ \\
\hline & and & Fontar \\
\hline$a_{i}$ & דיa? & ה"ה \\
\hline & 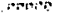 & 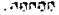 \\
\hline & Covitus & 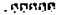 \\
\hline
\end{tabular}

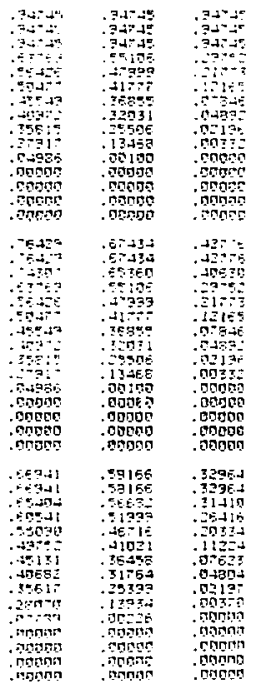

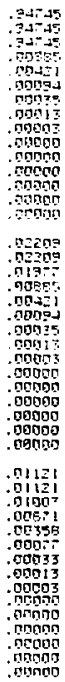
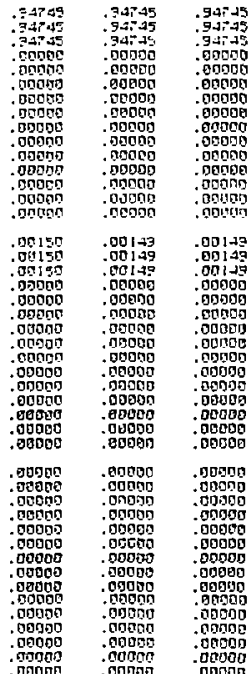


\begin{tabular}{|c|c|c|c|c|c|c|c|c|c|}
\hline$F: 1,1,-1,=$ & & & & & & & & & \\
\hline$+251-4$ & {$[-[+1] Z$} &.$\angle Z 75 E$ & .3 .195 & . 5993 &.$=5 \div 1 \equiv$ & - & , 30000 & נ. & .00000 \\
\hline 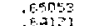 & Eling & Exis: & 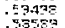 & 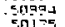 & $052: 2$ & 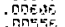 & 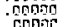 & & 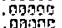 \\
\hline 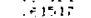 & Fns? & 5曰두. & Sung & $-4=2$ & OIEE & תיתגה & 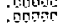 & ים & 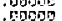 \\
\hline$\therefore 1$ & $\leq-1: 3$ & ELA & $x_{1}-1^{2}:$ & $\therefore-1 \mid F=$ & 17.42 & . & - & 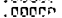 & ח \\
\hline 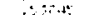 & $\therefore$ - & - 5 IF & $. A=111$ & 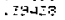 & . & gesta & rovar & , & . \\
\hline , मतE? & - $\rightarrow \square=5$ & , $41,4=$ & . J40E & .75 .45 & . & . & . Frites & . 0 & . ตอบดง \\
\hline 1477 & - $-15,53$ & $-4 \geq 5$ & .3391 & $-2 \ln 3$ & - & - Bno: : & 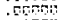 & - socrs & . \\
\hline . -1$]^{5} \cdot 17$ & גוd & . 2 ?0? & 35. & $=43.4$ & . $1=1=4$ & - gongz & 5000: & 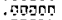 & . \\
\hline$\because 85 \%$ & . T.19日) & I & 89 & סנינו14. & : & 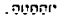 & 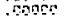 & - ถoอnู & 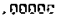 \\
\hline$-8,9-5$ & 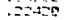 & I snae & inesa & nnd:? & nopis? & ח & cover & - Mogon & 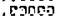 \\
\hline I & nruloj & 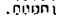 & החחספטח & רู & 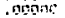 & STrong & - ongros & - & . כอסด \\
\hline 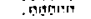 & - Yagn & 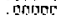 & . & 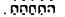 & - ocograt & - & - & - & . \\
\hline 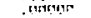 & 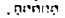 & 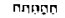 & 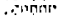 & 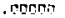 & . & 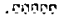 & 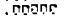 & 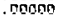 & 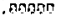 \\
\hline$\therefore$ & - जy & צִ & 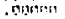 & 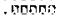 & $.18+67^{2}$ & ים & andis & - & סָסתה ת \\
\hline$r: \ldots 1,51=$ & & & & 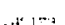 & 出识 & & 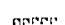 & Raynn & 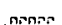 \\
\hline 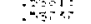 & 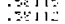 & 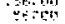 & 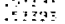 & , & : & 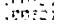 & 9 & - & צחים \\
\hline$=319=$ & $\therefore y=9$ & EIEj & magf & . & $.195 i^{\circ}$ & $.002=$ & สnูก & . Encor & - EEcos \\
\hline$\therefore$. & Gone & $\therefore$ des & . E 111\%. & $.4 ? 38$ & . 1 1 & $.75-17$ & 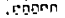 & - Basc I & 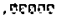 \\
\hline $.3=97$ & $\because 45 \%$ & $=2=5 i$ & $.470 \rightarrow$ ! & . Anב: & id? & . & 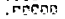 & 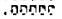 & 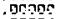 \\
\hline$\therefore 1=6 n$ & $6.592 z^{\circ}$ & Q &.-15373 & 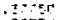 & $.25: 2$ & .00 & סחסתחמחת. & המסת & EסO \\
\hline :-9n. & ت & $25=1=$ & 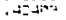 & $2+23$ & 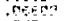 & Dncis & cosos & - morno & , ERTAs \\
\hline$\therefore+1=$ & . & 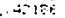 & $\because 75 x$ & . & C.sn & 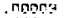 & 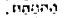 & 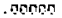 & . \\
\hline$+2+4+\varepsilon_{1}+1$ & 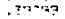 & $2=192$ & $z \ln 2$ & 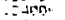 & 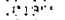 & - nome. & Coess & - Howis & . \\
\hline$\therefore+41$ & $\therefore$. & $2 \geq 1=5$ & $\therefore \because \leqslant-4$ & $L=7$ & Dי & 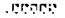 & 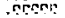 & צחת & , ngene \\
\hline 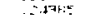 & $\therefore 7=3$ & . בn: & $.1=1=1$ & Scte? & $\therefore$ & STo & Forses & 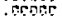 & 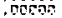 \\
\hline 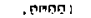 & 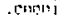 & - Donesi & 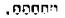 & . & 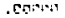 & 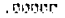 & 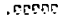 & - orone & פהפחה \\
\hline 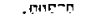 & 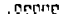 & ספיחום . & ?ִחדם & 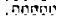 & 19ים & 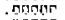 & הםris & - cconos & פמסטס, \\
\hline חהחחח. & 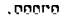 & 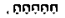 & 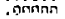 & 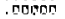 & 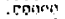 & . cos? & . & . & coone \\
\hline : & חים & הู่าด & . ดอกกล" & . & היומרח ה & coson & . ตถอตถ & - & - \\
\hline 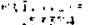 & $\because \overrightarrow{2} 0$ & $2175 \mathrm{E}$ & $-1+0^{\circ}$ & $\sin 131$ & & & & & \\
\hline$\because 2 \geq 2=$ & $\begin{array}{ll}3 \\
\cdots 15\end{array}$ & . & 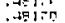 & 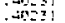 & : & 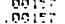 & 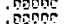 & $\begin{array}{l}\text { - Denga } \\
\text { ongang }\end{array}$ & - ougag \\
\hline$\therefore \operatorname{sen}$ & $=-4$ & $=1,0$ & $.4-5.9:$ & :39 & $\because 75=$ & גוd & תים & - & סירודים \\
\hline$\therefore 4$ & $\therefore \quad$. & $\because 12$ & $.41-2+$ & 20 & $128: 5$ & $.61=$ & סדים & - cons & Ealit: \\
\hline$\therefore \ln =$ & $.4+81$ & $-105=2$ & $-\rightarrow$ - 4 & $+-15 .$. & $\ldots$ & .5 & - & - conoti & - cogon \\
\hline$\therefore=7$ & . $A$. E : : & 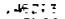 & - +otus= & . & x $5:$ & : & . Ens? & . 61475 & . 00000 \\
\hline$\therefore \cdots$ & 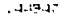 & IE: & . & $.15+2$ & M: & . & 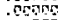 & זמתח & ספטס \\
\hline - & $.4]=94$ & . WE 5.5 & . 30.2 & $\therefore 8 \geq$ & $0 \geq 2$ & 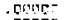 & . & . & חูתחת \\
\hline Ta110 & 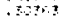 & SE6: & 7807 & $\because 4+$ & C: & . & - & - sanen & 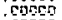 \\
\hline .395 & T. TER: & 31532 & - ZErfa & .17305 & - ח? & .9309 & 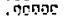 & הַתֵ & - Doder \\
\hline . & .275 & . & $1=321$ & . DeE -9 & Gon: & 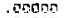 & . כอด & . coves & . 00000 \\
\hline 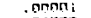 & 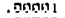 &. $\operatorname{cospos} 1$ & - מחצח & 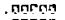 & 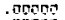 & 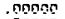 & .009 & .coosa & .00000 \\
\hline 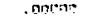 & היורדיזיזם & 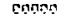 & 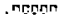 & 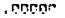 & 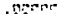 & . opntric & שםחסחפת. & 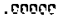 & . necon \\
\hline - Enrin." & 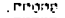 & ennes? & דיטדים & 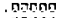 & 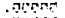 & . & - & 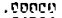 & ח \\
\hline : & חעם & . & 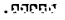 & costo & 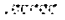 & cane & אים & - ogตñ & . \\
\hline A. & - $=$ กเ 1 & Antes & .120 .43 & $+c y$ & 47コС & $r$ ant & rongs & קספקו & סחסק \\
\hline$\Rightarrow+8$ & 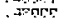 & MrFe & . & TeE: & ערכת & enti & 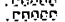 & connne & - coced \\
\hline $.485-4$ & . & .4501 & $.4 \leq \geq 5$ & TES & ags & דר & ים & लم⿳亠口冋? & חתחהתמם \\
\hline $.9=55$ & $.-1-1=0$ & . -15742 & $\therefore=13$ & 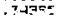 & 舟 & רִ & ז & - chsona & 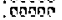 \\
\hline - it & יד - & ב & $045 \mathrm{n}=$ & $\div: \div=$ & . & 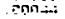 & 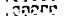 & 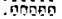 & : \\
\hline .45005 & $.1+395$ & .23017 & .39 .53 & .3182 & . CSE2 & .00025 & . mogea & - 5ocos & . eg900 \\
\hline $.4=832$ & $.4 \geq 230$ & .40786 & . 358 & .20953 & C $C \geq \leq 0$ & -0012 & .0ององ & .00000 & .05000 \\
\hline .40330 & $.396-15$ & .39082 & $.74-405$ & $.5=89$ & $0=58$ & . 0005 & .90000 & .00000 & . 00002 \\
\hline .75283 & .36517 & . 347 E6 & .30683 & .20156 & $.01 \geq 25$ & .covอ: & . odere & .00000 & . 8000อ \\
\hline .73180 & .32384 & . 빈중 & $.254:$ & .11 Es & . & . GDOمอ & .00000 & .00000 & . odae \\
\hline$+A$ AEB- & .25410 & . & .17268 & . DSE6 & . Dอed 1 & - overna & .00000 & .00000 & . อยฮอ \\
\hline Cnge & - Enกุด 1 & . Eone 1 & חסחספט. & . . & . BaDof: & - อDองอ & . ogeon & . อออรอ & - อвอย \\
\hline 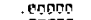 & 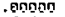 & . Bugra & . 098จ & - ВतूED & . TIDC믐 & - Dogas & . ออดกุ & . 00อูa & . องดอง \\
\hline 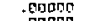 & - crena & . geded & - 0อפอ & . 00000 & . กูอดู & - & , 00000 & - องอย的 & . 9000 \\
\hline$\therefore 0000$ & המחמםם • & . Dotog & . O0DEE & 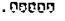 & . & .05000 & . 05000 & .00000 & . BDodo \\
\hline $\begin{array}{l}1 \\
-1518\end{array}$ & סטיה. & d $\geq 3 \mathrm{E}$ & $.3 \geq \geq \geq 5$ & .31510 & . &. $\operatorname{lng} 29$ & פ פognc & פבดต & agong \\
\hline म4 & -430 & A236 & $.33=3$ & $.315 \mathrm{IE}$ & QEEบ? & .00075 & סטימה & - อตถูล & טogos \\
\hline$\therefore 11=\sqrt{1}$ & .27546 & $4 \geq=13$ & . 3ans &.$~ I I S E S$ & NE $\lambda \overrightarrow{\text { Tे }}$ & . חกอ2อ & $.0000 \pi$ & .00000 & .90000 \\
\hline . 13807 & . $4 \geq 112$ & . JITEE & 4. & 3 . 304 & Den1s & 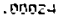 & . & - ganos & .00000 \\
\hline - - ᄀㅗㄹ & . $А 2 \geq B$ & .49916 & .37713 & . & - 925 & . องด1E & . 0ก0อ5 & . ององ & . Jopá \\
\hline $.4163 a$ & .41009 & $.3956 \mathrm{~B}$ & .36254 & .380 .2 & $.0 \neg \mathrm{EE} i$ & נון & .00 อดอ & .0อกออ & .00000 \\
\hline 9 & 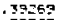 & .37564 &, $3+2=0$ & $.25+163$ & . $0=8 \div$ & . enges & .00000 & . Вอดอย & . ออฮอก \\
\hline $\begin{array}{l}7.183 \\
30100\end{array}$ & . 37058 & .35 גل & $.316=$ & .21385 & .21719 & . ตnoe: & .00000 & . & . EDOEO \\
\hline $\begin{array}{l}-35100 \\
.1433\end{array}$ & - 2.45!11 & .32525 & . วEこะ & -17004 & $.80-12$ & . 65801 & . 0อפอง & - D0000 & . อชอง \\
\hline $\begin{array}{l}71332 \\
-2956\end{array}$ & 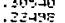 & $\begin{array}{l}.25019 \\
19324\end{array}$ & -25659 & R9E & 0टाE & - & - כ9פספ & - ㅁg잉 & - Ageop \\
\hline . Egodol & 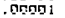 & . conel & . סองลอง & הסחסטים & $\begin{array}{l}.0000 ! \\
.00001\end{array}$ & $\begin{array}{l}.00800 \\
.00000\end{array}$ & . & - 000000 & .00000 \\
\hline 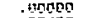 & 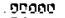 & .90000 & 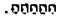 & החת נים & 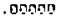 & סטסחטת ת. & .00000 & .00000 & .00000 \\
\hline חם & 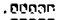 & $.00 \mathrm{cos}$ & . Degen & . ngroga & . & . & . 0706n & . ธององ & .00000 \\
\hline$=$ & 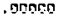 & . ถูกEE & חָח & & . กาดg & ( & . Oดen & . & .00005 \\
\hline a & IIF.T? & 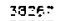 & .JPES & $=68.10$ & $.017=0$ & . กمอด & . อnega & . & .80000 \\
\hline נה & .397 & .8826 & . SasE & . T68 & $.0 \geq-0$ & ตngos & - תogng & & .00000 \\
\hline 40151 & , $39 \sigma_{1}, 50$ & 36156 & . 4358 & . & . 01698 & הפסטס. & . DODoc & 19000. & . 30000 \\
\hline 79855 & - 392.6 & $3 r 355$ & . ZALE & $.26=40$ & $.034 \geq 1$ & . novos & . I0000 & .00005 & .0005 \\
\hline $70=0$ & 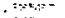 & . 조ำ & נריטד & .3577 & הכרס & - anda & .00009 & . อธกอบ & . อסอง \\
\hline $73 \overrightarrow{0}$ & 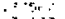 & & .214 & בַב & $.7=313$ & . & - Ducan & . 0000ถ & . 00050 \\
\hline . & - Fon & $0-250$ & . $3,+2$ & $=1 ;$ Jr & Sire- & - & 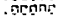 & - Eמסט & .00050 \\
\hline ? ?799 & $.12-25$ & $\therefore=2 \pm 7$ & . & ב & . & נ נ & . & . & .00000 \\
\hline + & .1319 & .2395 & $\therefore 01=$ & - $13 n^{2}=$ & . & 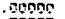 & - soche & סחסחפים & .00050 \\
\hline$=2 \cdot 3 \div 1$ & $.26+5$ & .5301 & .21393 & - TER II & gotsic & 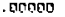 & . Ençe & . & .00000 \\
\hline$=21+5$ & . $3 \mathrm{E} \rightarrow$ & $+17-4$ & . 03200 & . DOES & 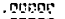 & . & .60005 & .0000 & .0000 \\
\hline . & נים & . & 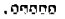 & . & . & ancona & $.0000 \%$ & . & อยถูกล \\
\hline . 5ู & 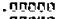 & . & . & - Troches] & . פด & . लถูอณ & - Donst & .00000 & coba \\
\hline . & 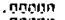 & - & יט: & 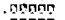 & - & . & . onang & . & aboga \\
\hline תטיאחתחים & ירופטרמחח . & 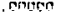 &. & 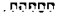 & . & 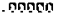 & - cengar & 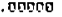 & . comer \\
\hline
\end{tabular}




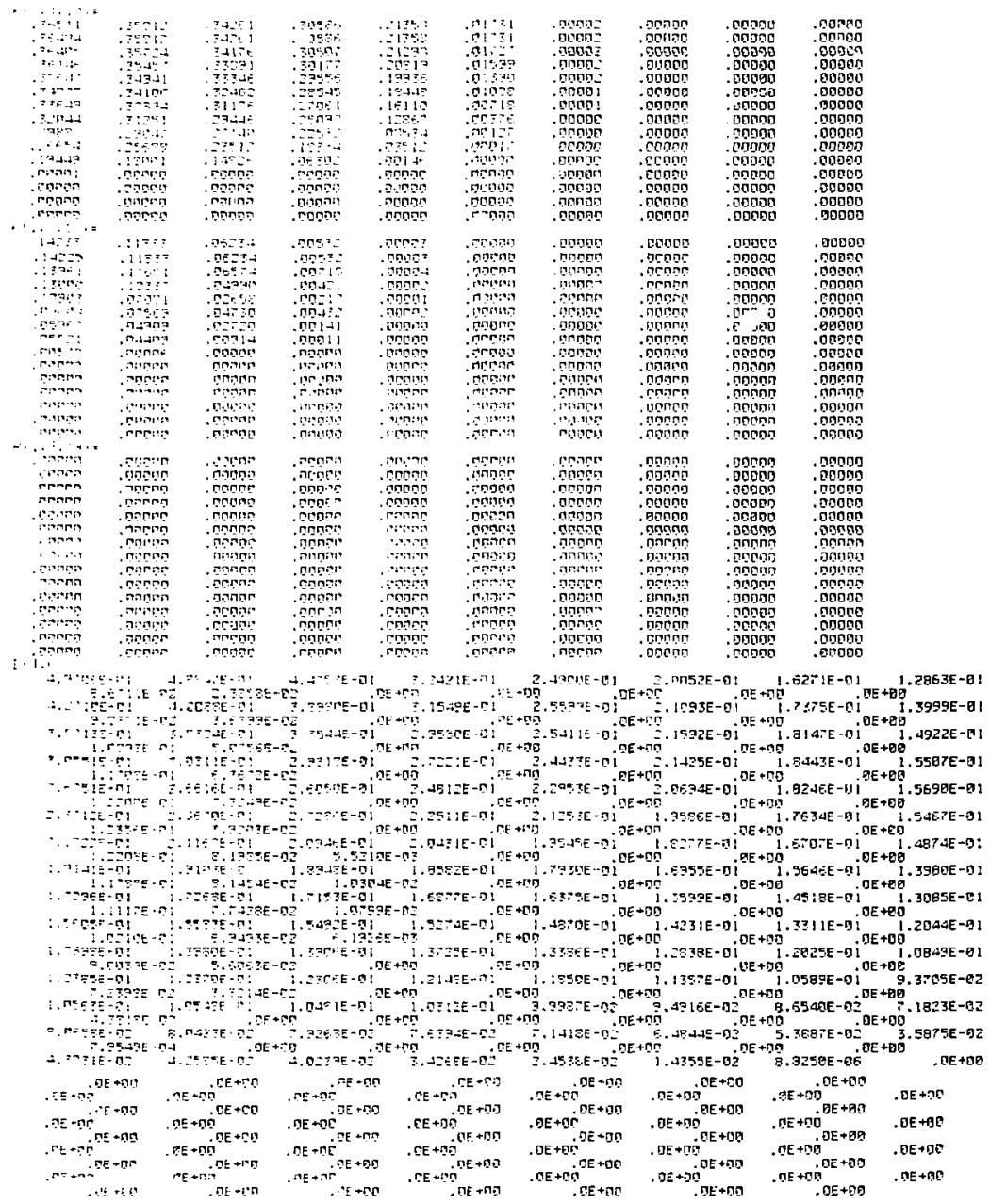




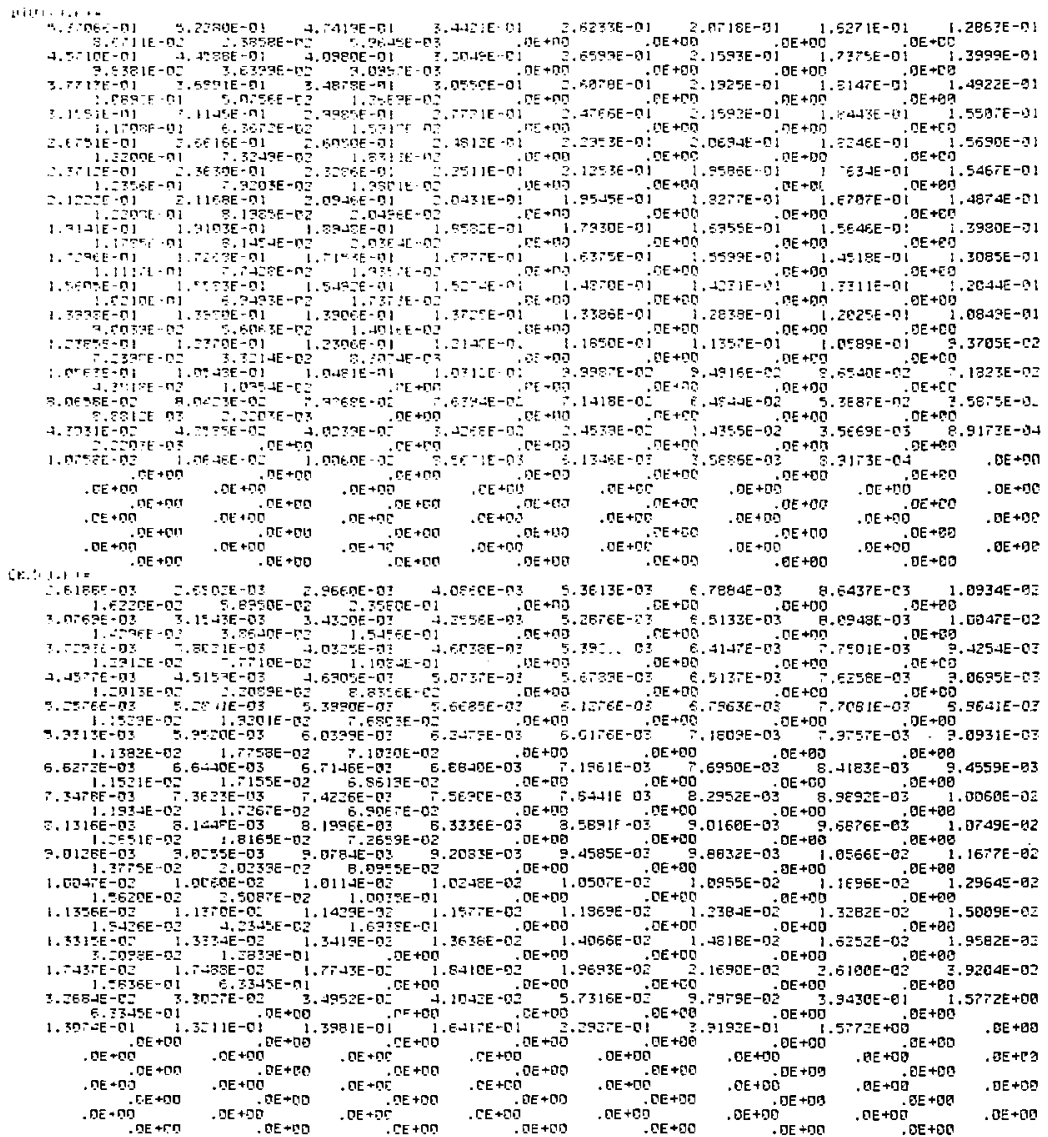




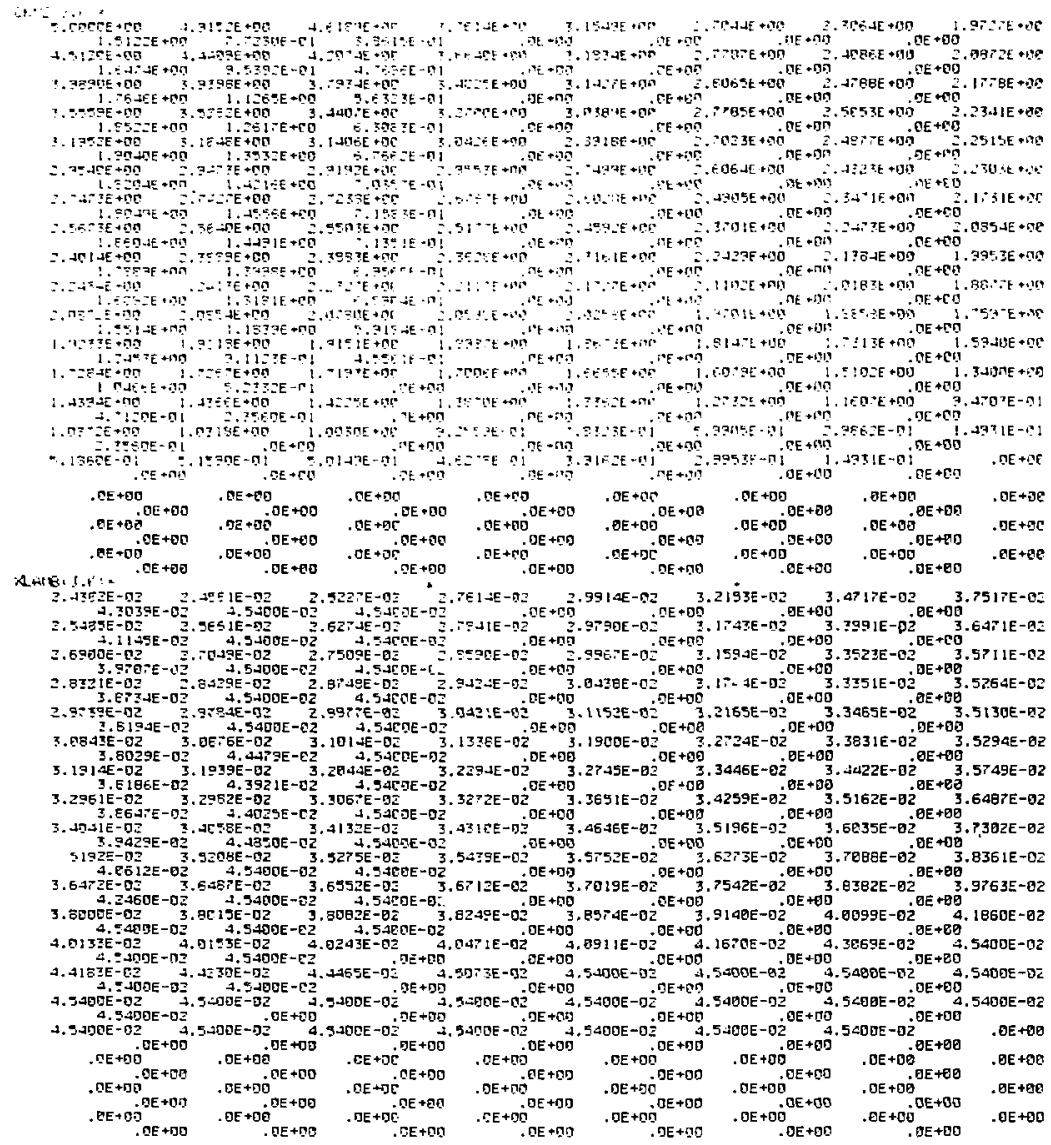


ot.

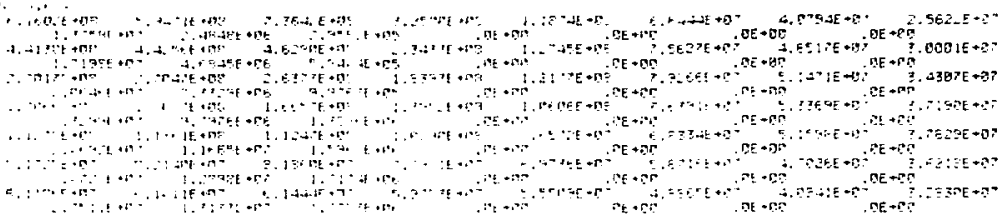

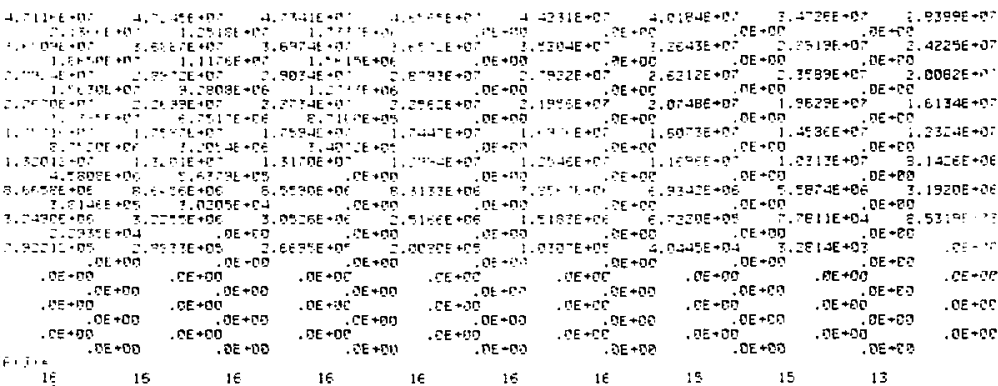

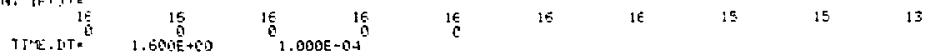

